\title{
Using Artificial Intelligence And Machine Learning To Develop Synthetic Well Logs
}

\author{
Marwan Mohammed Alnuaimi \\ wvu,mma0042@mix.wvu.edu
}

Follow this and additional works at: https://researchrepository.wvu.edu/etd

Part of the Geological Engineering Commons, and the Petroleum Engineering Commons

\section{Recommended Citation}

Alnuaimi, Marwan Mohammed, "Using Artificial Intelligence And Machine Learning To Develop Synthetic Well Logs" (2018). Graduate Theses, Dissertations, and Problem Reports. 3747.

https://researchrepository.wvu.edu/etd/3747

This Thesis is protected by copyright and/or related rights. It has been brought to you by the The Research Repository @ WVU with permission from the rights-holder(s). You are free to use this Thesis in any way that is permitted by the copyright and related rights legislation that applies to your use. For other uses you must obtain permission from the rights-holder(s) directly, unless additional rights are indicated by a Creative Commons license in the record and/ or on the work itself. This Thesis has been accepted for inclusion in WVU Graduate Theses, Dissertations, and Problem Reports collection by an authorized administrator of The Research Repository @ WVU. For more information, please contact researchrepository@mail.wvu.edu. 


\title{
USING ARTIFICIAL INTELLIGENCE AND MACHINE LEARNING TO DEVELOP SYNTHETIC WELL LOGS
}

\author{
Marwan Alnuaimi \\ Thesis submitted to Benjamin M. Statler college of engineering and mineral \\ resources \\ at West Virginia University \\ in partial fulfillment of the requirements \\ for the degree of \\ Masters \\ in \\ Petroleum and Natural Gas Engineering \\ Shahab Mohaghegh, $\mathrm{PhD}$, chair and research advisor \\ Sam Ameri, PhD \\ Kashy Aminian, $\mathrm{PhD}$ \\ Petroleum and Natural Gas Engineering \\ Morgantown, West Virginia \\ 2018
}

Keywords: Artificial intelligence, machine learning, synthetic well logs

Copyright (C) 2018, Alnuaimi 


\begin{abstract}
USING ARTIFICIAL INTELLIGENCE AND MACHINE LEARNING TO DEVELOP SYNTHETIC WELL LOGS

Marwan Alnuaimi
\end{abstract}

There has been an increase in the need for energy in the recent past. Oil and gas stand as the source of energy that are widely used. The oil and gas reservoirs are targeted for the purposes of field development. The conventional methods of reservoir characteristics require computing techniques that are unique and complex, some of which are labor and time intensive. Mohaghegh argues that all efforts must be tried and made possible to apply Petroleum Data analytics in production and management of reservoir so as to earn a maximum return (Mohaghegh, Shale Analytics, 2017). Different methodologies have been applied to derive synthetic well logs from existing logs using technologies such as the artificial neural networks which can be used when well logs are absent due to several factors such as difficulty in the logging operation and the tool timing. The aim of this research is to explore the form and the nature of artificial intelligence and machine learning (neural network systems) to develop synthetic well logs and to explore this technology's capabilities of building new strategies seeking development of oil and gas fields. By obtaining the data and feed it to the neural network the results demonstrate that developing synthetic well logs using artificial intelligence and machine learning is a feasible approach for the enhancement of formation evaluation and reservoir characterization. Artificial intelligence is a reliable and promising technology that can significantly contribute to solving petroleum engineering related problems especially when it comes to the importance of fast decision-making processes. 


\section{DEDICATION}

I wish to dedicate this thesis to my parents who has the biggest influence in making me the person I am today. 


\section{ACKNOWLEDGMENTS}

Praise be to Allah, Lord of all creation, for all the blessings that contributed to the success of this research. The words are racing, and the phrases are crowded to get organized thanking you my parents, who raised me to the person I am today, for all the love and support.

Tremendous appreciation goes to everybody who supported me during my master's study, especially Dr. Shahab D. Mohaghegh, my research supervisor and my personal mentor, for taking me through this tremendous life experience and research. He is a helpful dedicated supervisor and a great friend. I would like to appreciate my committee members Prof. Sam Amire and Dr. Kashy Aminian for their continued support and valuable advices and recommendations during my graduate study.

I would like to acknowledge Intelligent Solution Inc. "ISI" for their contribution in this research by providing "IMprove" software which was the core of this study. Special appreciation to Abu Dhabi National Oil Company “ADNOC” for sponsoring my graduate study, for providing me with the needed support, for proving the data used in this research. Great appreciation also goes to Petroleum and natural gas graduate students for their valuable contributions in success of this research, especially LEADS teammates Maher, Amir, Ayodeji and Hasan who guided me and were there for me whenever I needed help.

Finally, my sincere gratitude is for my beloved wife for her support, patience and understanding through this experience, for my brothers and sisters who encouraged and fully supported me in my life, for my family who provided me with all the needed love and warm feelings. 


\section{TABLE OF CONTENTS}

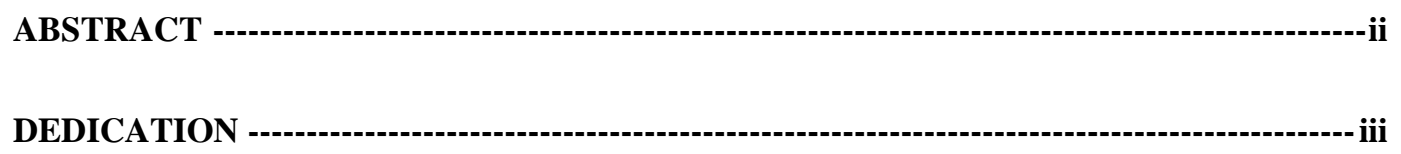

ACKNOWLEDGMENTS---------------------------------------------------------------------------------- iv

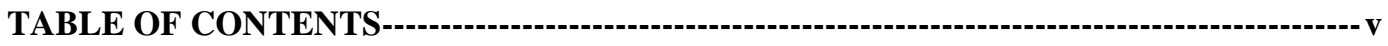

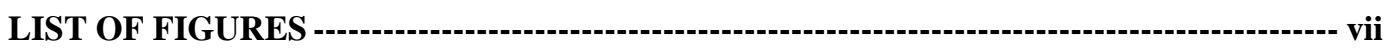

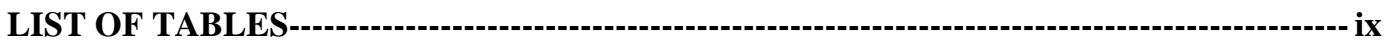

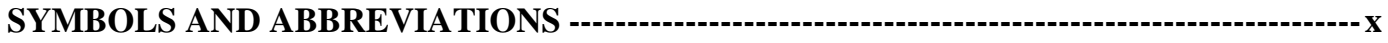

CHAPTER I: INTRODUCTION AND BACKGROUND INFORMATION --------------------1

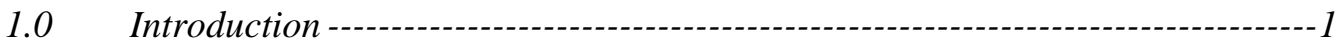

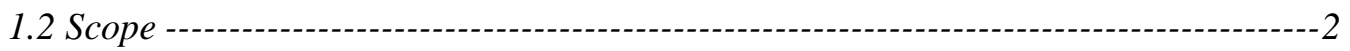

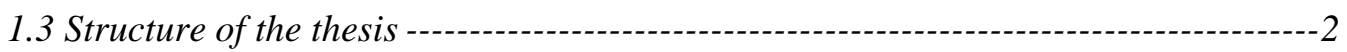

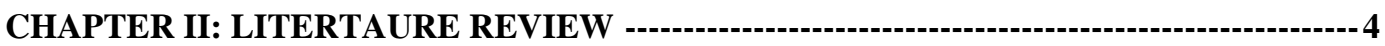

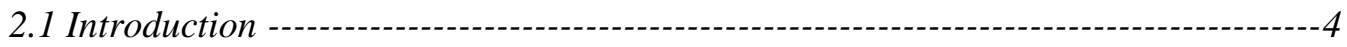

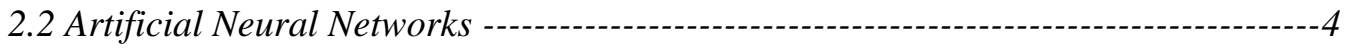

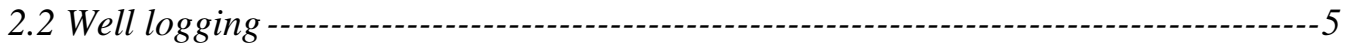

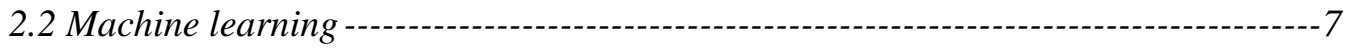

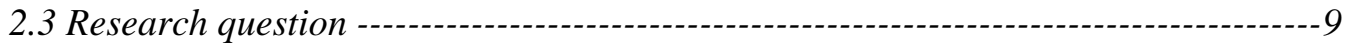

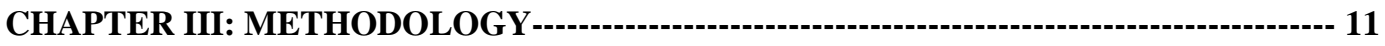

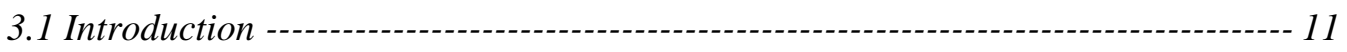

3.2 Research method/ approach -------------------------------------------------------------- 11 
3.4 Data processing--------------------------------------------------------------------------------- 14

3.5 IMprove software ------------------------------------------------------------------------- 16

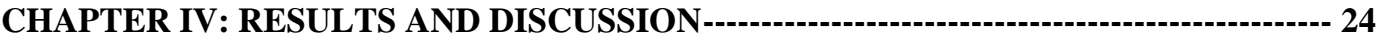

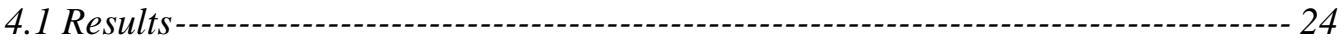

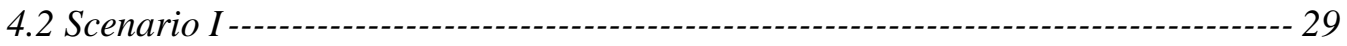

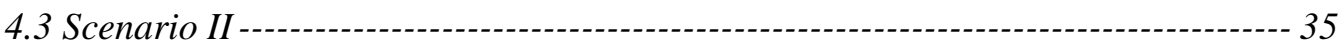

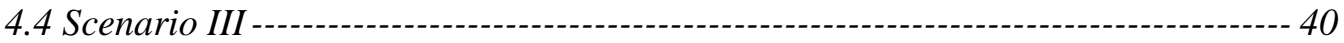

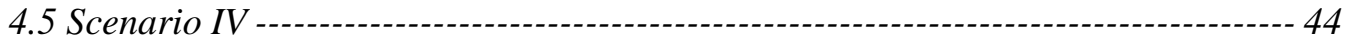

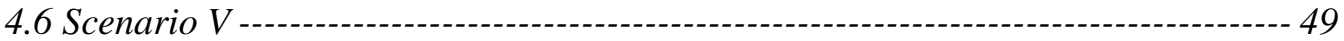

4.7 Scenario VI --------------------------------------------------------------------------------------- 52

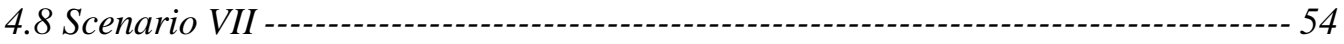

4.9 Scenario VIII ----------------------------------------------------------------------------------- 56

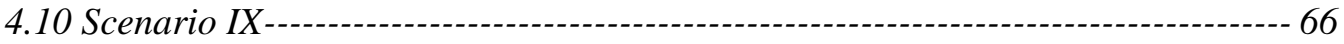

CHAPTER V: CONCLUSION AND RECOMMENDATIONS -------------------------- 73

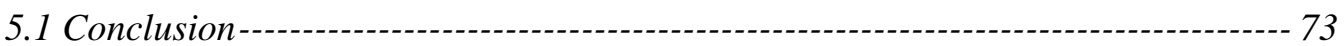

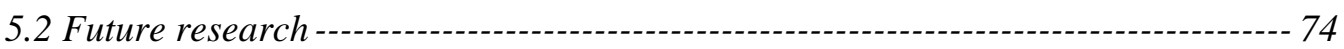

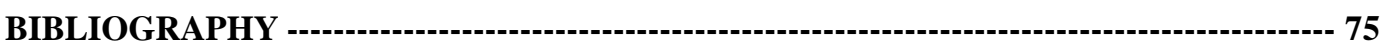




\section{LIST OF FIGURES}

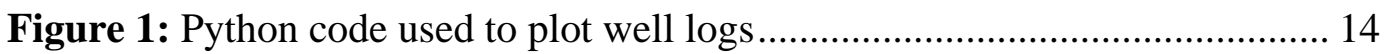

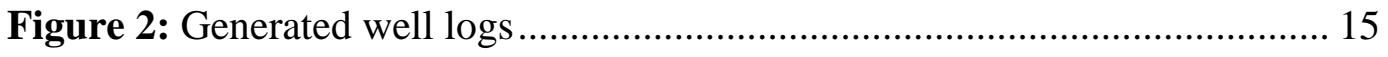

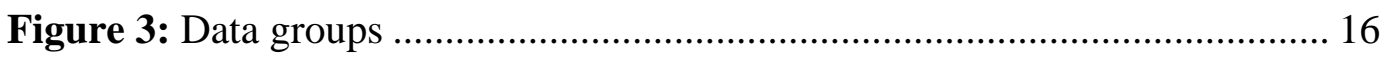

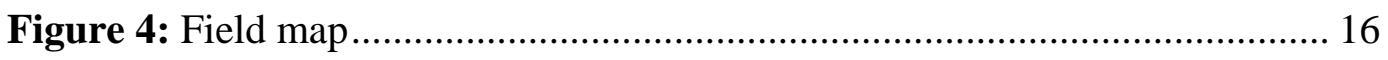

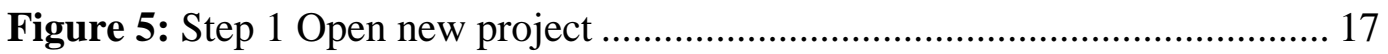

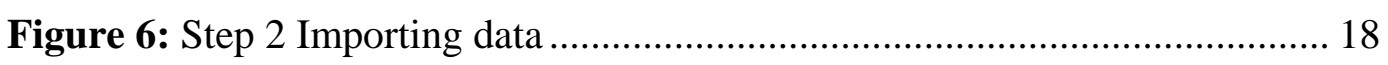

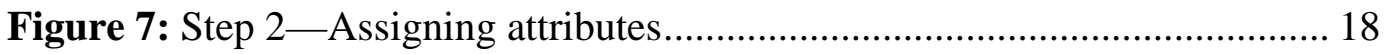

Figure 8: Step 3-- Analyzing the imported data .......................................... 19

Figure 9: Step 4--Running the key performance indicator (KPI) ...................... 19

Figure 10: Step 5-- Selecting the data to be processed in the run....................... 20

Figure 11: Step 6-- Designing the neural network........................................ 20

Figure 12: Step 7-- monitoring the calibration / training graph......................... 21

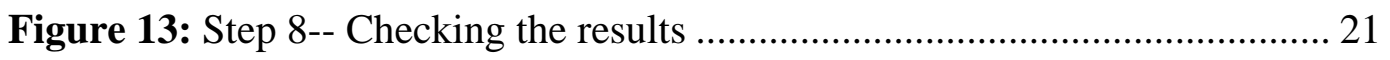

Figure 14: Step 9- Importing the second set of data ...................................... 22

Figure 15: Step 10- Generating the messing data using “Deploy Model” tap..... 22

Figure 16: Step 11- Exporting the output to an excel sheet............................. 23

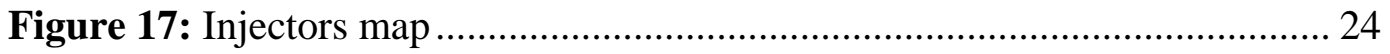

Figure 18: Training result scatter plot......................................................... 25

Figure 19: Training result cross plot...................................................... 25

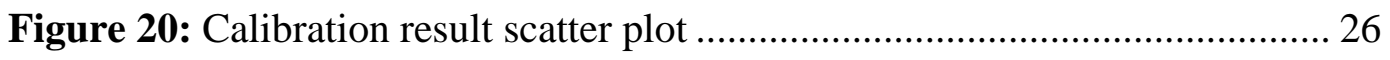

Figure 21: Calibration result cross plot.................................................... 26

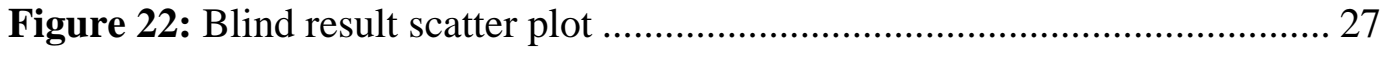


Figure 23: Blind result cross plot.................................................................... 27

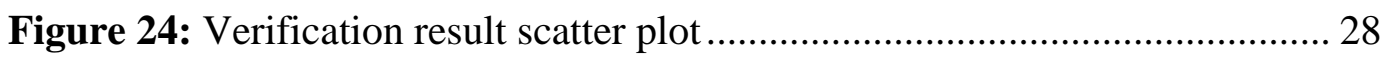

Figure 25: Verification result cross plot ......................................................... 28

Figure 26: Generated output “NN-PHIE” and actual value "PHIE” ................... 29

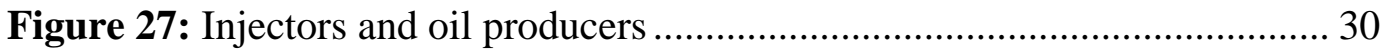

Figure 28: Training result scatter plot................................................................ 30

Figure 29: Training result cross plot.................................................................. 31

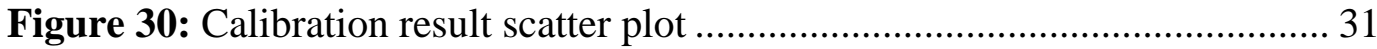

Figure 31: Calibration result cross plot............................................................ 32

Figure 32: Blind result scatter plot ............................................................... 32

Figure 33: Blind result cross plot..................................................................... 33

Figure 34: Verification result scatter plot ......................................................... 33

Figure 35: Verification result cross plot ........................................................... 34

Figure 36: The generated "NN-ILD" and actual value "ILD".............................. 34

Figure 37: Training result scatter plot............................................................. 35

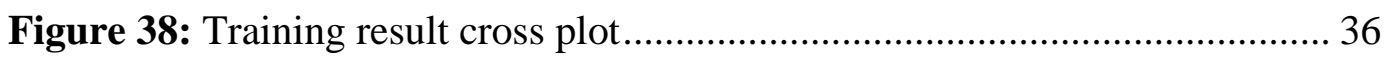

Figure 39: Calibration result scatter plot .......................................................... 36

Figure 40: Calibration result cross plot............................................................. 37

Figure 41: Blind result scatter plot ............................................................... 37

Figure 42: Blind result cross plot................................................................. 38

Figure 43: Verification result scatter plot........................................................ 38

Figure 44: Verification result cross plot ........................................................... 39

Figure 45: Outcomes for scenario II ........................................................... 39 


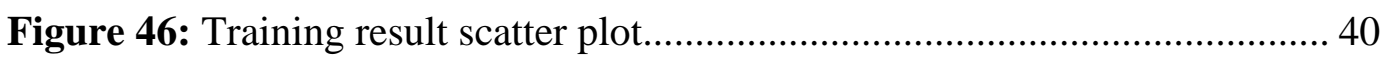

Figure 47: Training result cross plot............................................................... 41

Figure 48: Calibration result scatter plot ......................................................... 41

Figure 49: Calibration result cross plot........................................................... 42

Figure 50: Blind result scatter plot ................................................................ 42

Figure 51: Blind result cross plot.................................................................... 43

Figure 52: Verification result scatter plot ............................................................. 43

Figure 53: Verification result cross plot .......................................................... 44

Figure 54: Outcomes for scenario III................................................................ 44

Figure 55: Training result scatter plot................................................................ 45

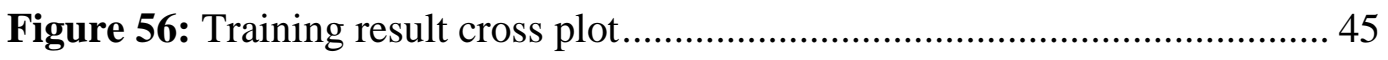

Figure 57: Calibration result scatter plot ............................................................. 46

Figure 58: Calibration result cross plot............................................................... 46

Figure 59: Blind result scatter plot ............................................................. 47

Figure 60: Blind result cross plot.................................................................... 47

Figure 61: Verification result scatter plot ............................................................. 48

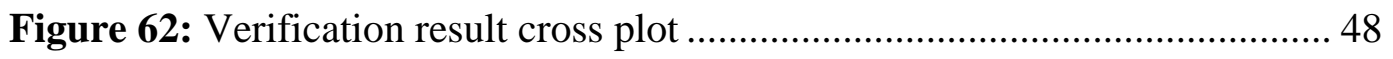

Figure 63: Outcomes for scenario IV ............................................................ 49

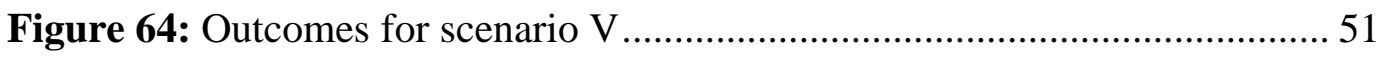

Figure 65: Outcomes for scenario VI ........................................................ 54

Figure 66: Outcomes for scenario VII …………………................................. 56

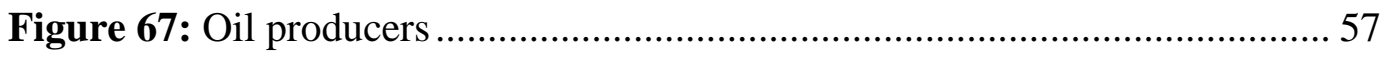

Figure 68: Training result scatter plot............................................................... 57 
Figure 69: Training result cross plot............................................................... 58

Figure 70: Calibration result scatter plot ....................................................... 58

Figure 71: Calibration result cross plot.......................................................... 59

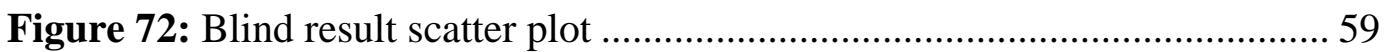

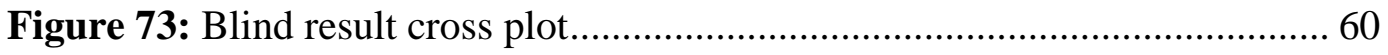

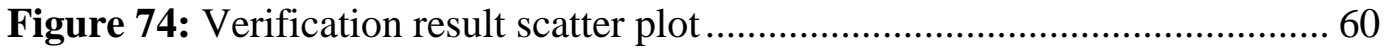

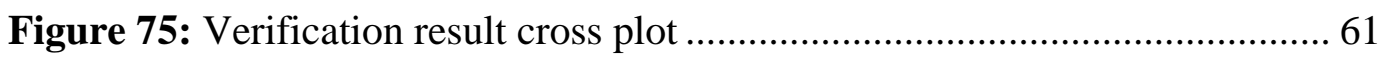

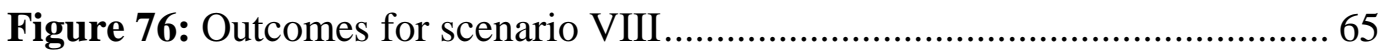

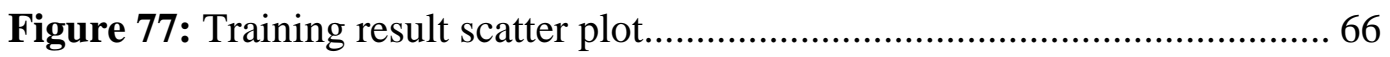

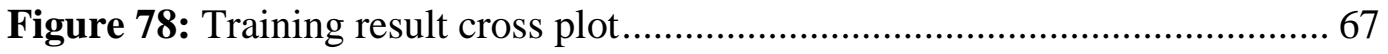

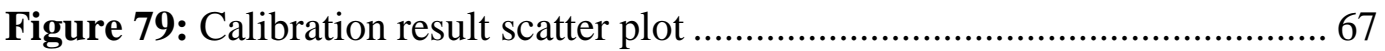

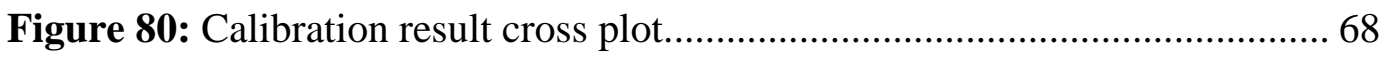

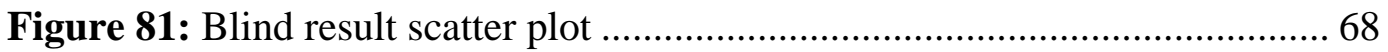

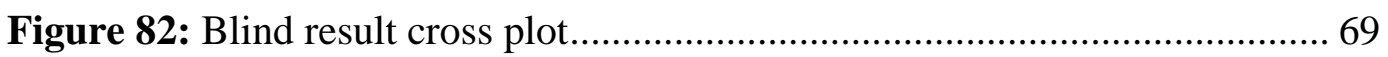

Figure 83: Verification result scatter plot ......................................................... 69

Figure 84: Verification result cross plot ........................................................... 70

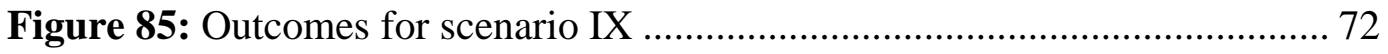




\section{LIST OF TABLES}

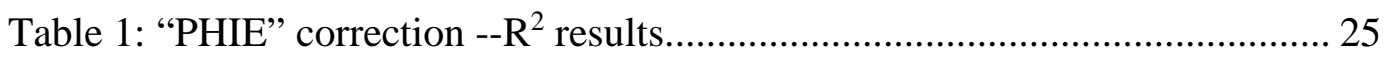

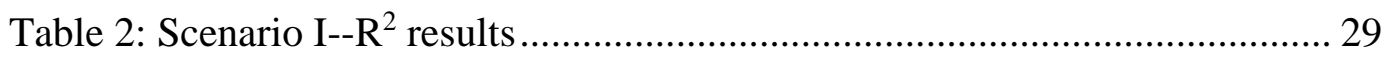

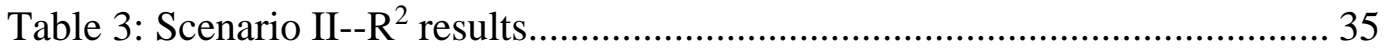

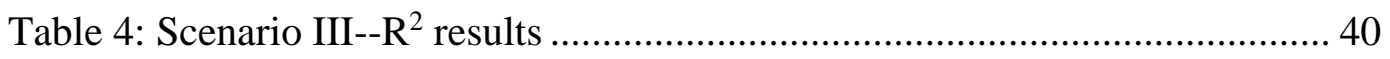

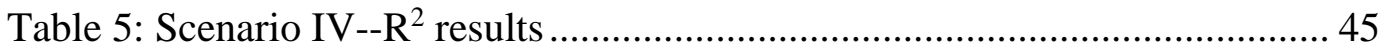

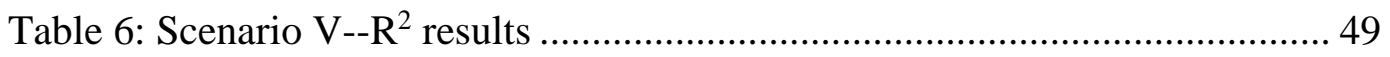

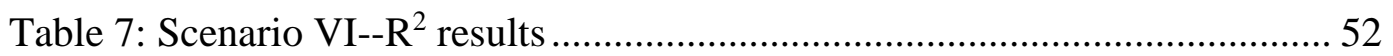

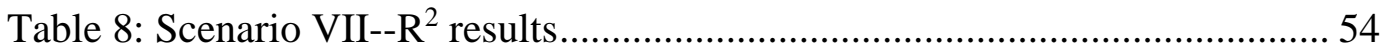

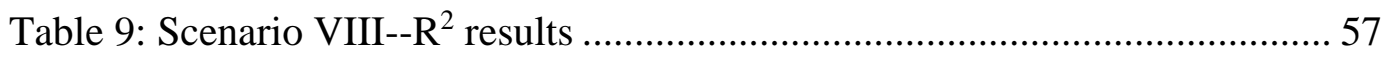

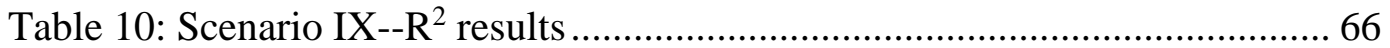


SYMBOLS AND ABBREVIATIONS

$\begin{array}{ll}\text { ILD } & \text { deep induction resistivity } \\ \text { MSFL } & \text { Micro spherically focused resistivity log } \\ \text { LLS } & \text { Shallow resistivity } \\ \text { RT } & \text { True resistivity } \\ \text { GR } & \text { Gamma ray } \\ \text { NPHI } & \text { Neutron porosity } \\ \text { PHIE } & \text { Effective porosity } \\ \text { RHOB } & \text { Bulk density } \\ \text { SW } & \text { Water saturation } \\ \mathrm{ft} & \text { US feet }\end{array}$




\section{CHAPTER I: INTRODUCTION AND BACKGROUND INFORMATION}

\subsection{Introduction}

There has been an increase in the need for energy in the recent past. Out of all these, oil and gas stand as the source of energy that is widely used. The reservoirs of oil and gas are targeted for the purposes of field development. The methods of conventional reservoir require computing techniques that are relatively unique and complex, some of which are labor and time intensive. Mohaghegh argues that all efforts must be tried and made possible to apply Petroleum Data analytics in production and management of reservoir so as to earn a maximum return (Mohaghegh, Shale Analytics, 2017). Different methodologies have been applied to derive synthetic well logs such as the artificial neural networks (ANN) which can be used when well data information is absent due to several factors such as difficulty in the logging operation and the tool timing. This can also occur as result of variable of interest non-inclusion. The aim of this research is to explore the form and nature of artificial intelligence technology and its applications in the oil reservoirs and building strategies of field development.

The well logs derived directly from the field are one of the most crucial elements in petroleum engineering that would assist evaluate formation of the hydrocarbons. However as argued obtaining data directly from the field has very many limitations. Due to these limitations present, artificial intelligence work has been viewed as the best and strongest tool which can aid in supplementing such information and help generate the synthetic well logs. The sets of tools that are developed in this analysis address the need for developing the respective well logs in synthetic form. This topic is important to the petroleum engineering because of the fact that synthetic well logs are designed to analyze the reservoir characteristic in regions that require log sets of where they are incomplete or absent. The implementation is important as much value may be extracted to help in production exploration. 
Petroleum Data analytics involves use of data driven analytics in gas and oil industry which helps in production process optimization (Mohaghegh, Shale Analytics, 2017) .The research that will be conducted involves employing artificial intelligence networks as the tool.

Mature fields have a huge number of wells which has been drilled and completed in different phases of the field development processes, sometime the difference between two phases experience a change in the technology used or the tools, hence some of the wells or for many of the wells some of the logs are completely missing. Furthermore, sometime some of the logs for some of the wells are end up with many gaps in well logs and considered as bad logs due to the facts that equipment goes wrong and it is not caught be the operators. Using artificial intelligence and machine learning to develop synthetic well logs can address all of the above situations.

\subsection{Scope}

The implementation exercise aims at cutting the costs incurred. The process of the intelligence network was accomplished by the use of Regression Neural Network (RNT) and wire line logs generated from some wells that had neutron, resistivity logs, gamma rays and density (Bassaganya-Riera, J. (Ed.). , 2018). The generation was achieved through two exercises that were almost similar although having some minor variations in the operation of Shale. The first comprised the entire major wells for verification, training, and calibration. The subsequent exercise utilized only $80 \%$ of the wells for training and calibrating and preserved the $20 \%$ of the wells for verification.

\subsection{Structure of the thesis}

This project comprises of five core chapters. This chapter has provided an elaborate introduction and background information to the research topic, besides highlighting the 
problem being investigated along with the scope of the research. Chapter two provides a critical and in-depth review of the published empirical and theoretical literature on the use of artificial intelligence and machine learning in the development of synthetic well logs. The chapter also presents a critical review of studies that have been conducted in relation to the topic at hand. It also provided definitions of essential concepts related to the subject topic and highlights the literature gap that the present study seeks to fill, upon which a set of research questions has been derived. The third chapter provides a detailed discussion of the research methodology and design employed whereby the data collection and analysis tools used are presented. The fourth chapter presents the analysis and discussion of the results obtained while the fifth chapter highlights the main conclusions and recommendations arrived at in this project, besides providing a direction for further study. 


\section{CHAPTER II: LITERTAURE REVIEW}

\subsection{Introduction}

The previous chapter has provided the introductory information regarding the study whereby elements such as introduction and background information to the research topic, problem statement, and structure of the document have been presented. The present chapter presents a critical review of the extant body of literature regarding the subject topic. In particular, themes such as the concept of intelligence networks and well logging have been critically discussed. The research gap that the present study seeks to close has also been presented besides providing a list of the questions that the study sought to answer.

\subsection{Artificial Neural Networks}

Different techniques have been combined both in the Oil and Gas industry to ease optimization of production operations. As a result, shale analytics offer an implementation pathway for all and alternative solutions to the methods that have been applied in the industry for long. Shale analytics implements petroleum Data analytics in all issues relating to shales (Mohaghegh, Shale Analytics, 2017). There exists many speculations and opinions on what takes place as we concentrate on completing drilling wells. However, it is crucial to note that most of these speculations and opinions are never supported by data and facts. The truth remains that although data is collected when performing operations in the oil and gas industry, the knowledge obtained has never been enough to help optimize operations in obtaining the hydrocarbon resources.

Past studies indicate that intelligence networks were previously used to predict the varied properties of reservoirs, such as permeability, porosity, and the saturation of fluids, whilst ensuring that the cost of expensive processes is significantly reduced in the wake of acquiring those properties. In addition, intelligence networks were also adopted in the generation of synthetic well logs, reservoir modeling and the formation characteristics analysis. 
With the latest advancements in the recovery of hydraulic fracturing and the recovery of shale, machine learning was successfully applied in the identification of sweet spots in the process of exploring reservoirs of shale wells (Mohaghegh, Shale Analytics, 2017) .

A study conducted by (Bassaganya-Riera, J. (Ed.). , 2018) sought to predict the production of hydrocarbons from the formation of geological processes by the use of techniques of computer modeling. They found that artificial neural network is critical in imitating the processes of thought in the brain of human beings (Cranganu, C., Luchian, H., \& Breaban, M. E, 2015). The intelligence networks encompass the use of techniques, solutions or workflows that can help increase production and recovery from shale plays (Mohaghegh, Shale Analytics, 2017) .

\subsection{Well logging}

The process of well logging is undertaken by the use of devices that are lowered into a well and made to measure the formation properties through nuclear, electrical, or methods of acoustic. It is applied in drilling a well or in the determination of the production capacity in the reservoirs of hydrocarbons. The data can be applied in determining the drilling feasibility of drilling more wells in the region, whilst selecting the final height of the well that is under the drilling process. This is in line with shale analytics that mostly deals with field measurements (hard data) and data generation to accomplish various artificial intelligence works (Mohaghegh, Shale Analytics, 2017).

Many researchers have ventured their intelligence to matters affecting well logs. There exist activation functions that are available for every network of connection. For the recognition of the artificial intelligence networks with external systems, the processing of information offers the answer of the methodology and the end result of addressing the problem (Mohaghegh, Shale Analytics, 2017). What is more, (Gibert, K, Vincent Botti, 
and Roman Reig-Bolano, 2013) came up with a set of characteristics that are used to identify intelligence networks.

They argued that an intelligence network possesses connection arrangements called Architecture. The learning or training algorithms refers to the method that determines the weight in the network connections.

In carrying out the research, a noteworthy consideration must be taken into account to make sure that artificial neural networks (ANN) estimation phases are successful. Mohaghegh argues that it is critical to focus strongly on quality control and filtration of the input data to the intelligence network related to the mechanism of splitting out the logs in a metrical manner (Mohaghegh, Shale Analytics, 2017). Good adjustments must also be made to ensure success in the validation process. (Cranganu, C., Luchian, H., \& Breaban, M. E, 2015) defined an artificial intelligence network as a cluster of information in a system that is obliged to execute the data that is similar to models of mathematics of the biology of human neural system. In the cognition of human beings, some performances take place that make use of artificial intelligence network. They came up with some characteristics of neurons, including

- Neurons are some of the simplest elements that are perceived to affect information processing.

- There are some connections in neurons that are responsible for passing signals.

- Every link in connections has weights that are allocated, and which are responsible for transmitting signals.

- Every neuron possesses a function that is non-linear in nature and which are used in the determination of an output with summation of weighted and input signals.

What is more, (Gibert, K, Vincent Botti, and Roman Reig-Bolano, 2013) came up with a set of characteristics that are used to identify intelligence networks. They argued that an intelligence network possesses connection arrangements between the neurons that are called Architecture. There exist activation functions that are available for every network of connection. For the recognition of the artificial intelligence networks with external systems, the processing of information offers the answer of the methodology and the end 
result. Every neuron is connected directly to another and has the ability to send a single signal at any given time, after which they are broadcasted to one or more neurons.

A study that was undertaken by (Acton, Q. A., 2012) indicated that the primary concern for most engineering practitioners is that models of neuron networks define the extent to which they show different variations from the systems of biological neurons.

On the contrary, others think that the differences are countered by the net's ability to play a function while performing certain obligations. There are visible similarities in the neuron's structure and the processes of the elements. The individual neurons that are acquired from different species are somewhat similar that the neural networks that are contained in the system. A neuron comprises of cell or soma body and has two branch types. They are regarded as the axon and the dendrites. The nucleus comprises of information in the cells of the body. This is the kind of information that is known as the plasma, and highly contains the tools that are used in the production of the elements required by neurons.

\subsection{Machine learning}

Many studies indicate that machine learning relies on a set of applications that have been extensively used in the past 30 years. Accordingly, their increased use is attributed to the tremendous growth that was witnessed in the field of petro-technical data. To date, they are regarded as something that is of utmost necessity. Artificial Neural Networks are a form of computing system whose functionality is inspired by the networks of biological neural systems. Their efficiency explains their wide use in the oil and gas sectors. They help practitioners in the sectors to deal with huge volumes of well and seismic data.

The field of artificial intelligence networks could be defined as the adaptable node networks which are designed to perform tasks that rely on data that can be exposed and experienced, without the need to program them with the use of rules that are task-specific. They are designed in such a way that information is channeled in the same way as the brain 
functioning. For instance, the program is designed to classify and recognize images according to the different elements that they reflect. The majority of machine-based learning have three main characteristics.

- They have the ability to explain outcomes that exist.

- They can make predictions about the future

- They can avail a set of recommendations that can be used to manage risks and make decisions.

The features are a part of wider strategy to permit the applications of predictive analytic and machine learning in the production and field optimization. The methodologies of machine learning are further divided into supervised and unsupervised learning. Unsupervised learning focuses on soft data or input data. Its main goal is to seek for similar tenets in the data and process them by classifying into appropriate groups that reflect similar points or characteristics. There is a model that is prepared and designed to deduct structures that are available in the input data. The exercise could be undertaken using mathematical processes in reducing systematically any redundant elements or organizing the data that reflect similar patterns. Some of the associated algorithms include dimensionality, clustering, association rule, and reduction learning.

On the other hand, supervised learning includes those with input data that is a clearly known label. There is model preparation that adheres to a strict process of training with the aim of imparting the required predictions. In case of mistakes, corrections are made to ensure that the predictions are correct. The process of training goes on until the model achieves the needed accuracy. This is because of parameters such as the right accuracy level with respect to the training data. The problems emanate from regression and classification.

Mohaghegh maintains that in recent years, there have been significant developments, such as the explosion in the quantity and size of data, GPUs development, and decline in the prices of hardware. The result has been extensive research into complex 
algorithms. There is a new class of techniques in machine learning that require the user to handle large data (Mohaghegh, Shale Analytics, 2017).

Deep learning is associated with algorithm learning machines that have the following characteristics.

- The learning process is highly supervised

- The learning process includes numerous layers that correspond to the various abstraction levels.

They make use of a cascade of numerous layers of units that are non-linear processing for transformation and extraction features. Every successive layer makes use of the output that is extracted from previous layers as their input.

\subsection{Research question}

The aim of this research was to develop the understanding of how machine learning could be used in order to generate synthetic well logs, specifically for wells that are missing certain types of well logs. Implementing this approach aims to ensure that the huge operational costs for companies is reduced drastically. The study sought to examine the nature of missing data that was related to the production logs and be able to predict the levels of production in the oil and gas reservoirs.

From a historical perspective, data logs have missing data or gaps that are attributed to limitations if the methodologies and tools that feature in the process of data collection. To be able to make predictions and be able to examine the gaps that are connected to the data points the model of Back Propagation is used to acquire data (both existing and nonexisting). 
This research sought to test the statement: Artificial Intelligence is capable of extracting the required information and learn from the data that is available from the existing well logs in order to generate new (synthetic) well logs for wells that are missing such logs. 


\section{CHAPTER III: METHODOLOGY}

\subsection{Introduction}

As noted in the introduction chapter of this study, the core purpose of the current research was to explore the form and nature of artificial intelligence network systems to develop synthetic well logs as well as examine the capability of artificial intelligence technologies in building new strategies seeking development of oil and gas fields. The achievement of this aim and the accompanying research questions necessitated the development of an exhaustive methodological framework that would guide the researcher in the entire study. In this regard, the current chapter logically presents the various methodological components observed by the researcher when conducting this study. The chapter highlights the research approach/ methods and design adopted, as well as the data collection and analysis techniques employed by the researcher.

\subsection{Research method/ approach}

The approach adopted includes the use of artificial intelligence networks as the sole tool by applying the data that was acquired from conventional well logs. A major step is to establish the number of wells that is in existence in our field. To get access, it is established that the data would be presented in form of LAS file. The form of data is critical in providing actual values for all the logs run on the wells. After careful evaluation, a critical analysis is also important in determining the number of well logs that would be used in carrying out the project. Out of the chosen wells, it is important to establish the number of wells that would be set aside as blind wells to test the accuracy of the machine learning.

The study involves analyzing information and data acquired from the wells that are situated in the given field. An excel sheet would be used to determine how the data would be used for each well. The first step is studying and understanding the location of the reservoirs with the aim of getting a sense of the values with varied properties. Studying the 
reservoirs would ensure that there is generation of a table with initial values to be able to make comparisons and ensure that the values are within the set range.

\subsection{Research strategy}

The research strategy includes exploratory design. The choice is informed by the need to explore how machine learning aid in generation of synthetic well logs. In other words, the aim is to understand how data is fed into machines and make them intelligence to the point of predicting future or missing outcomes. As argued by Dr. Mohaghegh, establishing the use of machine learning to generate synthetic well logs must follow a specific step so as to obtain good results. The steps will be applied in this research are:

- Obtaining the data from the established field of study.

- Studying and understanding the location of the reservoirs with the aim of getting a sense of the values with varied properties.

- Filtering and organizing the data in a coded form.

- For each run, divide our dataset into two groups, first group will have all of the well logs data, second group will have some wells with missing logs.

- Some wills will be chosen from the first group that have all of the well logs and will be called "blind wells", those wells will be used to test the performance of the log generation.

- Use IMprove software to generate the missing logs in the second group.

- After generating the messing logs, validate the results using the blind wells and compare the actual data with the generated one.

Obtaining data from mature fields has its own challenges such as the huge number of wells in the field and difference in completion time among those wells. Since the technology used in oil and gas industry involves a rapid development, data obtained from mature fields affected by this fact and in many cases the researcher end up having huge differences between data from old wells and recent completed wells. This fact requires a 
remarkable effort from the researcher to uniform the data and use different python codes to extract and analyze the data in our research particularly.

Studying the location of the field and analyzing the reservoir properties provide the values awareness for the researcher. This step is very important and will save a lot of time and efforts preparing the researcher for the next parts of the research, for example knowing the minimum and maximum ranges of the reservoir properties values will build a scale for the predicted values at the end of each run of this research that researcher can evaluate and decide to complete the next steps or restart the training process.

Data obtained from the field usually comes with tens or hundreds of parameters and attributes. Therefore, the data need to be organized and filtered to be used efficiently in the research. Furthermore, some data format needs to be changed to the software data importing requirements.

Data partitioning is a well-known process used in machine learning process. Generally, it's the way of introducing the data to the software, for each run in this research, the data divided into two groups, first group will have all of the well logs data and will be used as training data, second group will have some wells with missing logs and will be used after training process ends to predict the missing logs.

Some wills will be chosen from the first group that have all of the well logs and will be called "blind wells", those wells will be used to test the performance of the log generation.

Once the data prepared, IMprove software is used to train the neural network using the training set. The software keeps training the neural network until the calibration error stop reducing. This process takes more than seven hours. After training process ends, the second set of data will be imported to the software to generate the missing logs. 
After generating the messing logs, actual values from "blind set” data plotted Vs. generated values using python code to validate and compare the results.

\subsection{Data processing}

Data was received from Abu Dhabi National Oil Company “ADNOC” in (LAS) format, 34 wells in the same field. As shown in (figure 2), data was extracted, filtered and then graphic well logs were plotted using Python code(figure 1) to get a better understanding of the field.

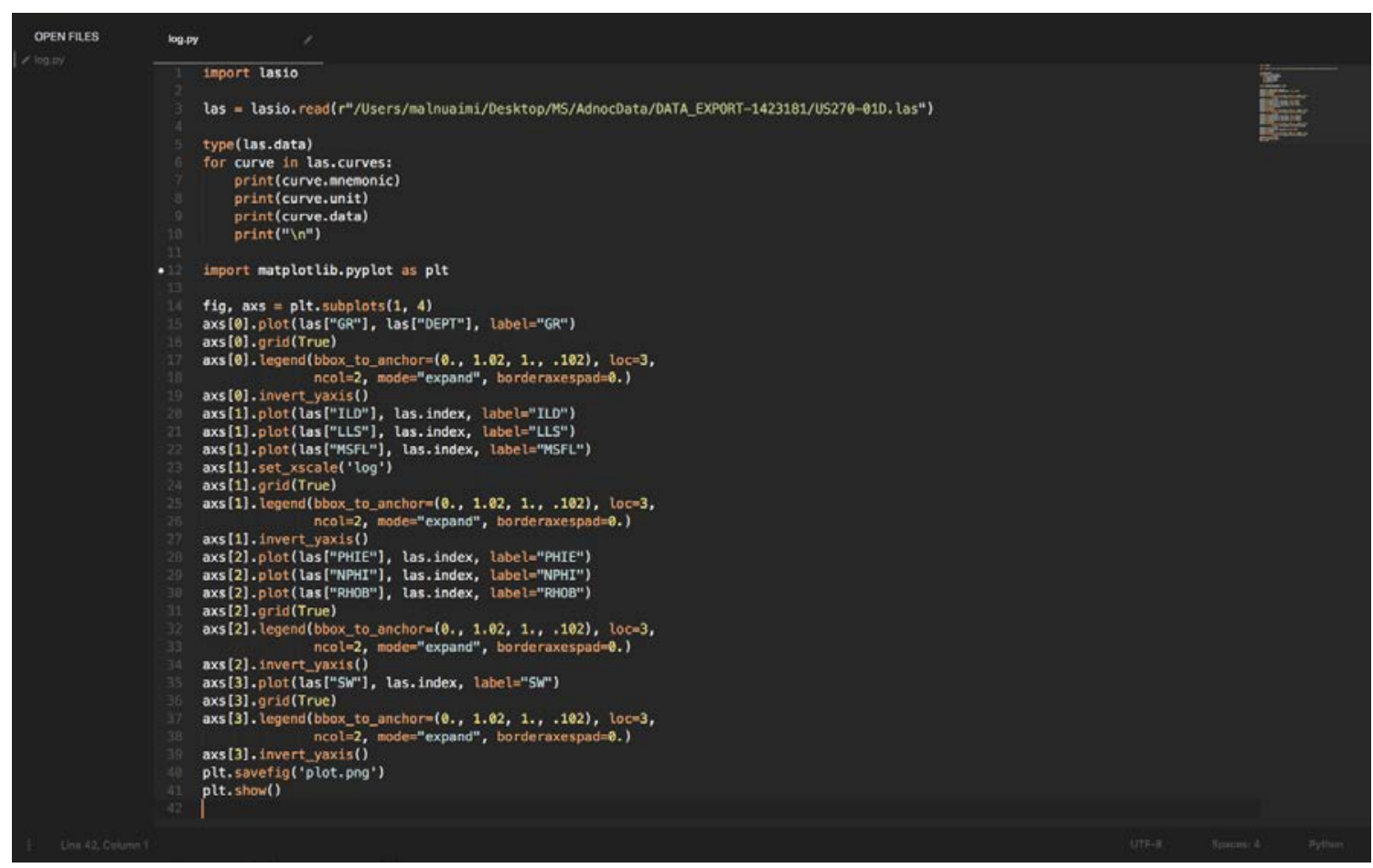

Figure 1: Python code used to plot well logs 


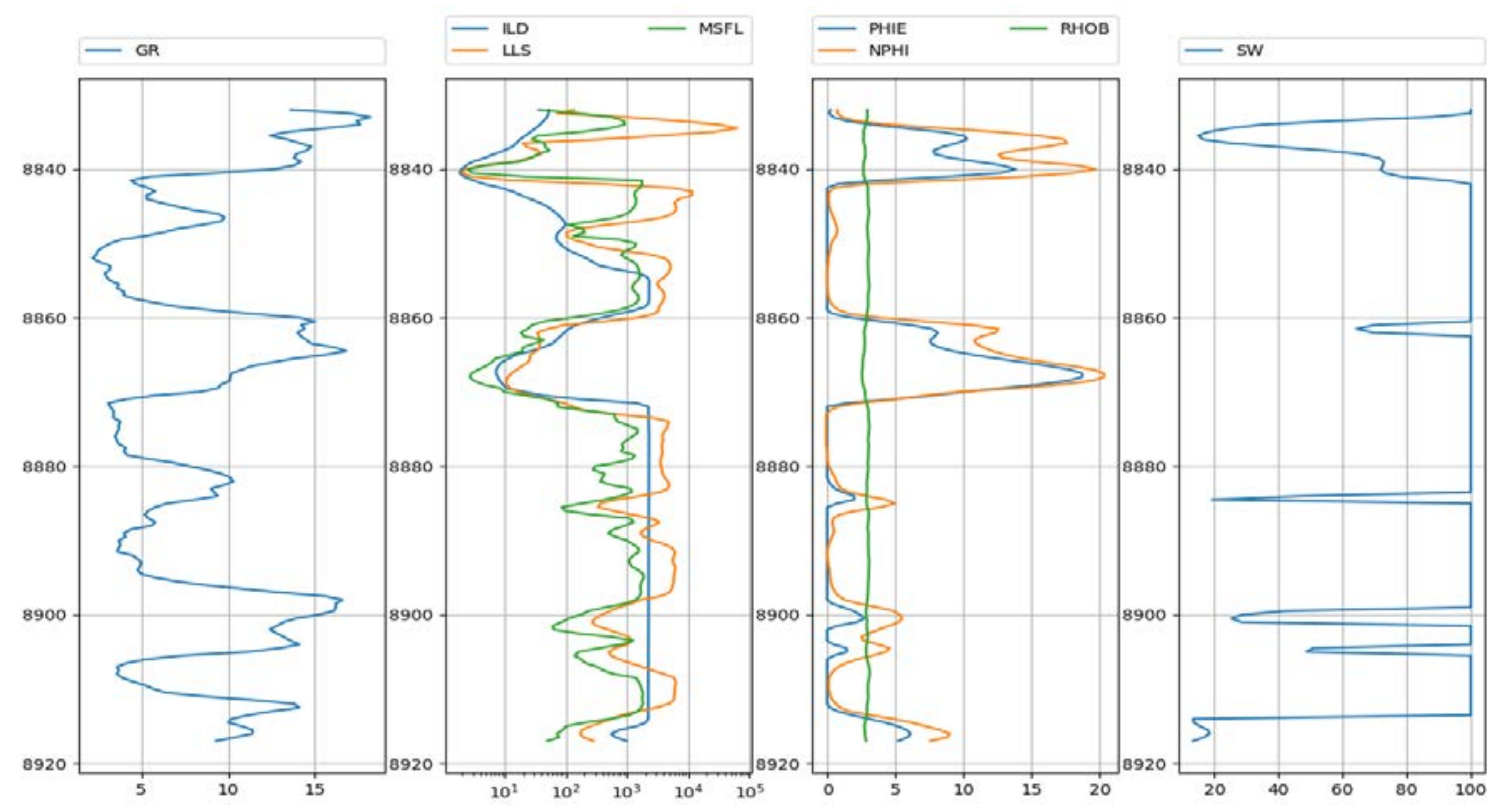

Figure 2: Generated well logs

All wells were divided according to well logs data availability as following:

- First group contains 8 wells with all well logs available

- $\quad$ Second group contains 8 wells missing one well log (ILD).

- Third group contains 2 wells missing one well log (LLS).

- Forth group contains 1 well missing one well log (PHIE).

- Fifth group contains 1 well missing two well logs (PHIE and ILD).

- Sixth group contains 1 well missing three well logs (MSFL, ILD and LLS).

- Seventh group contains 1 well missing three well logs (ILD, LLS and RT).

- Eighth group contains 4 wells missing four well logs (MSFL, ILD, LLS and RT).

- Ninth group contains 1 well missing four well logs (MSFL, ILD, LLS and RHOB).

- Tenth group contains 2 wells missing five well logs (MSFL, ILD, LLS, RT and NPHI).

- Eleventh group contains 2 wells missing sex well logs (MSFL, ILD, LLS, RT, RHOB and PHIE).

- $\quad$ The last three wells missing GR pulse other well logs.

Figure 3 illustrates the groups created after dividing all wells 


\begin{tabular}{|c|c|c|c|c|c|c|c|c|c|}
\hline \multirow{2}{*}{ Group } & GR & MSFL & LLS & ILD & RT & RHOB & PHIE & NPHI & SW \\
\cline { 2 - 10 } & GAPI & OHMM & OHMM & OHMM & OHMM & G/C3 & $\%$ & $\%$ & $\%$ \\
\hline 8 Wells & $\mathrm{X}$ & $\mathrm{X}$ & $\mathrm{X}$ & $\mathrm{X}$ & $\mathrm{X}$ & $\mathrm{X}$ & $\mathrm{X}$ & $\mathrm{X}$ & $\mathrm{X}$ \\
\hline 8 Wells & $\mathrm{X}$ & $\mathrm{X}$ & $\mathrm{X}$ & & $\mathrm{X}$ & $\mathrm{X}$ & $\mathrm{X}$ & $\mathrm{X}$ & $\mathrm{X}$ \\
\hline 2 Wells & $\mathrm{X}$ & $\mathrm{X}$ & & $\mathrm{X}$ & $\mathrm{X}$ & $\mathrm{X}$ & $\mathrm{X}$ & $\mathrm{X}$ & $\mathrm{X}$ \\
\hline 1 Well & $\mathrm{X}$ & $\mathrm{X}$ & $\mathrm{X}$ & $\mathrm{X}$ & $\mathrm{X}$ & $\mathrm{X}$ & & $\mathrm{X}$ & \\
\hline 1 Well & $\mathrm{X}$ & $\mathrm{X}$ & $\mathrm{X}$ & & $\mathrm{X}$ & $\mathrm{X}$ & & $\mathrm{X}$ & \\
\hline 1Well & $\mathrm{X}$ & & & & $\mathrm{X}$ & $\mathrm{X}$ & $\mathrm{X}$ & $\mathrm{X}$ & $\mathrm{X}$ \\
\hline 1Well & $\mathrm{X}$ & $\mathrm{X}$ & & & & $\mathrm{X}$ & $\mathrm{X}$ & $\mathrm{X}$ & $\mathrm{X}$ \\
\hline 3 Wells & $\mathrm{X}$ & & & & & $\mathrm{X}$ & $\mathrm{X}$ & $\mathrm{X}$ & $\mathrm{X}$ \\
\hline 1 Well & $\mathrm{X}$ & & & & $\mathrm{X}$ & & $\mathrm{X}$ & $\mathrm{X}$ & $\mathrm{X}$ \\
\hline 3 Wells & $\mathrm{X}$ & & & & & $\mathrm{X}$ & $\mathrm{X}$ & $\mathrm{X}$ & $\mathrm{X}$ \\
\hline 2 Wells & $\mathrm{X}$ & & & & & & & $\mathrm{X}$ & \\
\hline 3 Wells & & $\mathrm{X}$ & $\mathrm{X}$ & $\mathrm{X}$ & $\mathrm{X}$ & $\mathrm{X}$ & & $\mathrm{X}$ & \\
\hline
\end{tabular}

Figure 3: Data groups

Field Map

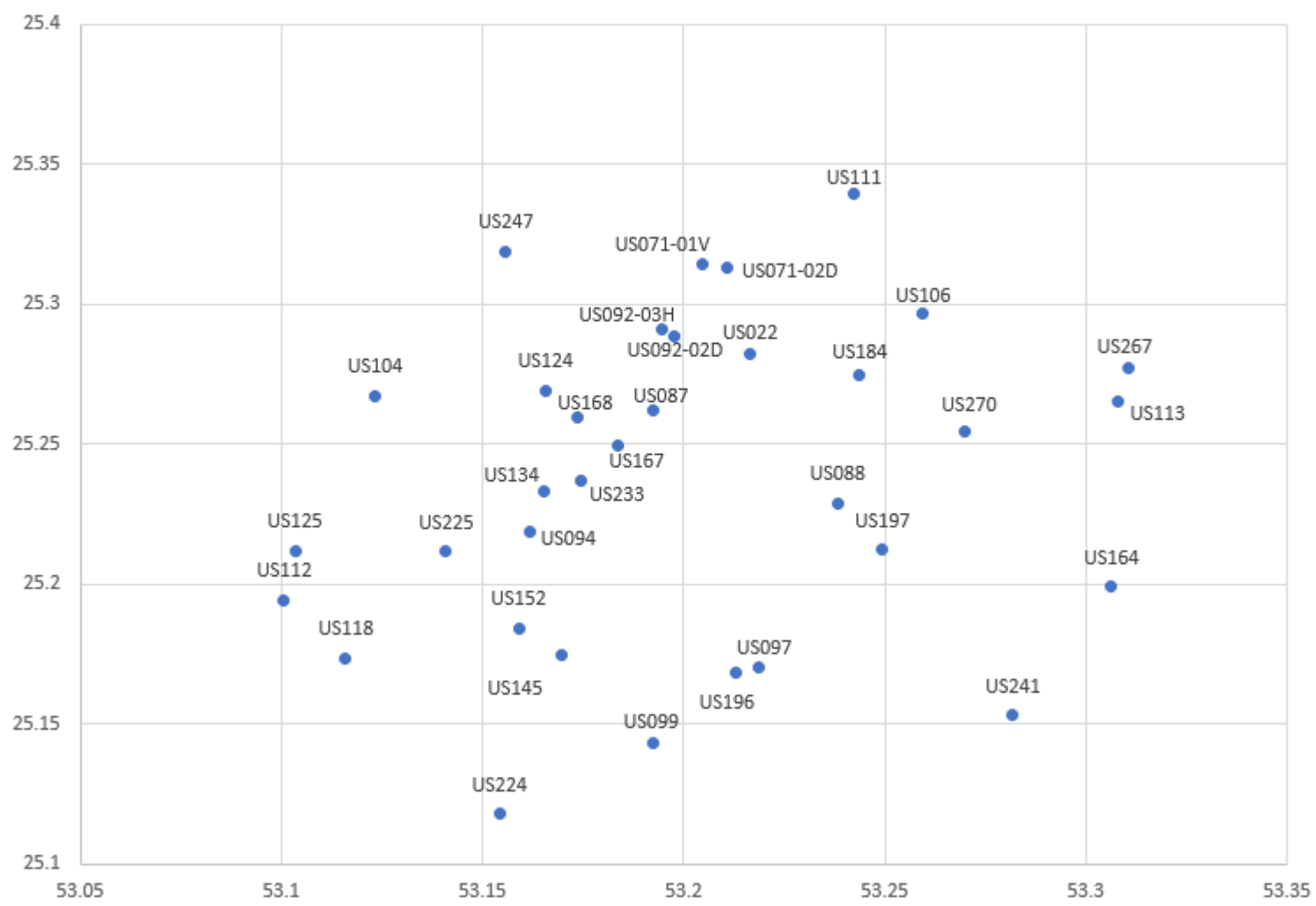

Figure 4: Field map

\subsection{IMprove software}

IMprove is a software built and maintained by "Intelligent solution Inc." to serve the need of using machine learning technique to generate synthetic well logs by training 
the neural network that belt in the software using the available data of the well and nearby wells in the same field. For each desired output (missing well log) we have to divide the data that will be used into two sets of data, training set (data containing every important well logs related to and including the desired output) and second set (data missing the desired output plus blind data that we already have its desired output hidden to test the accuracy of the output). Once we have a clear plan of the run, we train the neural network until the network "calibration set” stop improving, then stop training process and deploy the second set of data and generate the results.

For each run in the software we used the following steps:

- Start new project from "New project” tap and assign a name for the new project (Figure 5).

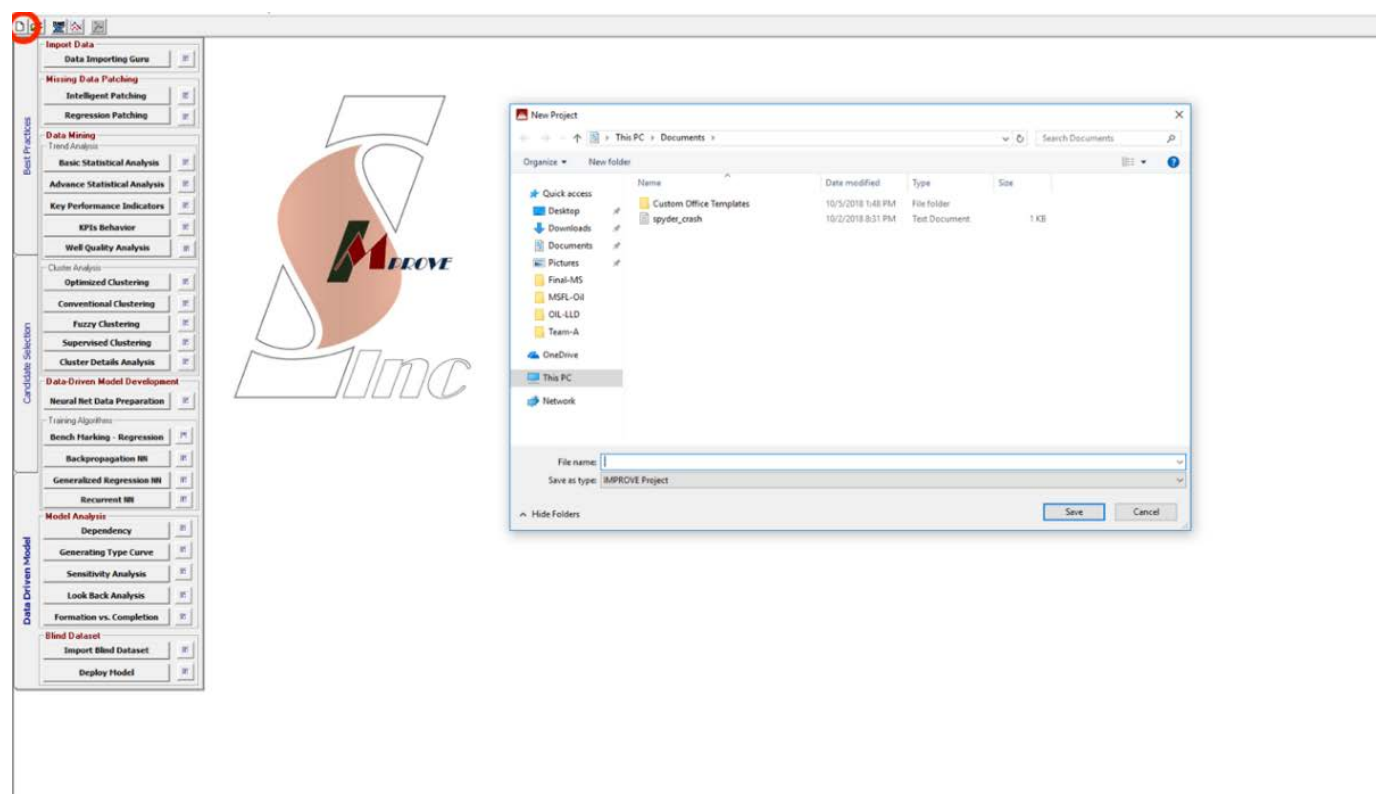

Figure 5: Step 1 Open new project

- Import training, calibration and validation data and set input / output attributes from “Data Importing Guru” tap (Figure 6 and 7). 

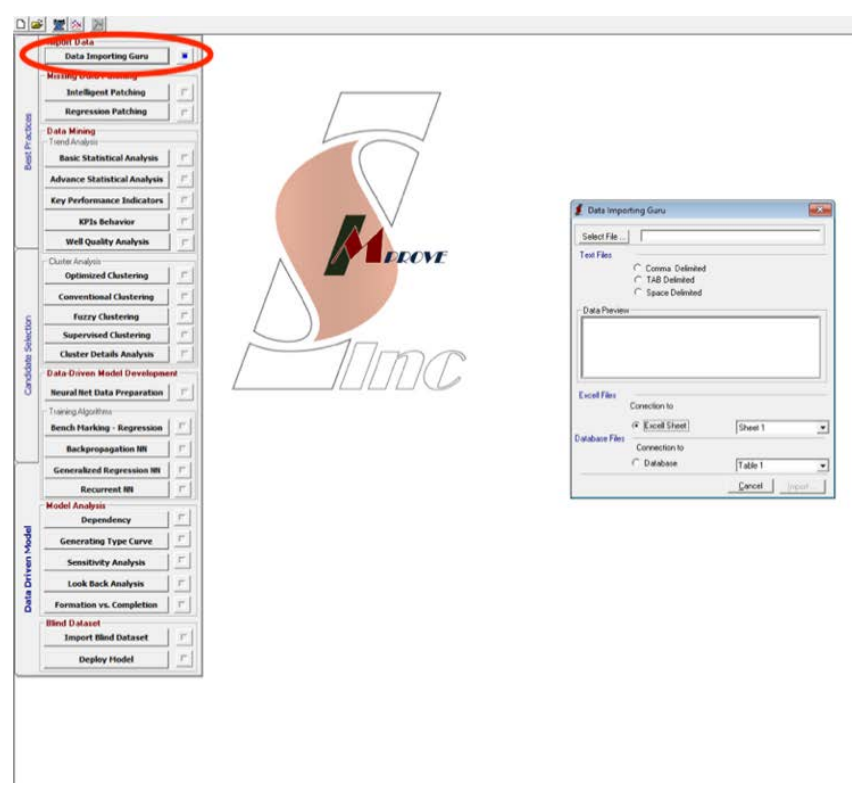

Figure 6: Step 2 Importing data

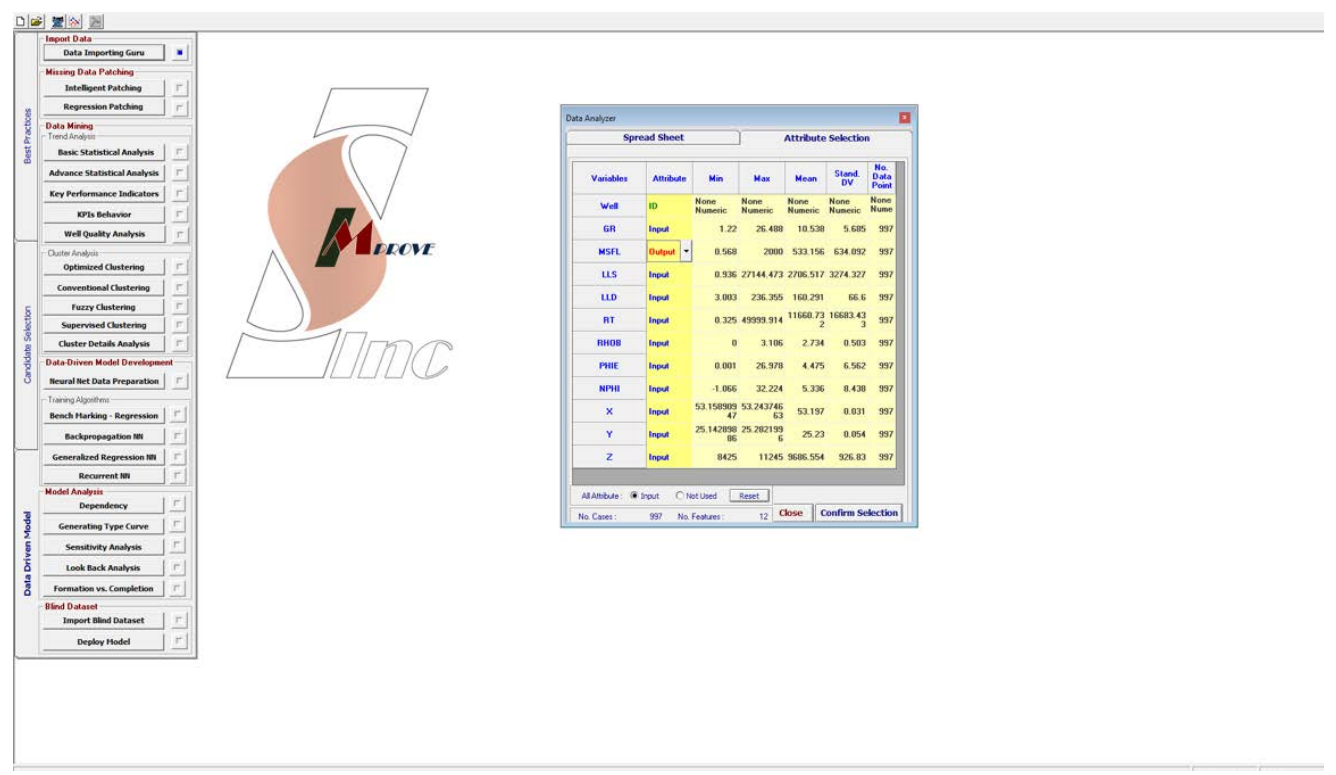

Figure 7: Step 2-Assigning attributes

- Analyse the imported data and understand the relation between the attributes from “Basic Statistical analysis” tap (Figure 8). 


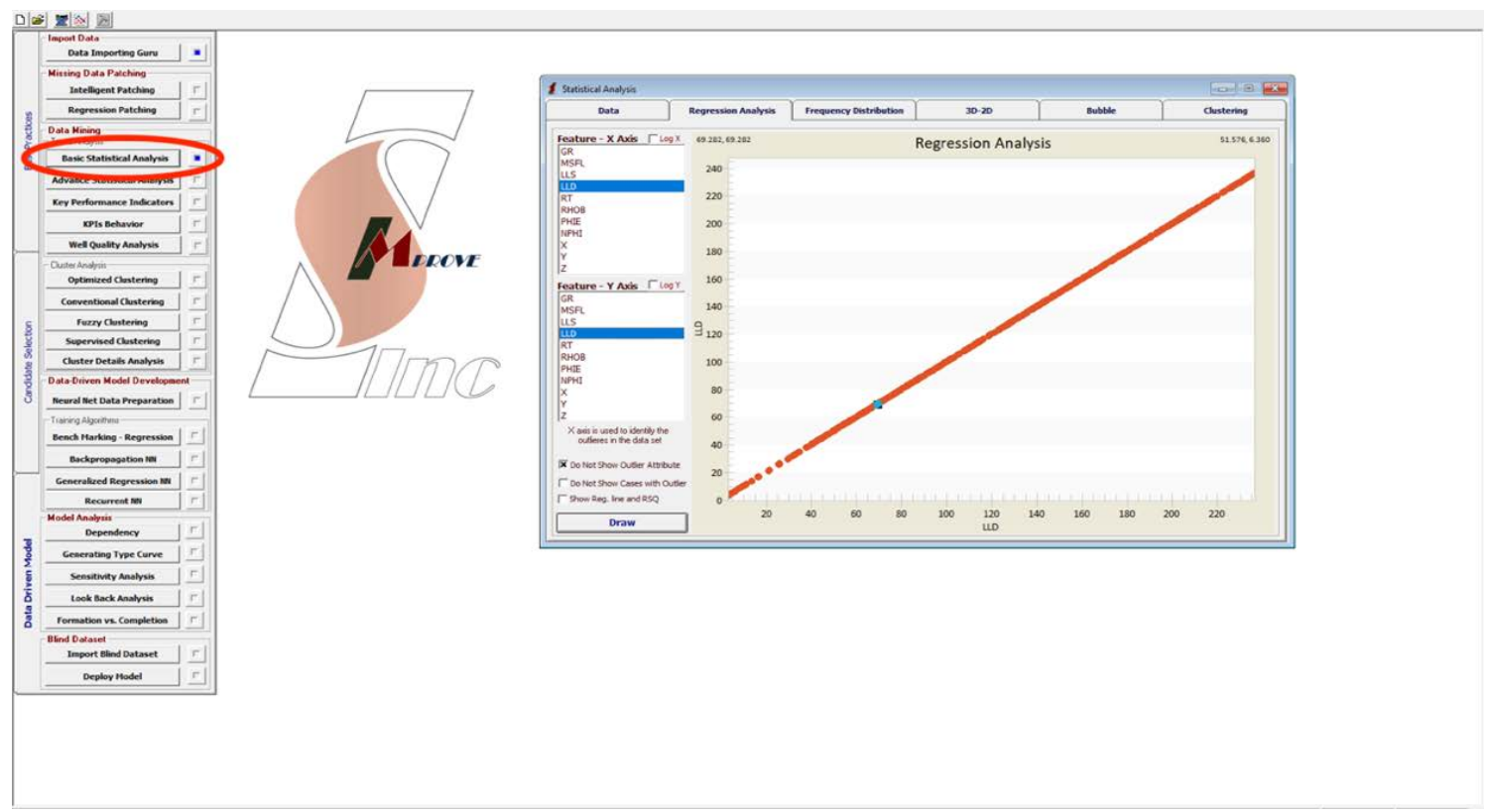

Figure 8: Step 3-- Analyzing the imported data

- Run key performance indicator (KPI) to get a better understanding about the important attributes and their influence to the desired output from "key performance indicators” tap (Figure 9).

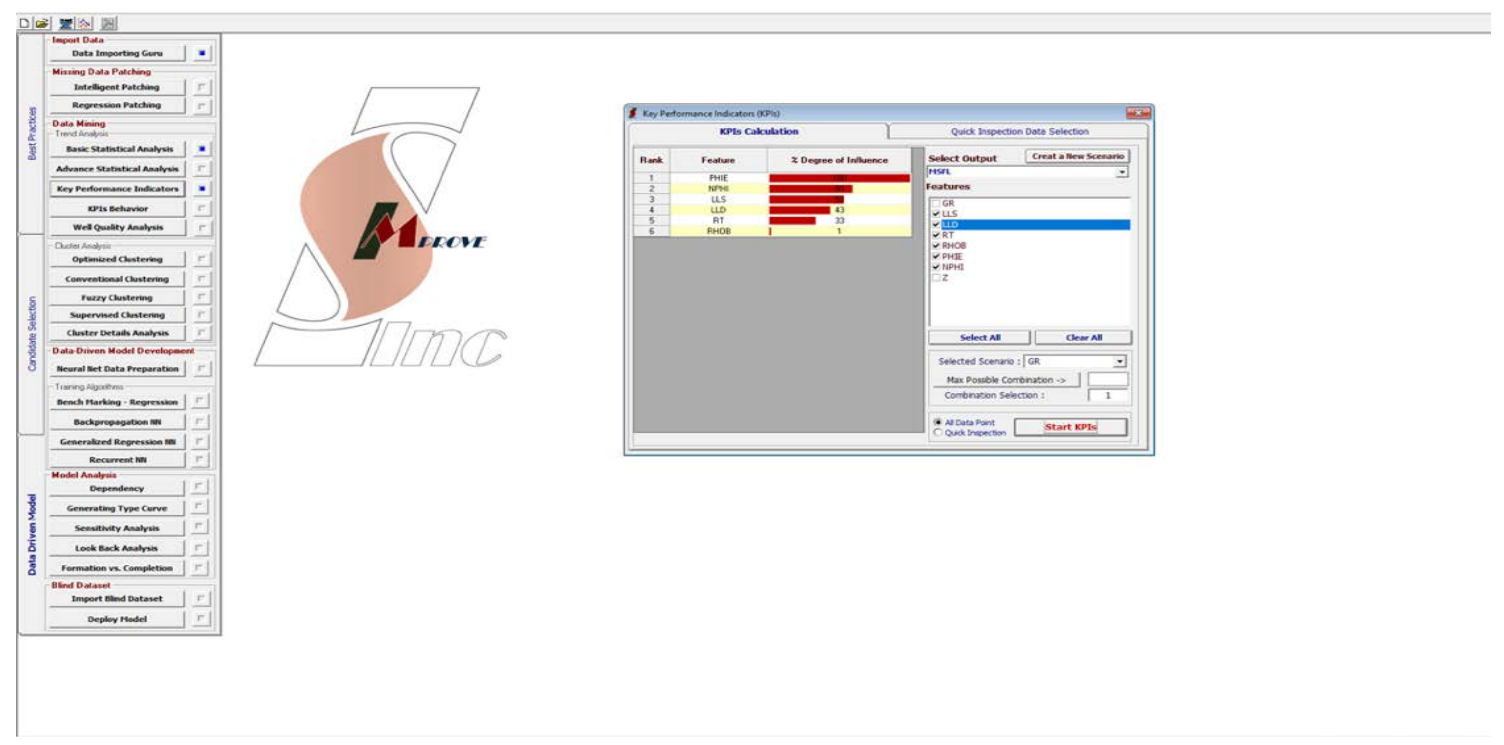

Figure 9: Step 4--Running the key performance indicator (KPI)

- Select the data that will be processed in the run and set the way and percentage of dividing the data to Training, Calibration and Verification from "Neural Net Data Preparation” tap (Figure 10). 


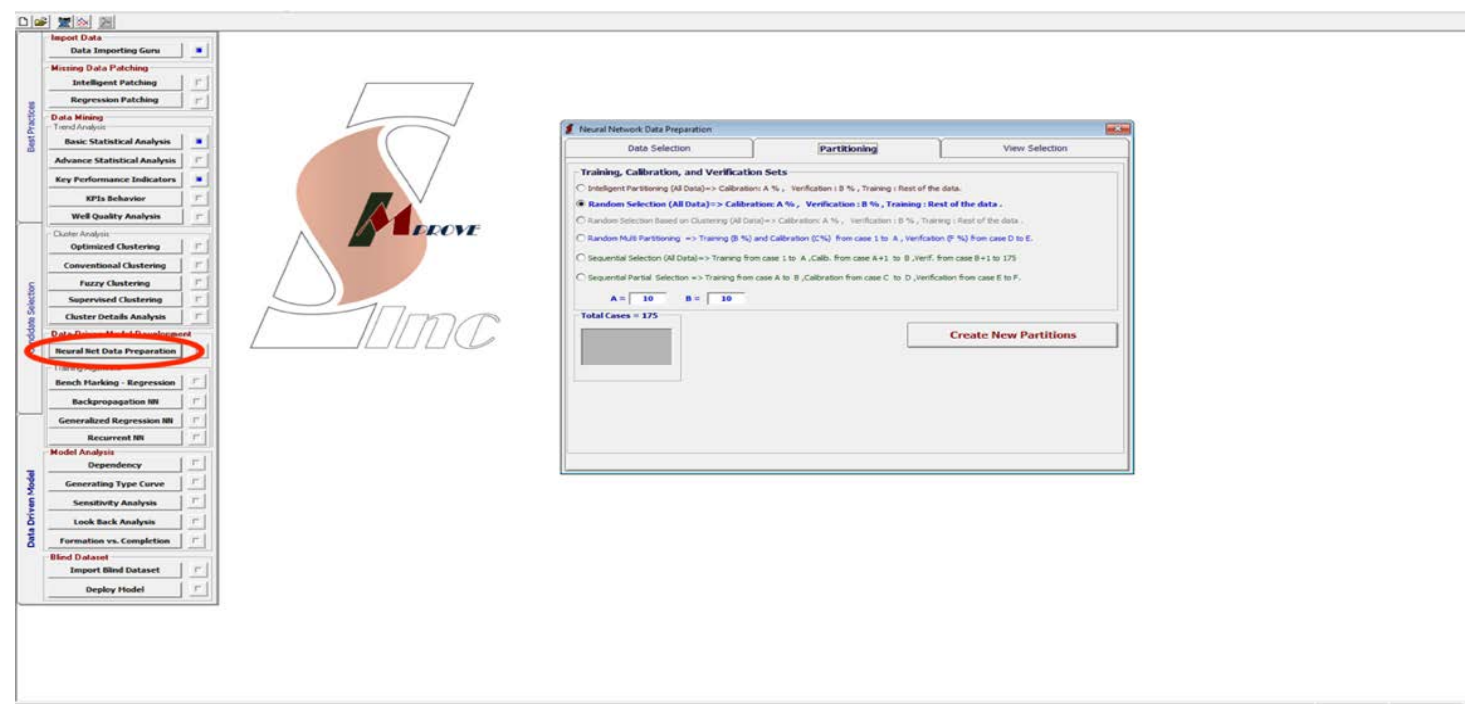

Figure 10: Step 5-- Selecting the data to be processed in the run

- Design the neural network by applying the suitable momentum, learning rate and hidden layer values and start training from “Backpropagation NN” tap (Figure 11).

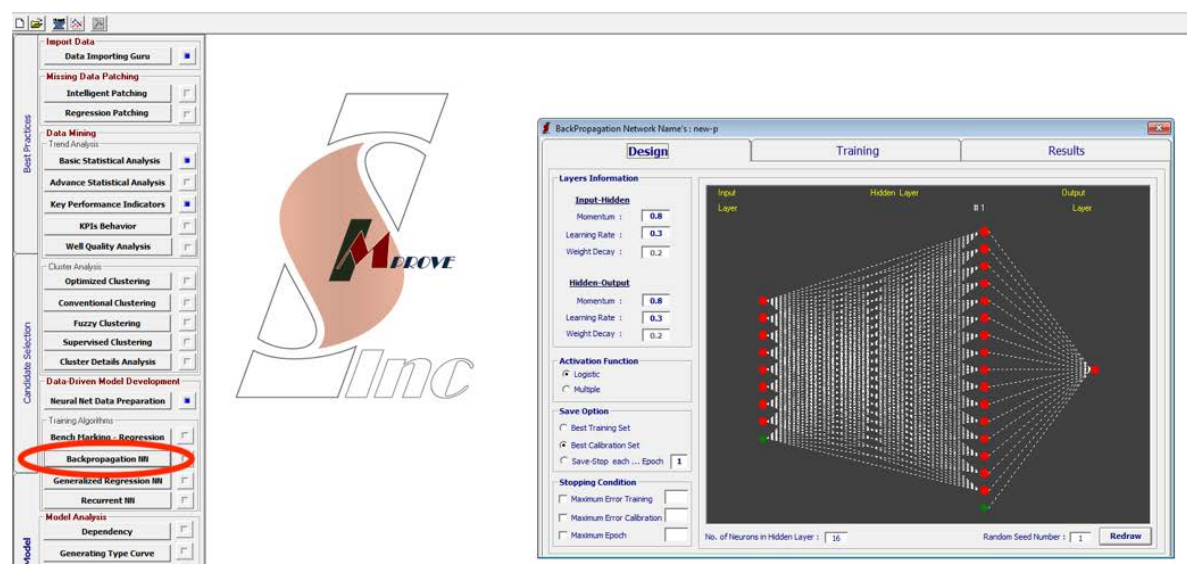

Figure 11: Step 6-- Designing the neural network

- Let the software run and keep monitoring the calibration / training graph until the calibration values doesn't get better anymore and stop the training process, the software will save the best calibration set anyway (Figure 12). 


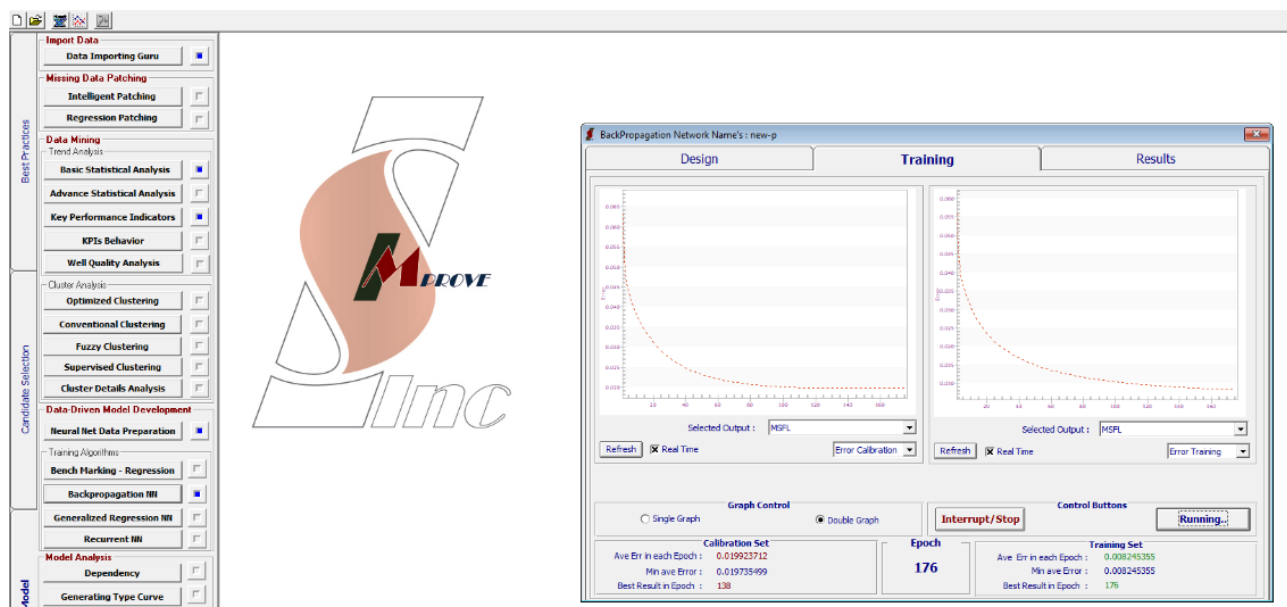

Figure 12: Step 7-- monitoring the calibration / training graph

- Once the calibration set stop improving, check the results of each attribute of the data involved in the training process (All, Training, Calibration, Verification and Blind). The better the $\mathrm{R}^{2}$ the more chances of getting accurate output (Figure 13).
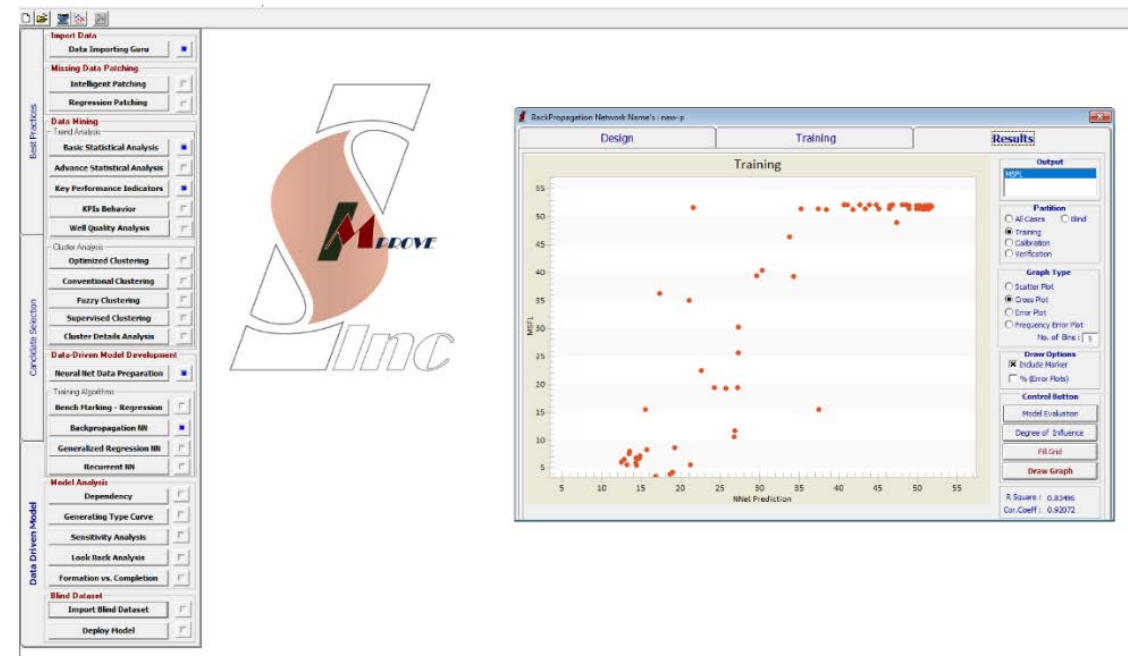

Figure 13: Step 8-- Checking the results

- Import the second set of data that has missing logs including the blind data from “Import Blind Dataset” tap (Figure 14). 


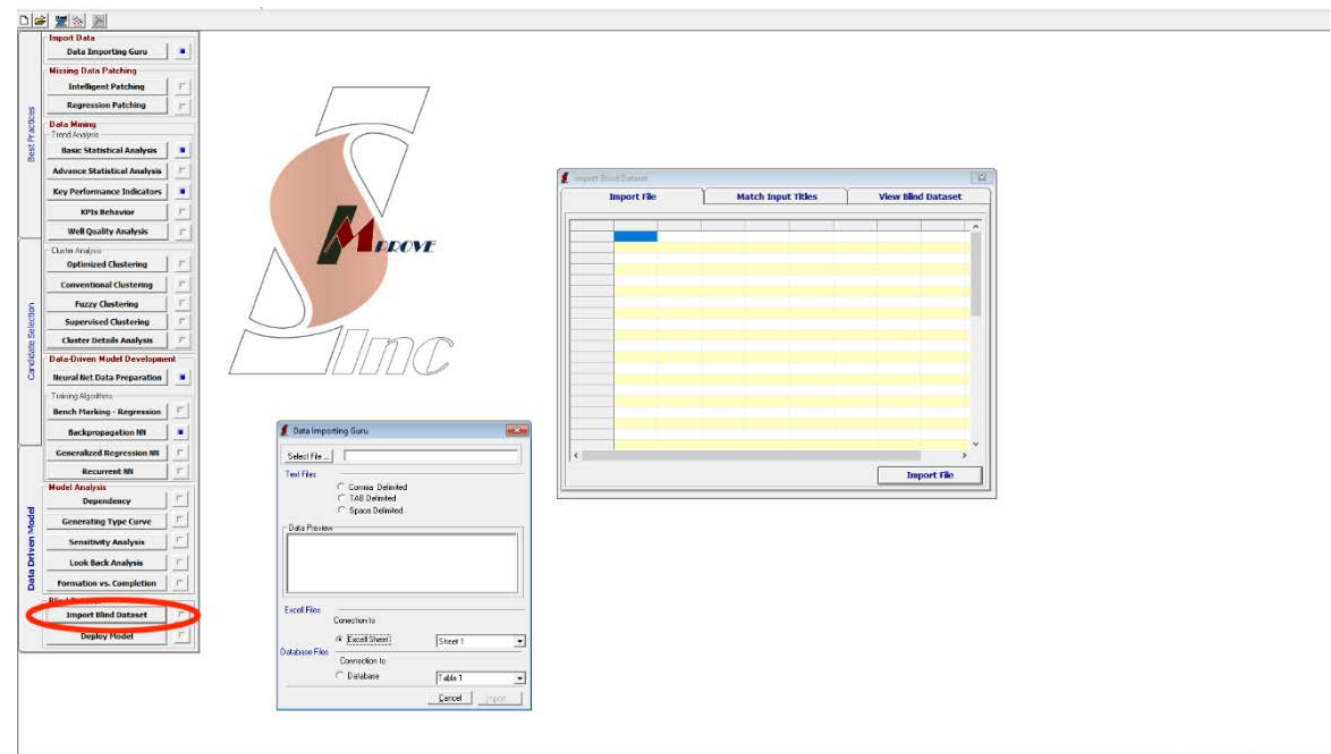

Figure 14: Step 9- Importing the second set of data

- Deploy the imported blind data and generate the messing data using "Deploy Model” tap (Figure 15).

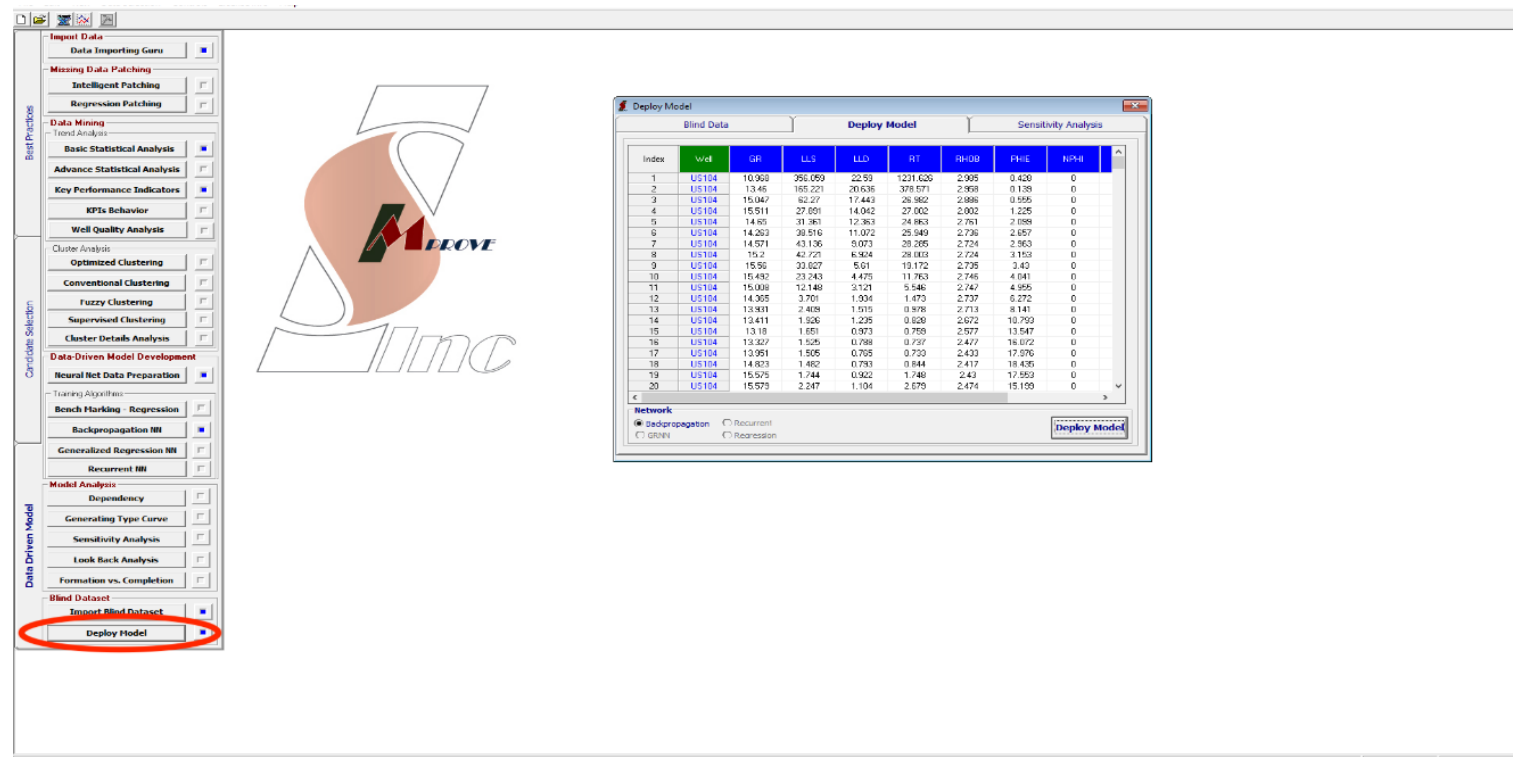

Figure 15: Step 10- Generating the messing data using “Deploy Model” tap

- After generating the results, export the output to an excel sheet and use the actual data of the blind set and plot both generated and actual values and check the accuracy of the output (Figure 16). 


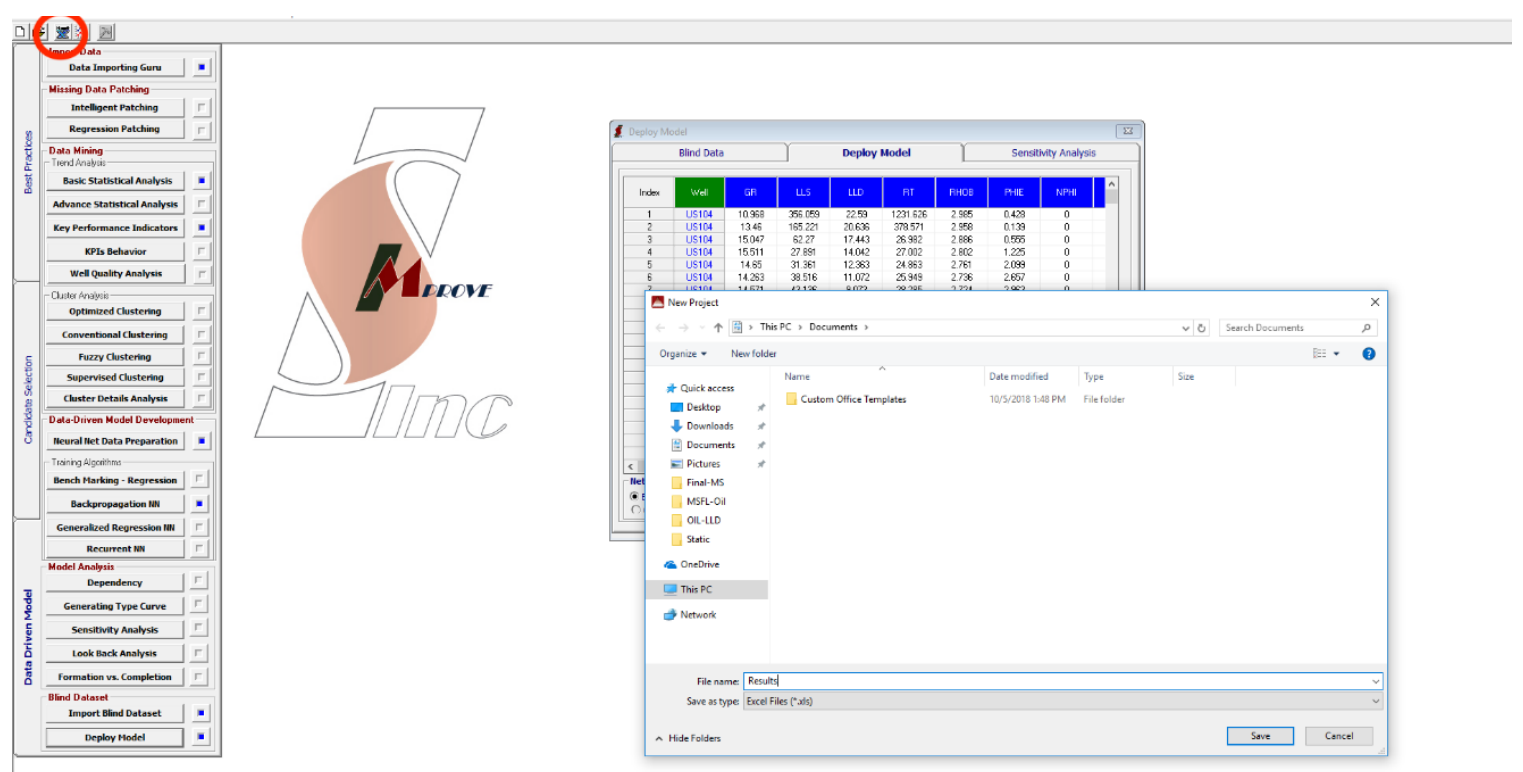

Figure 16: Step 11- Exporting the output to an excel sheet 


\section{CHAPTER IV: RESULTS AND DISCUSSION}

\subsection{Results}

After preparing the data, first group of data (7 injection wells) were selected as training set as shown in figure 17.

\section{Injectors Map}

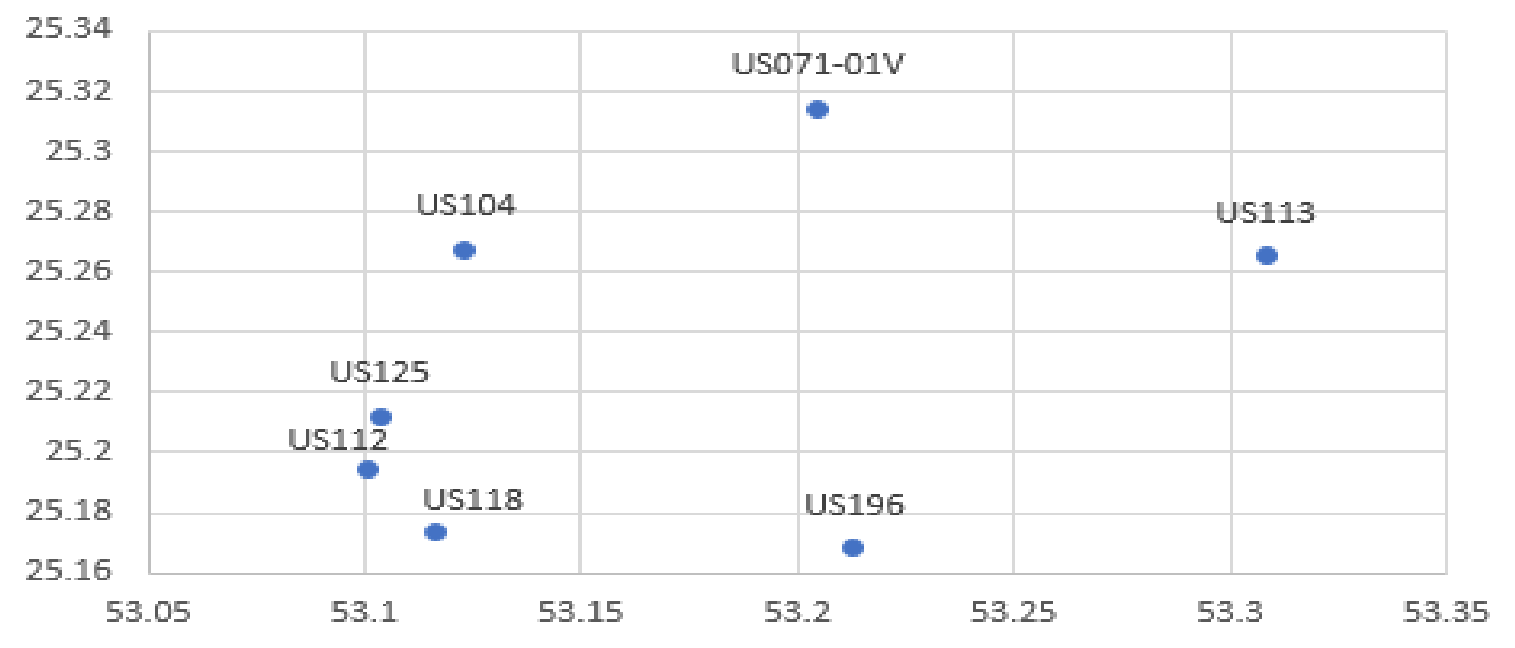

Figure 17: Injectors map

Porosity (PHIE) logs were noticed having many zero values, so It has been decided to correct the PHIE zero values since training process perform better when cell has any value other than zero. From the 7 injector wells, 1 well was removed and kept as a blind set and then all PHIE zero values were removed from the remaining 6 wells and set them as training data, then created a second set of data including the blind well in addition to zero PHIE values to deploy them after training the neural network. $\mathrm{R}^{2}$ results of the training process shown in table 1.

After generating the results, python code used to plot the generated output "NNPHIE" of blind well along with the actual value "PHIE” as it shown in (figure 26). 


\begin{tabular}{|c|c|c|c|c|c|}
\hline Partitioning & All & Training & Calibration & Verification & Blind \\
\hline $80-10-10$ & 97.1 & 97.4 & 96.2 & 94.1 & 95.3 \\
\hline
\end{tabular}

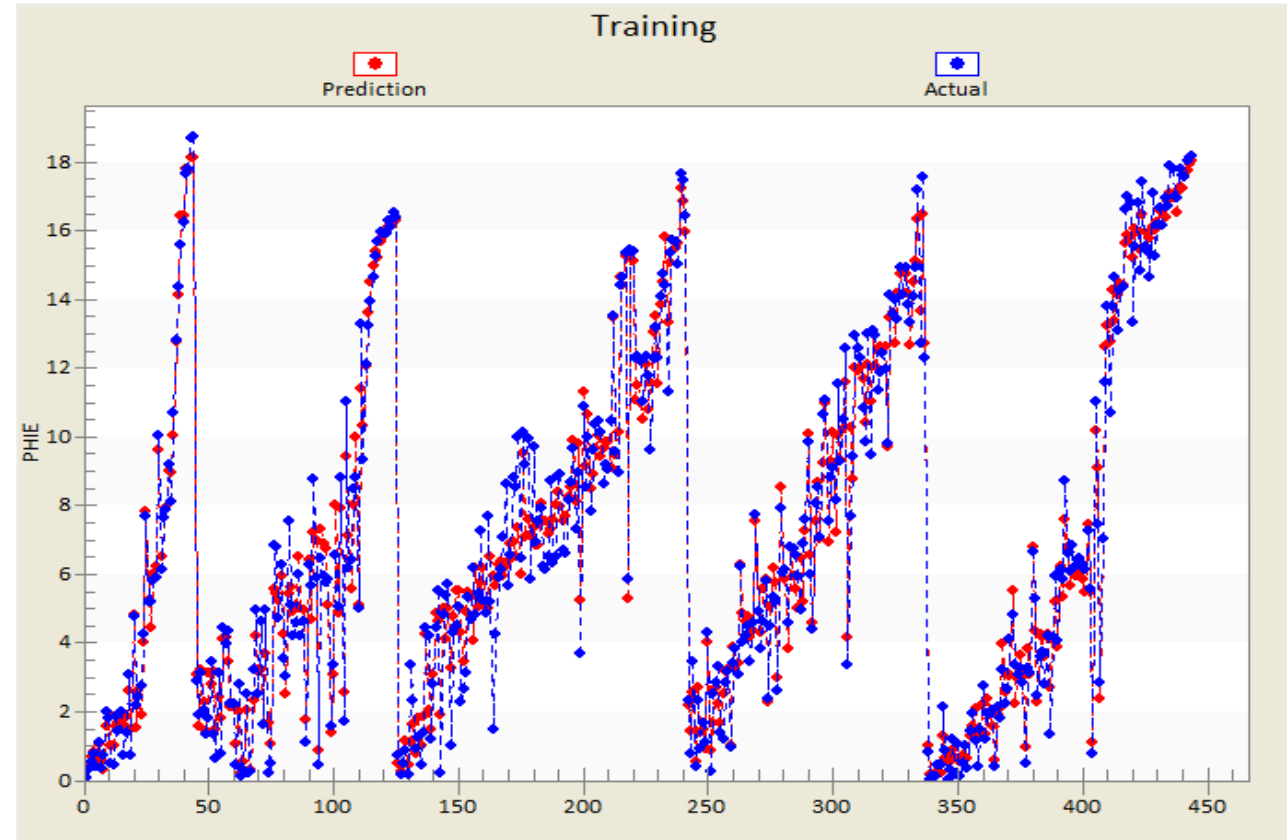

Figure 18: Training result scatter plot

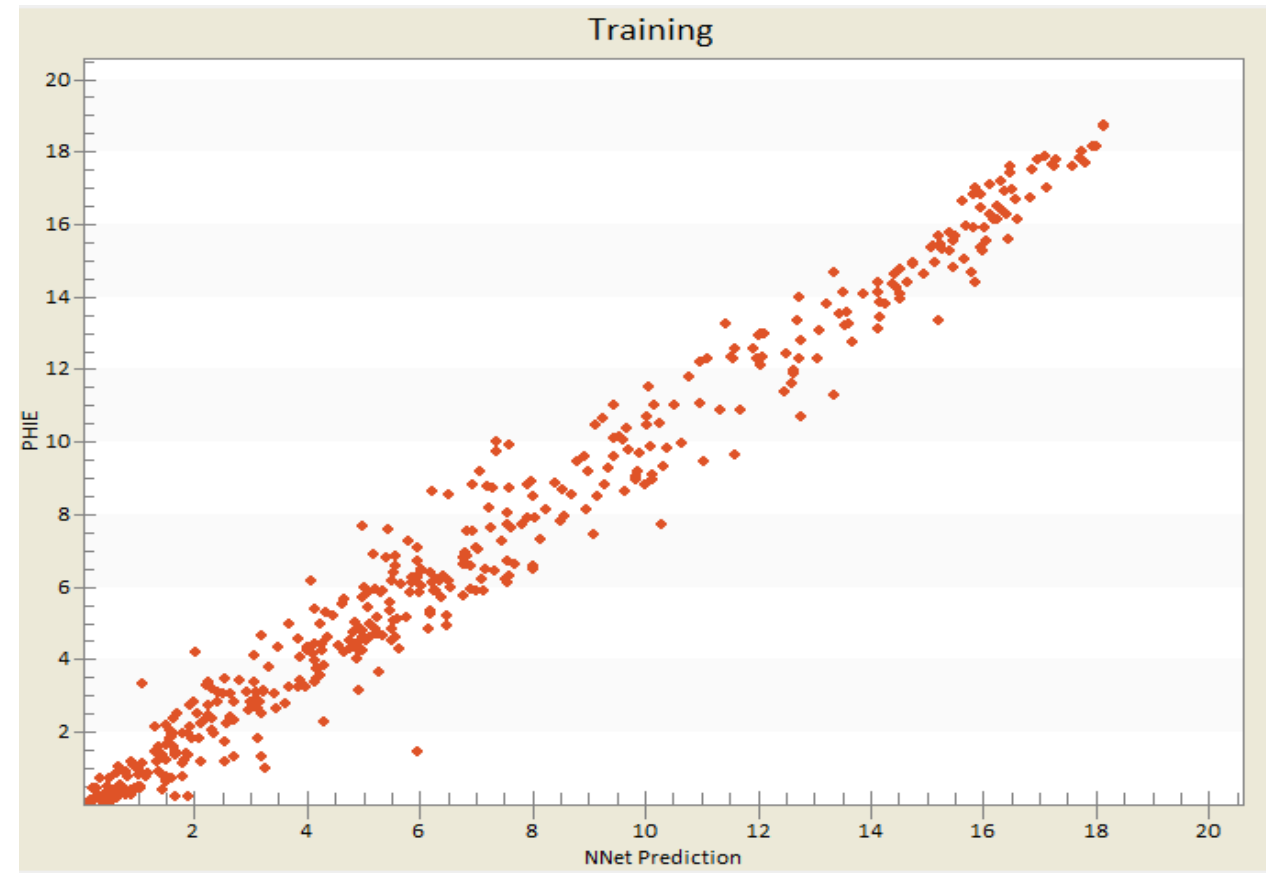

Figure 19: Training result cross plot 


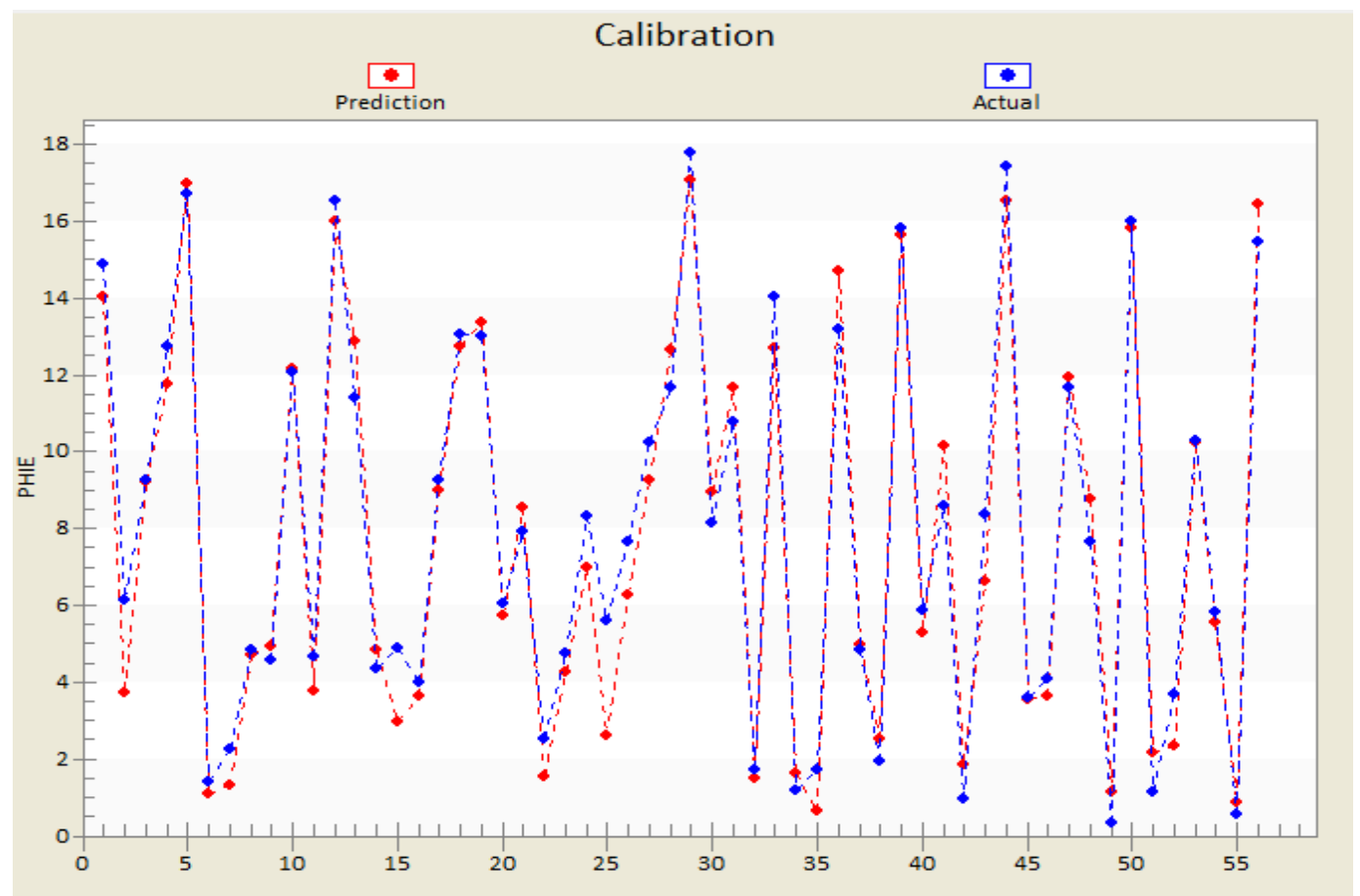

Figure 20: Calibration result scatter plot

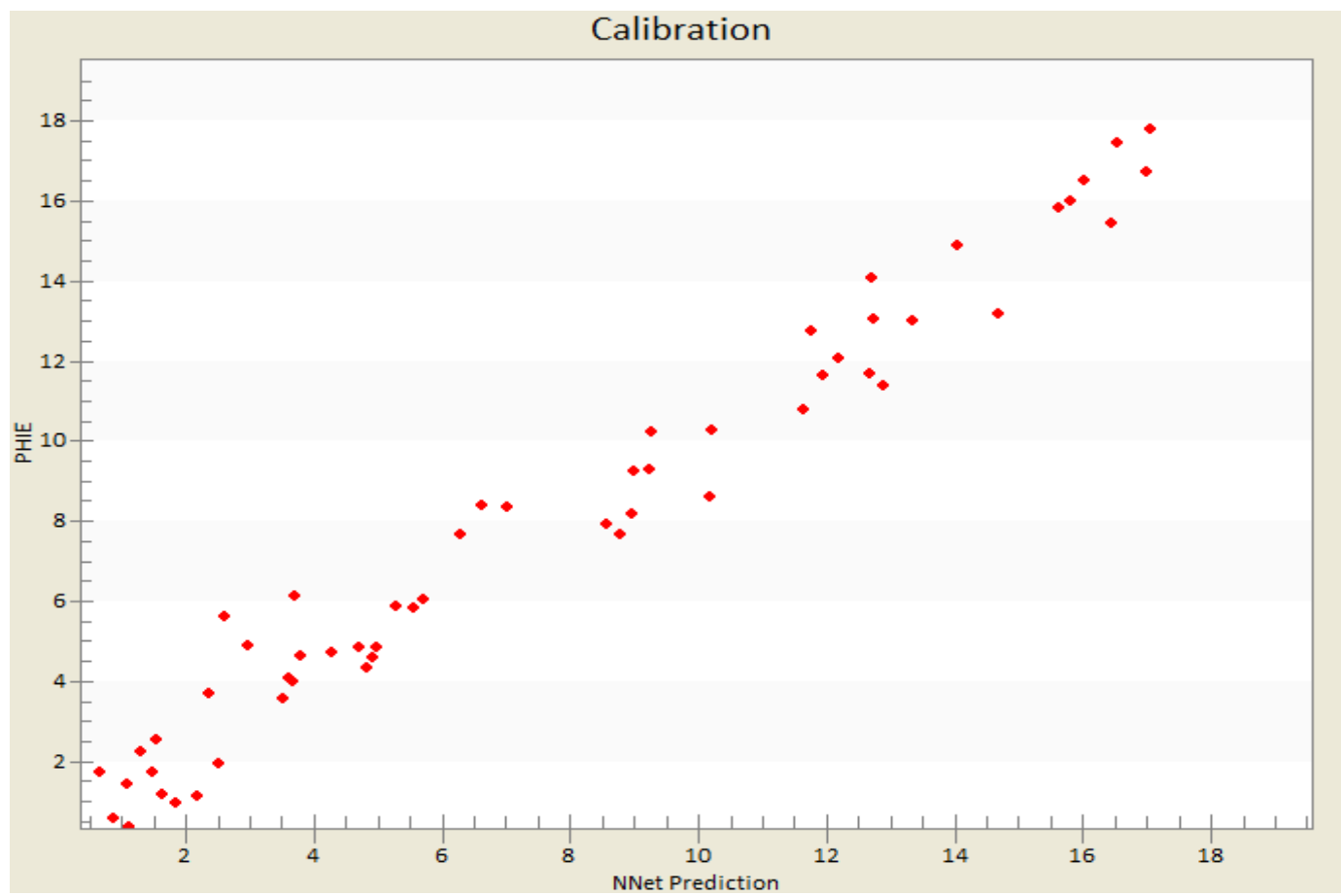

Figure 21: Calibration result cross plot 


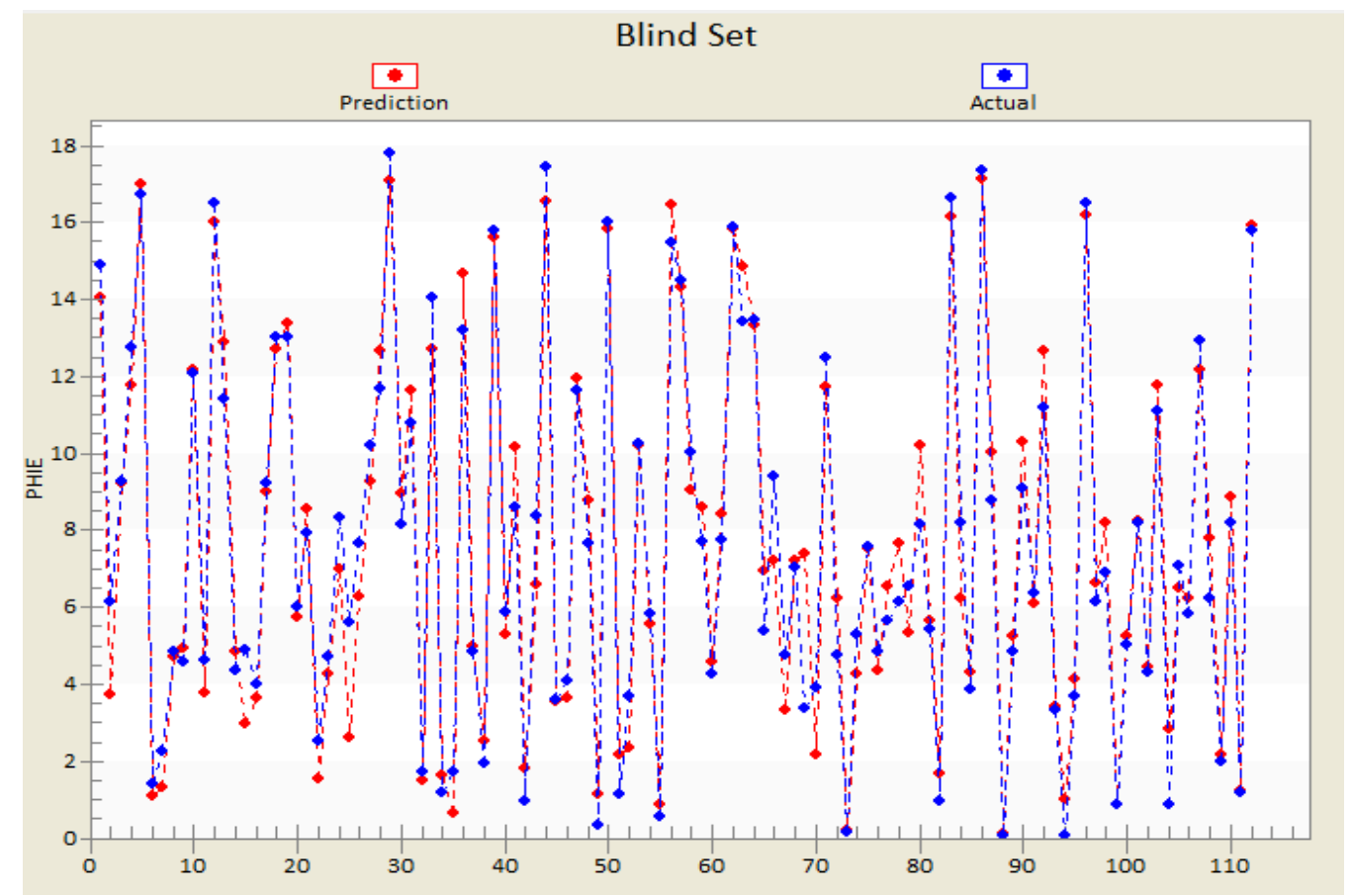

Figure 22: Blind result scatter plot

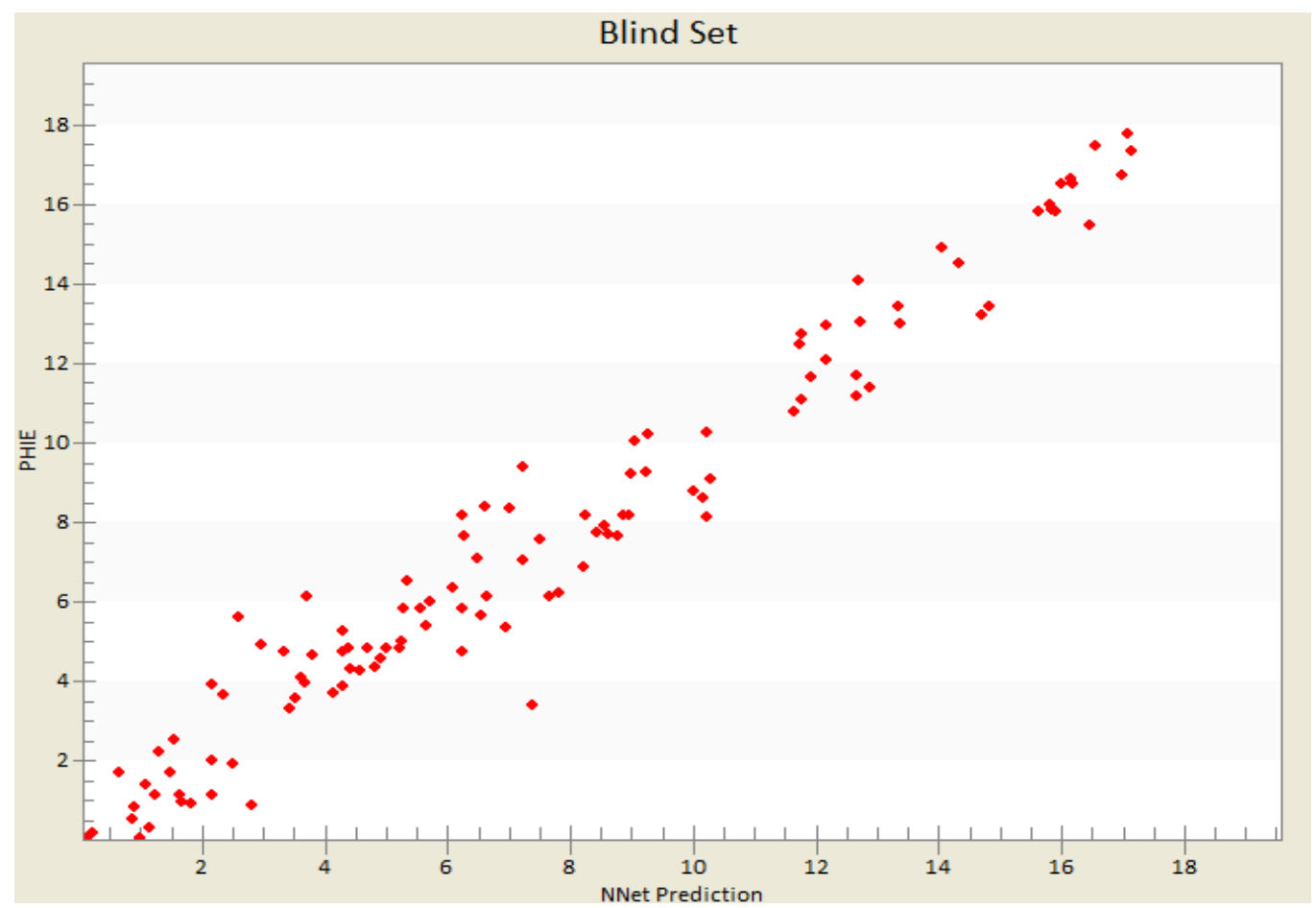

Figure 23: Blind result cross plot 


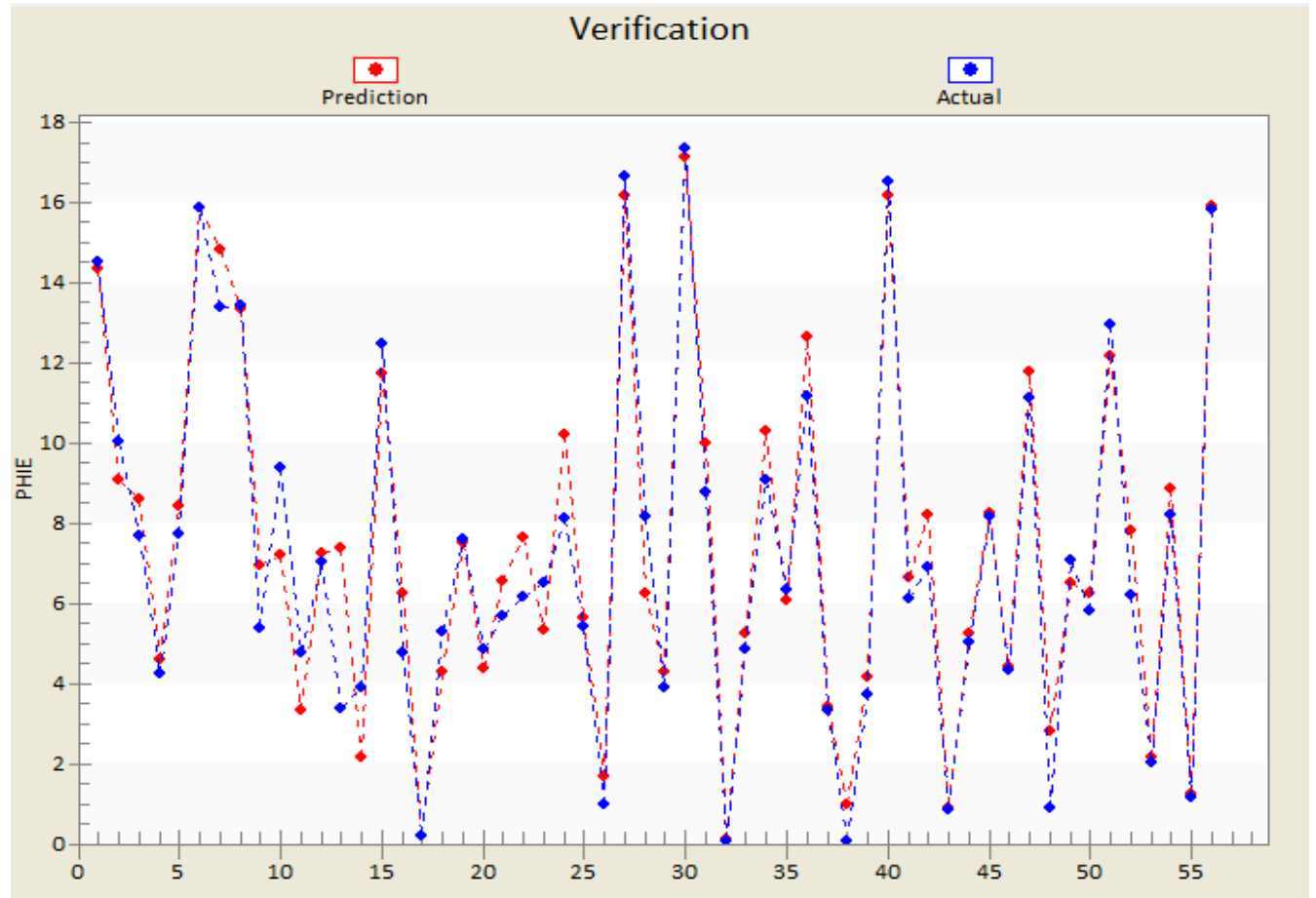

Figure 24: Verification result scatter plot

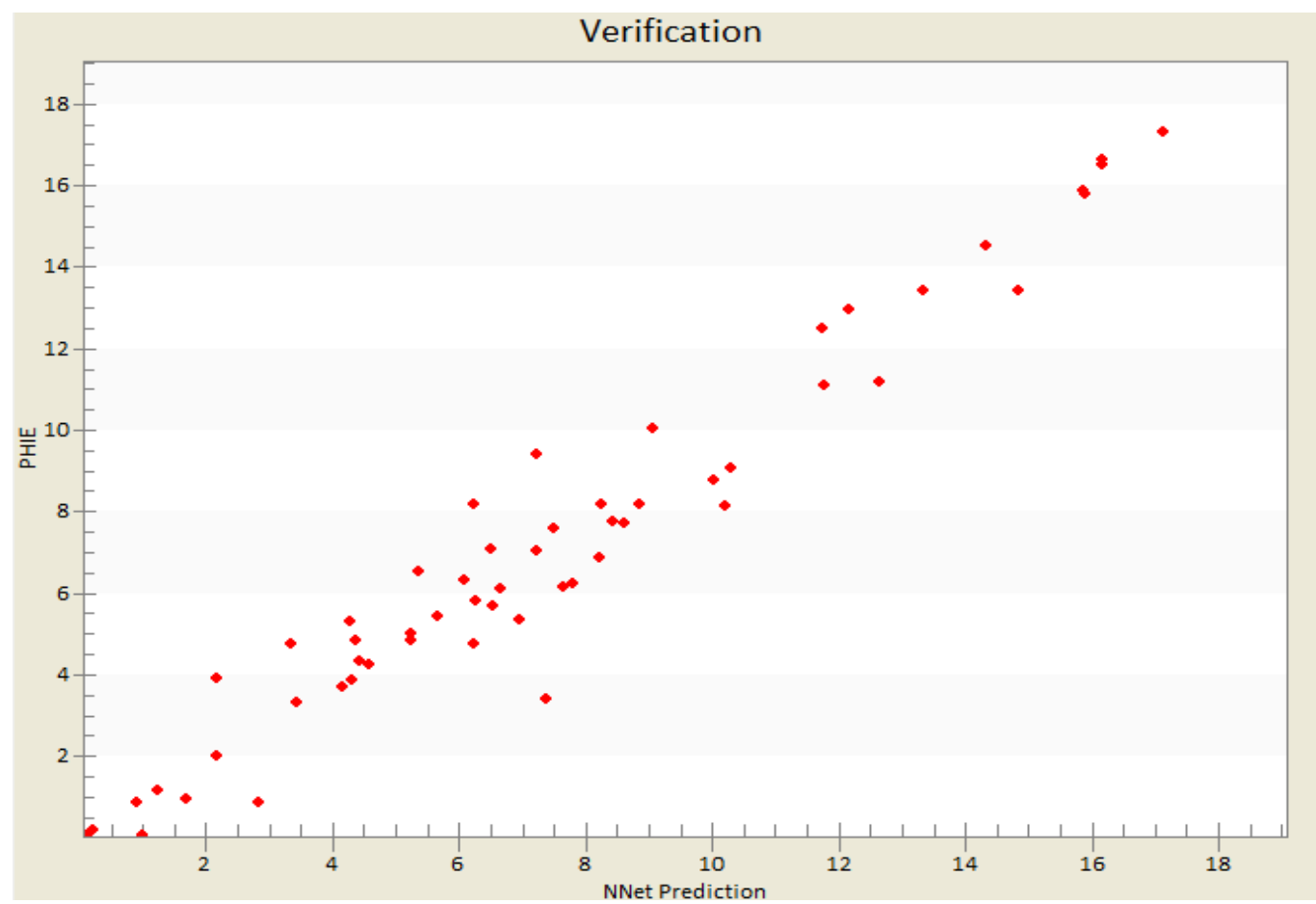

Figure 25: Verification result cross plot 


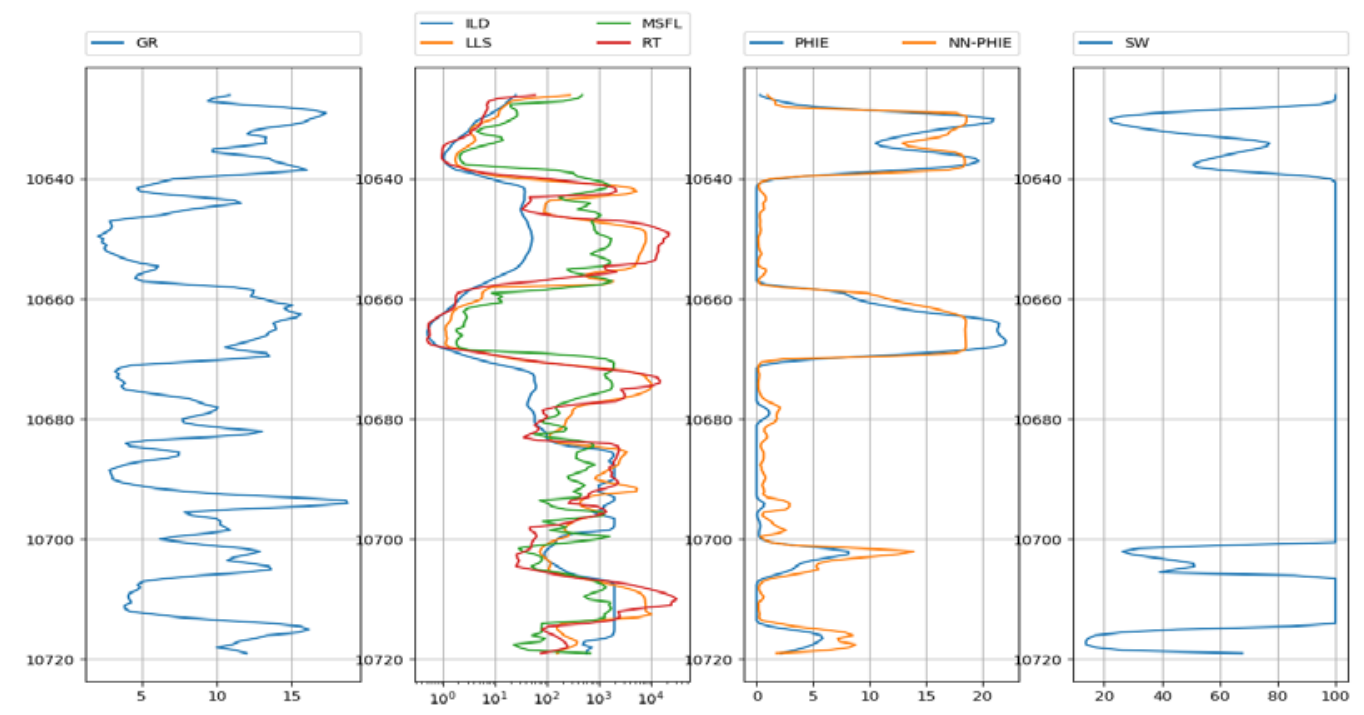

Figure 26: Generated output "NN-PHIE” and actual value "PHIE"

After evaluating the accuracy of the result, zero values were substituted by the generated values and combined them to the rest of the well data. Then that data was set as a training set and started training the neural network to generate ILD logs for 8 oil producers (the second group of data).

\subsection{Scenario I}

Five water injector wells and 1 gas injector were used as a training set and 1 water injector (US 125) as a blind set that deployed with 8 oil producer wells. $20 \%$ of the training set data used as calibration and validation in training process. $\mathrm{R}^{2}$ results of the training process shown in table 2 and the result of the blind well plotted against the actual value as it shown in (figure 36).

Table 2: Scenario $I--R^{2}$ results

\begin{tabular}{|c|c|c|c|c|c|}
\hline Partitioning & All & Training & Calibration & Verification & Blind \\
\hline $80-10-10$ & 95.1 & 97.1 & 88.5 & 86.2 & 87.4 \\
\hline
\end{tabular}


Injectors \& Oil producers

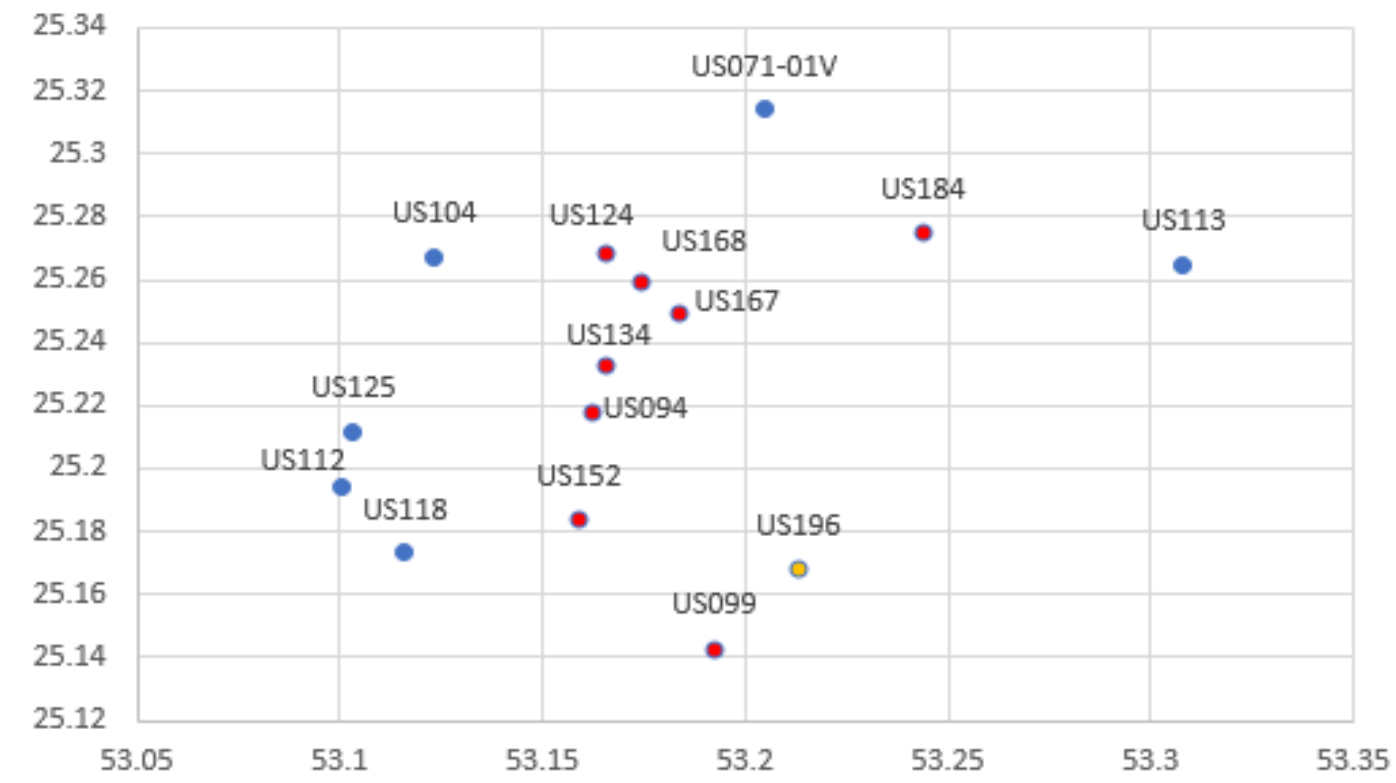

Figure 27: Injectors and oil producers

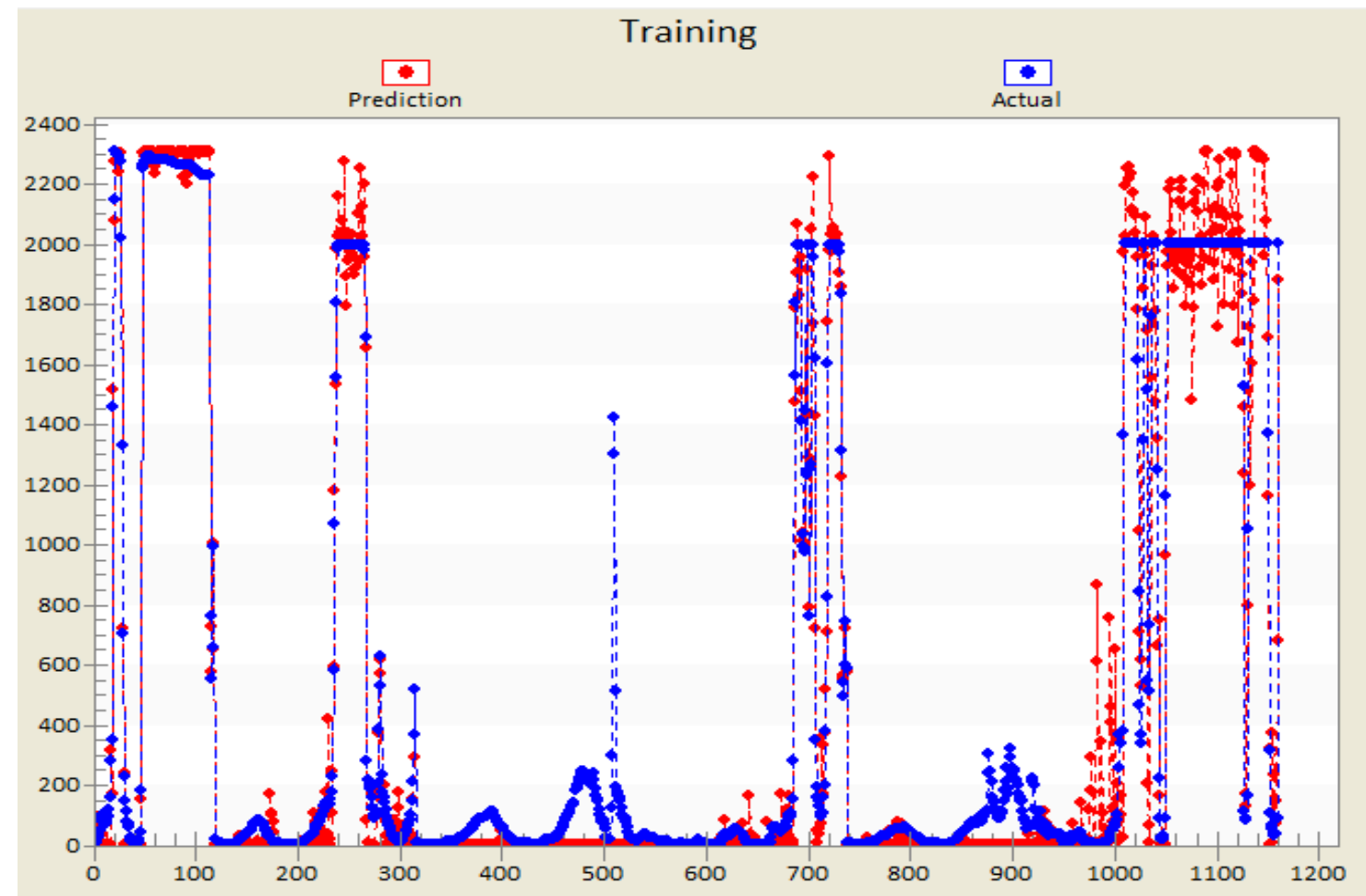

Figure 28: Training result scatter plot 


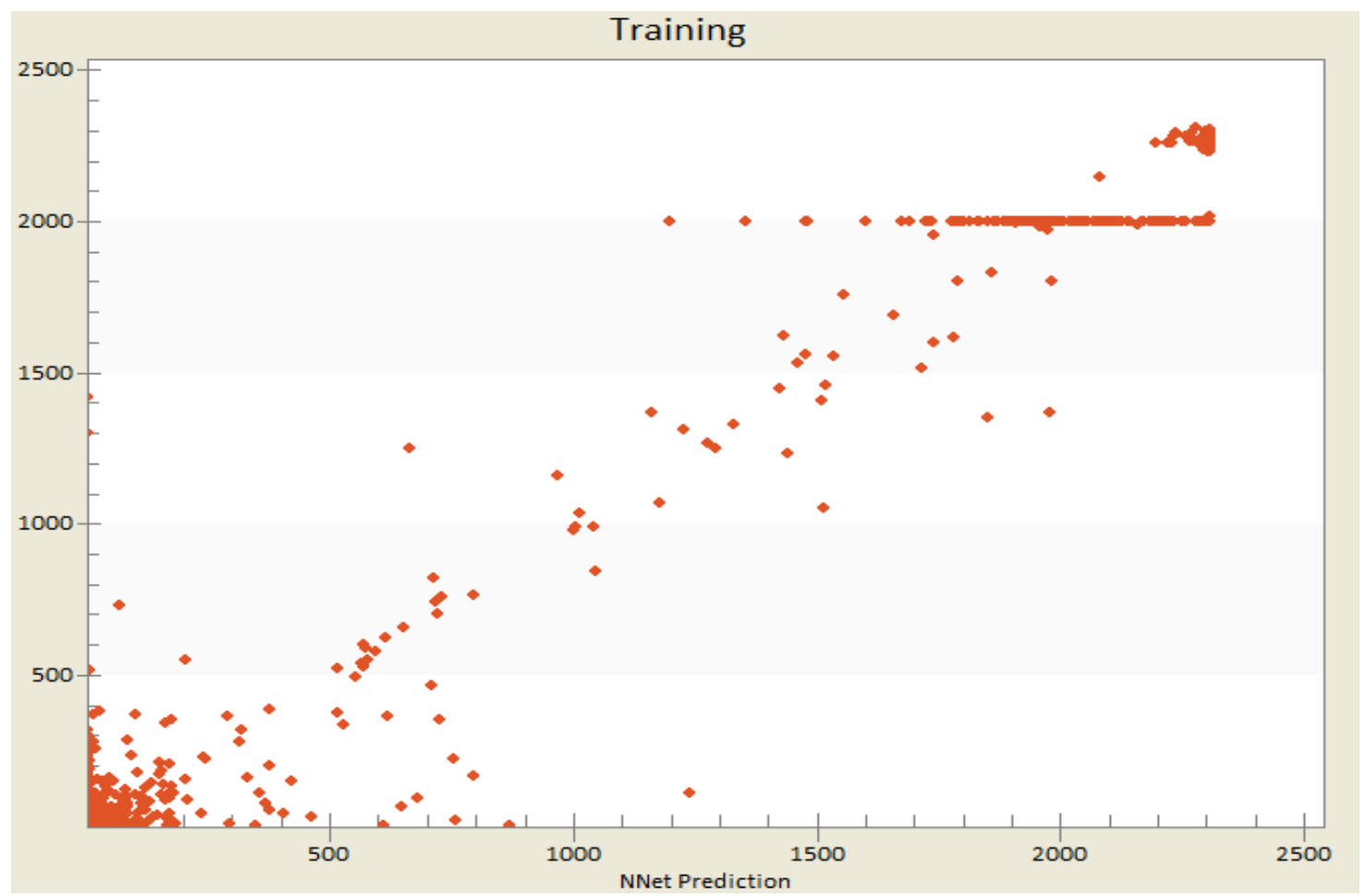

Figure 29: Training result cross plot

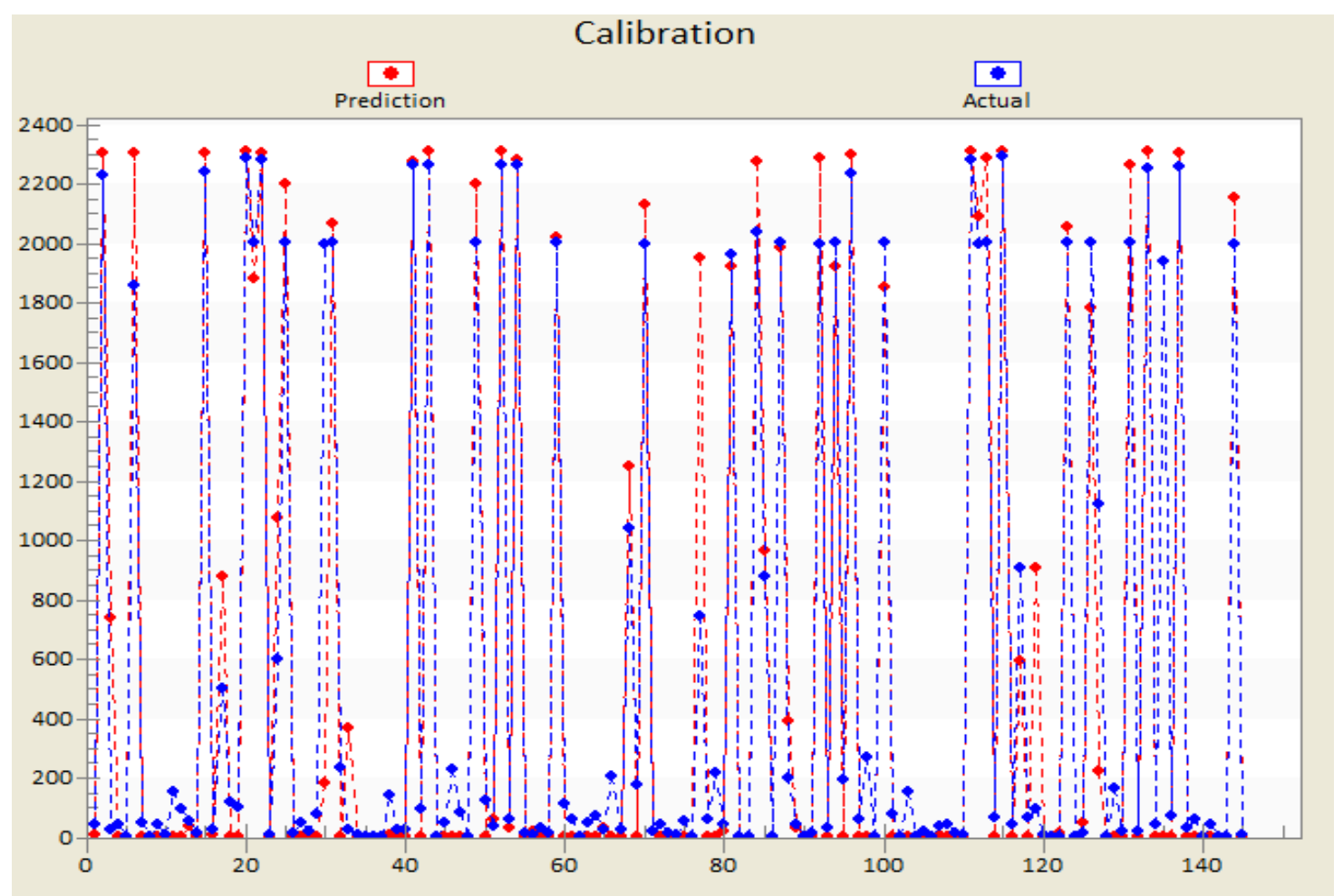

Figure 30: Calibration result scatter plot 


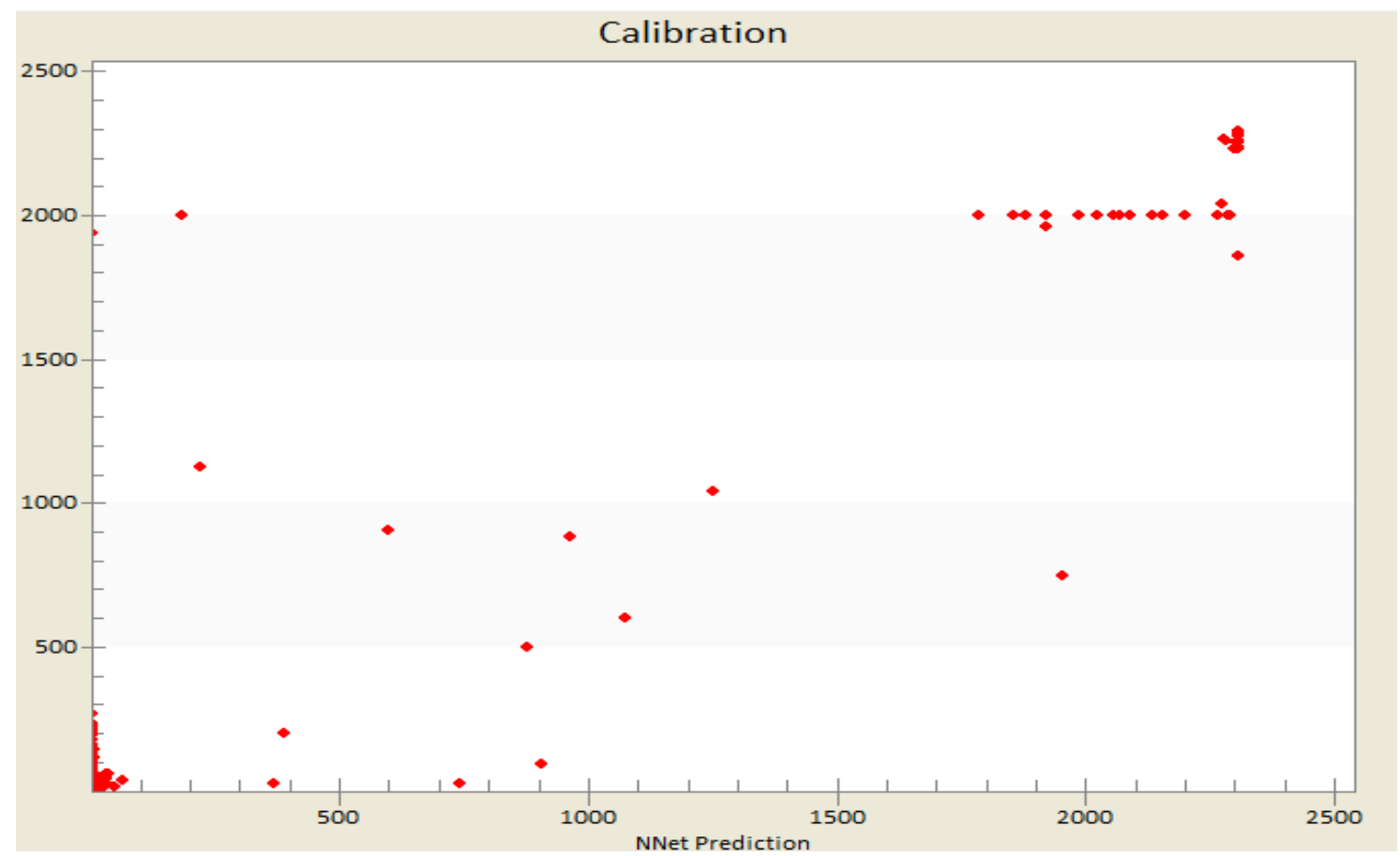

Figure 31: Calibration result cross plot

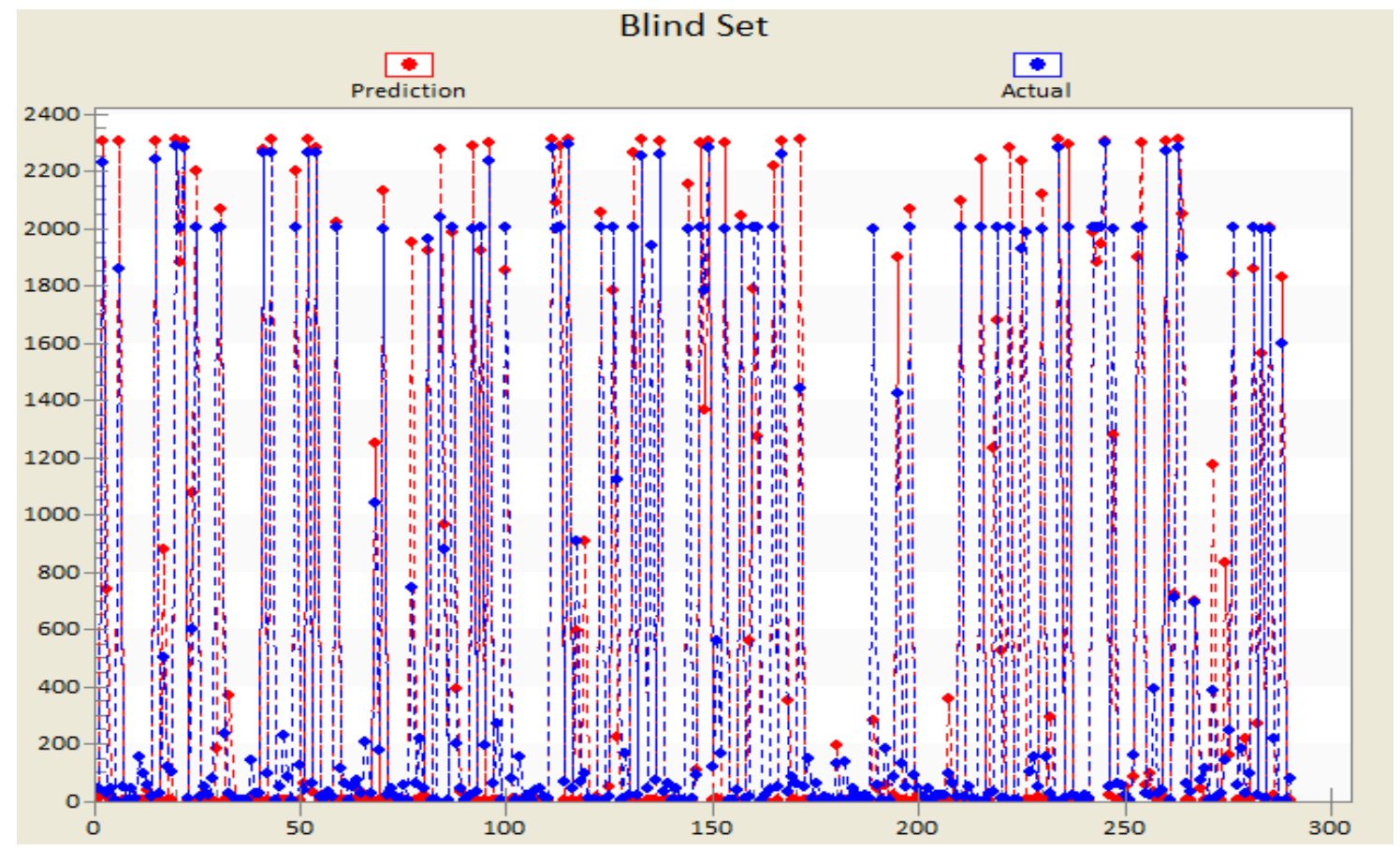

Figure 32: Blind result scatter plot 


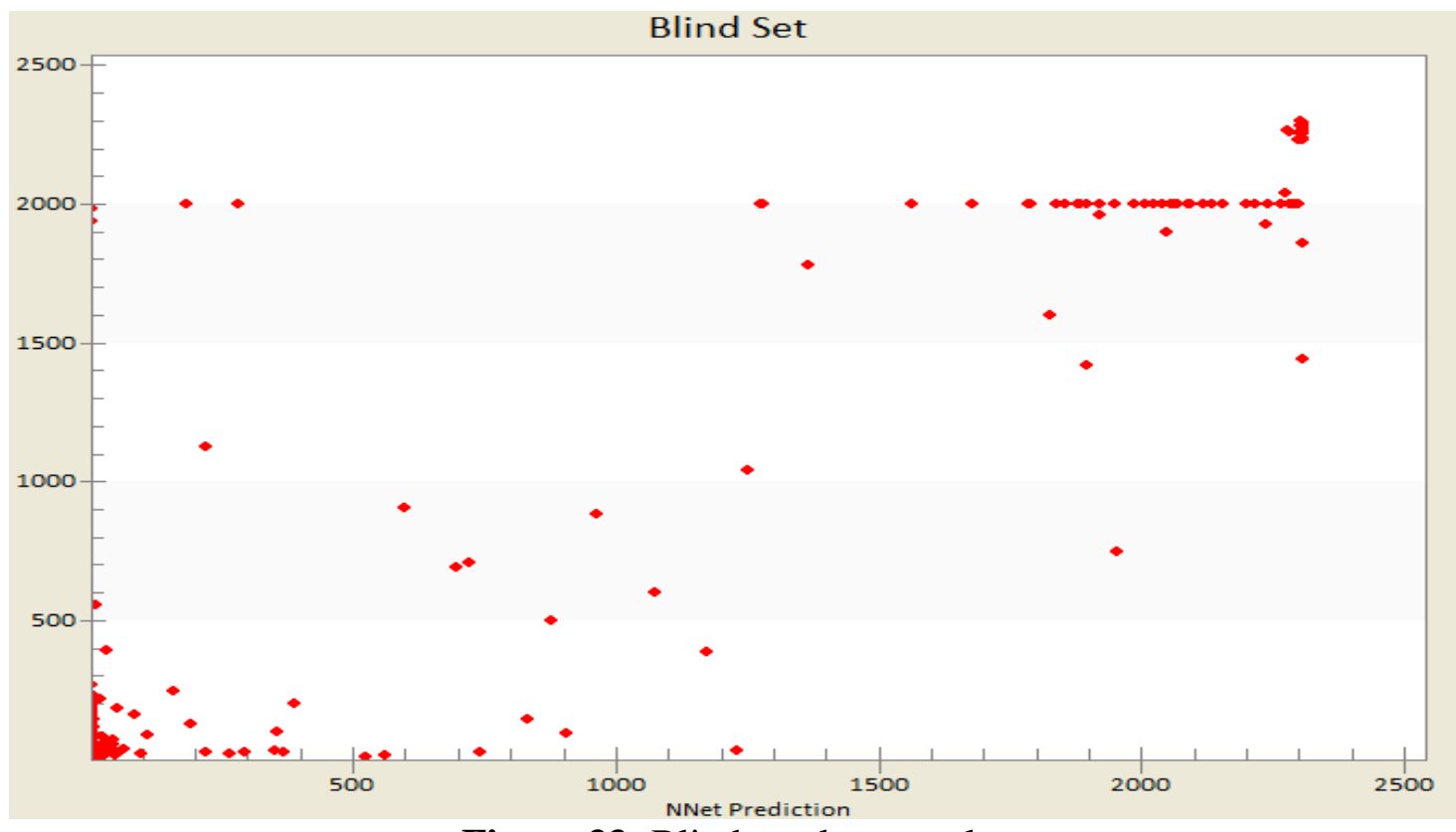

Figure 33: Blind result cross plot

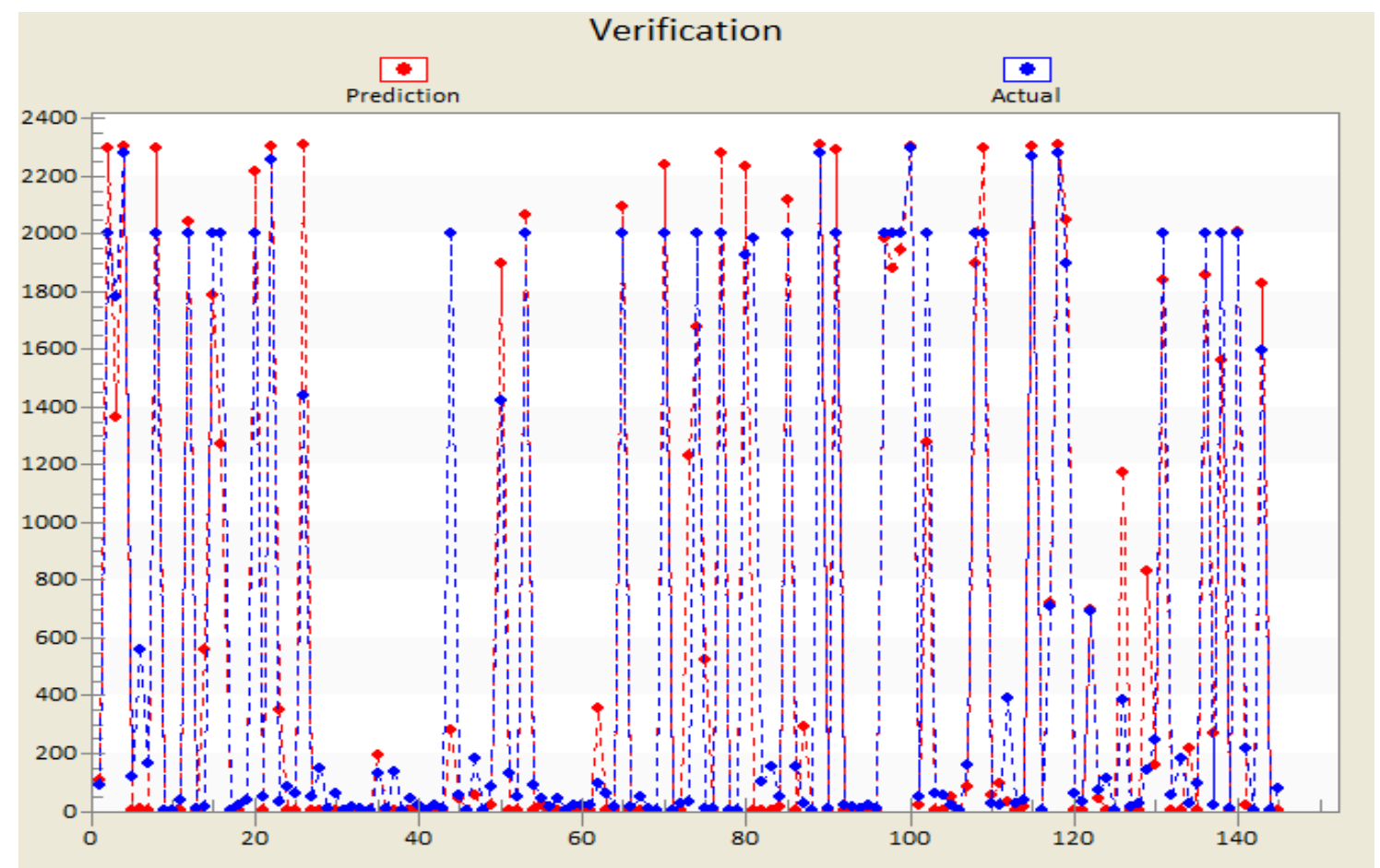

Figure 34: Verification result scatter plot 


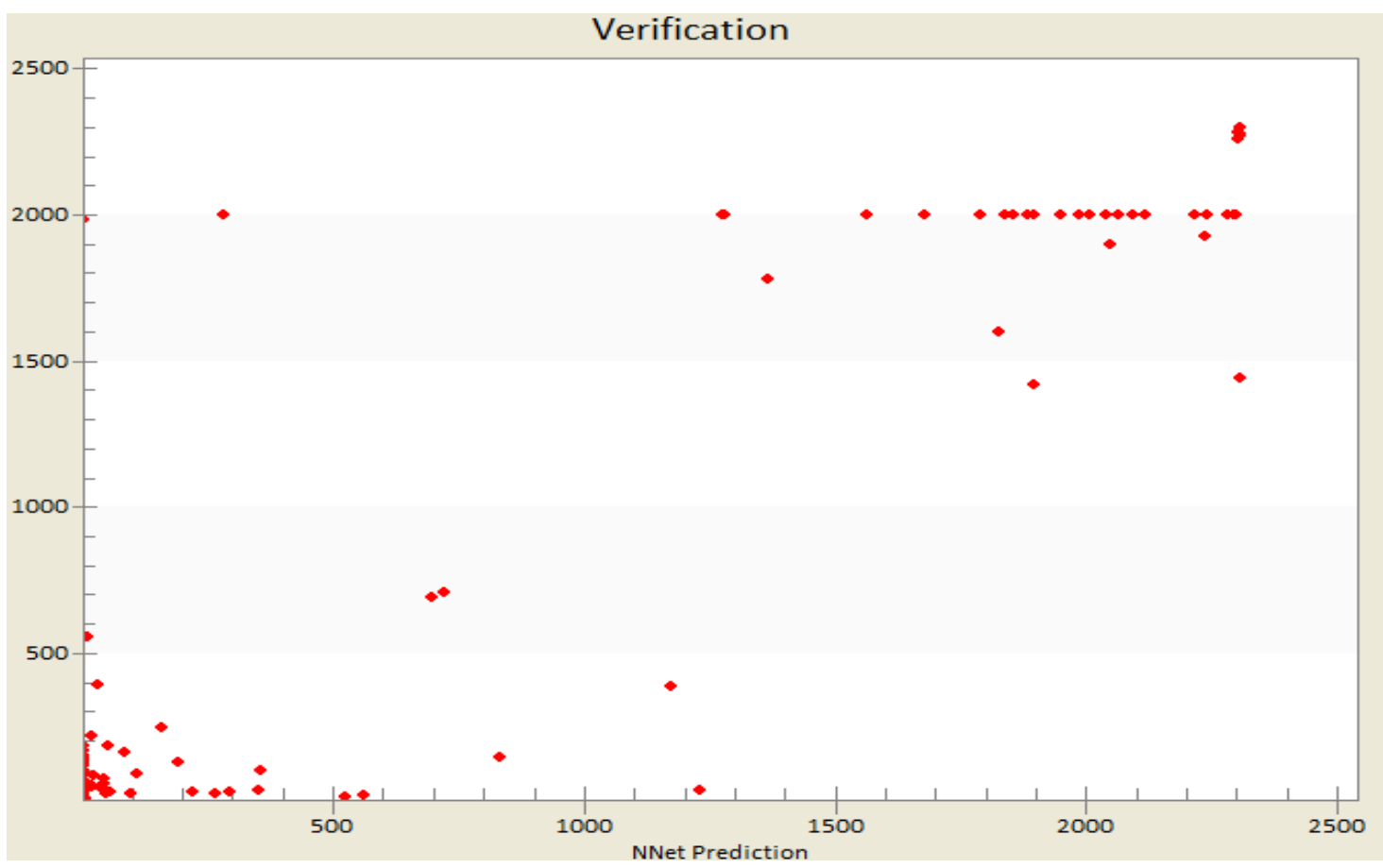

Figure 35: Verification result cross plot

US125
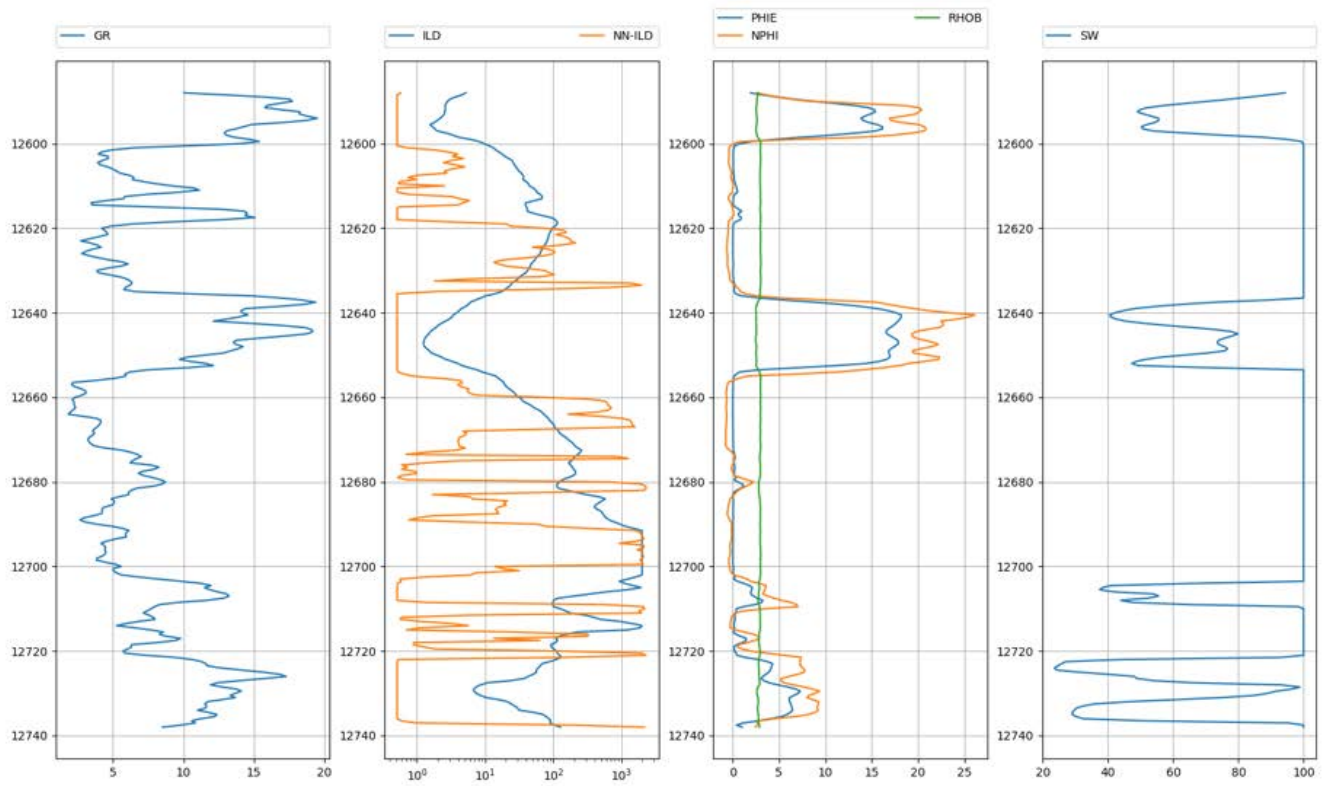

Figure 36: The generated "NN-ILD" and actual value "ILD" 


\subsection{Scenario II}

As shown in the (figure 36) the generated ILD has a huge error, it has been decided to eliminate the gas injector since It was noticed that it has a difference pattern during the training process and restart the training.

$\mathrm{R}^{2}$ results of the training process shown in table 3 and the result of the blind well was plotted against the actual value as it shown in (figure 45).

Table 3: Scenario II-- $R^{2}$ results

\begin{tabular}{|c|c|c|c|c|c|}
\hline Partitioning & All & Training & Calibration & Verification & Blind \\
\hline $80-10-10$ & 91 & 92.4 & 94.3 & 75.8 & 85.8 \\
\hline
\end{tabular}

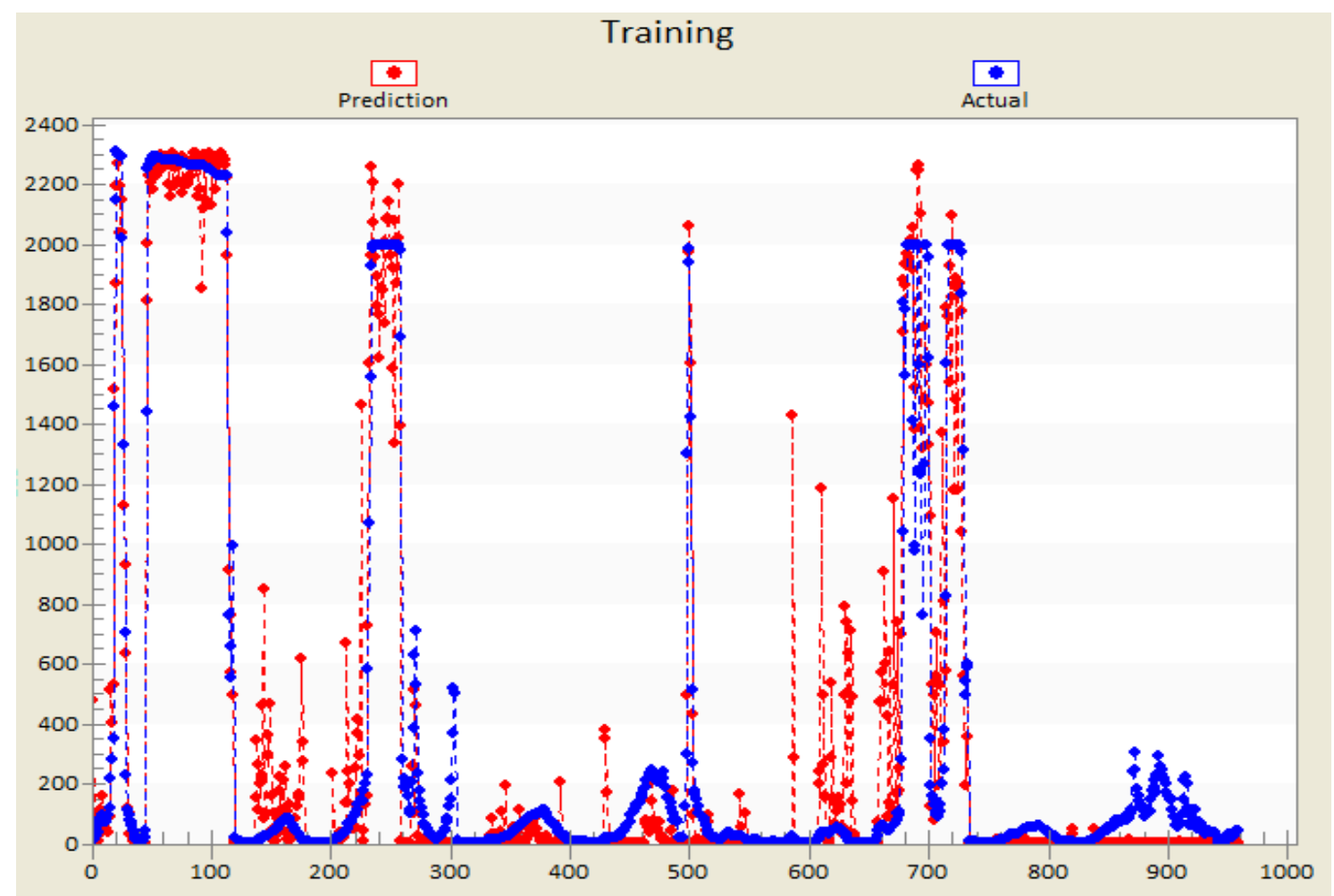

Figure 37: Training result scatter plot 


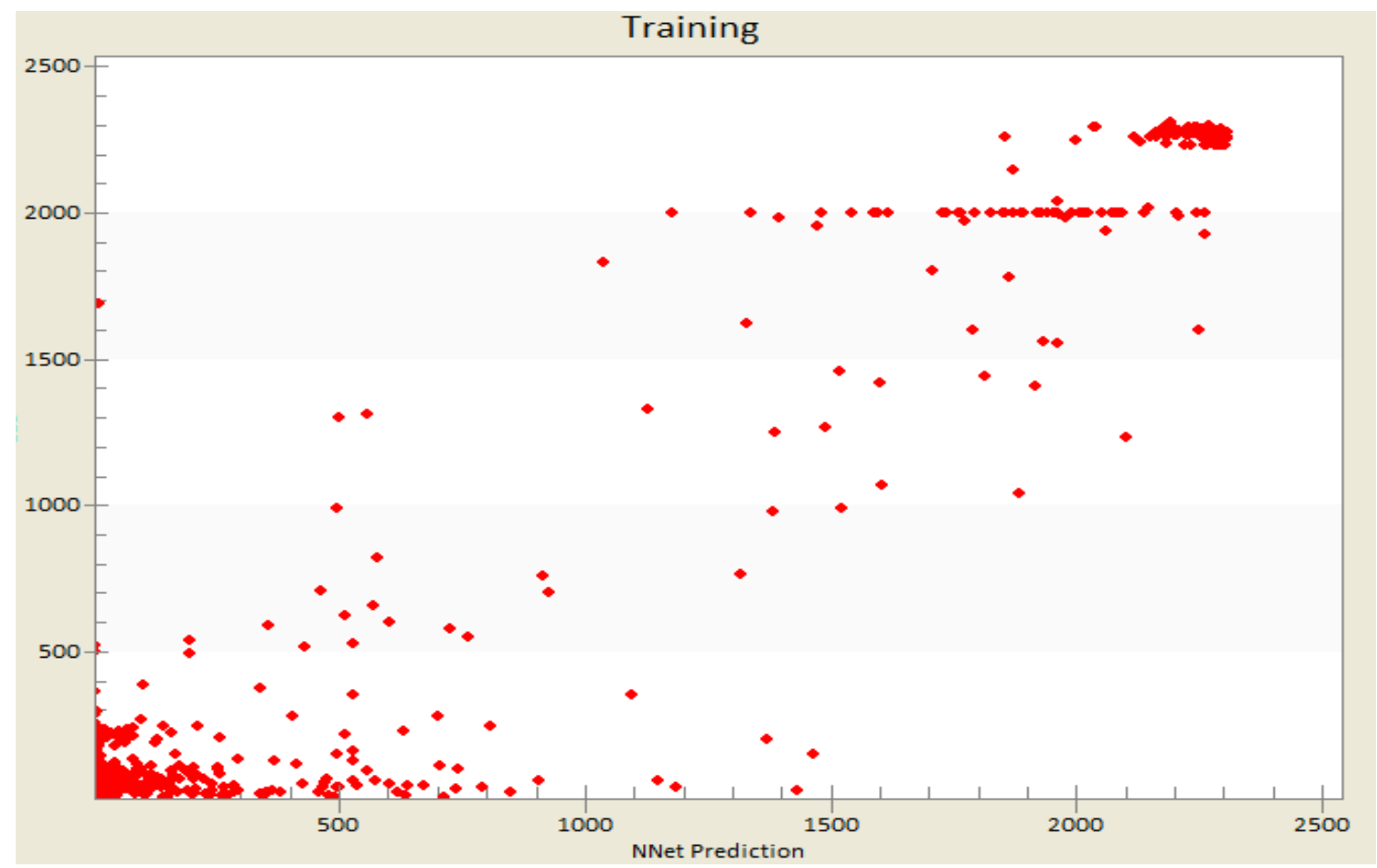

Figure 38: Training result cross plot

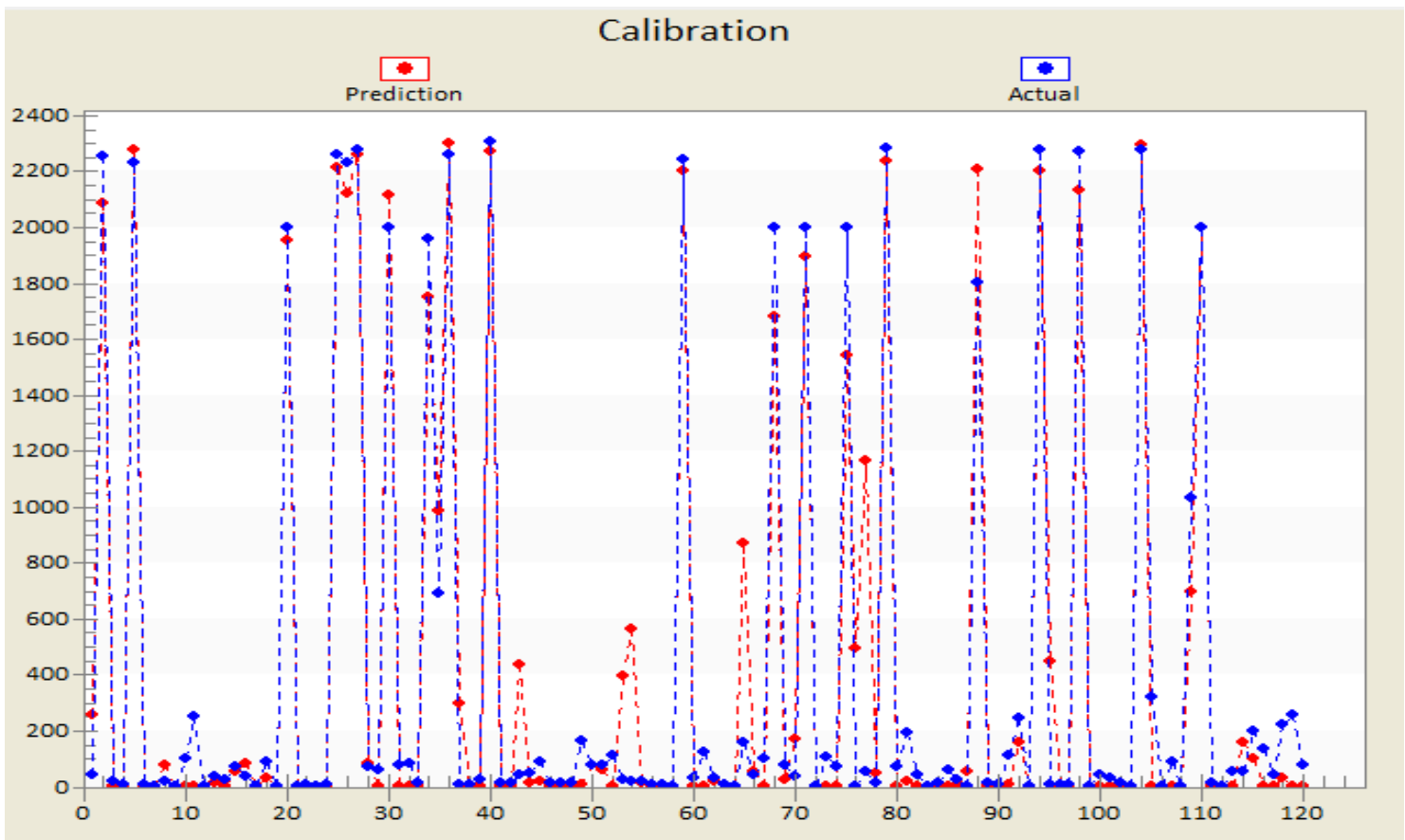

Figure 39: Calibration result scatter plot 


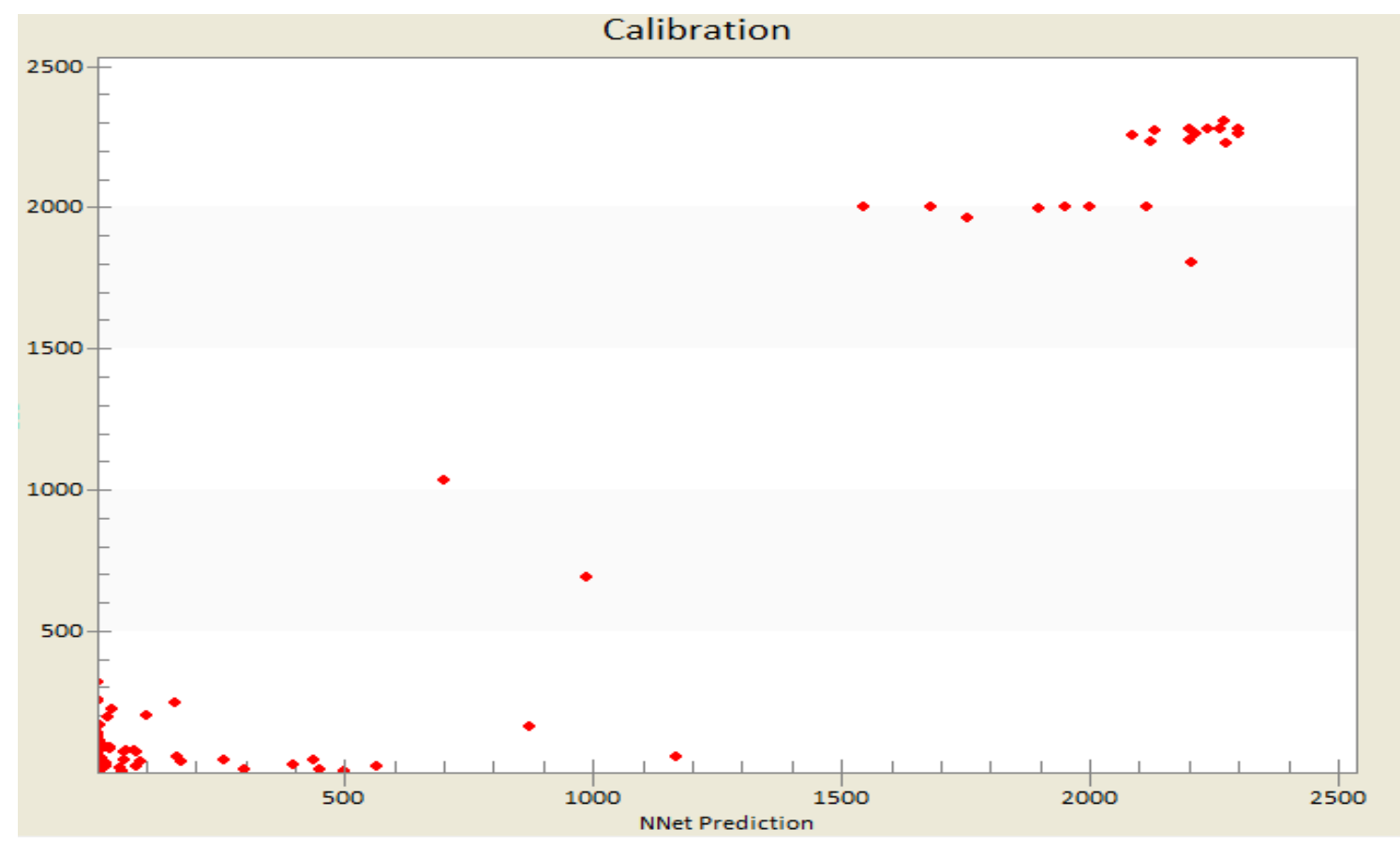

Figure 40: Calibration result cross plot

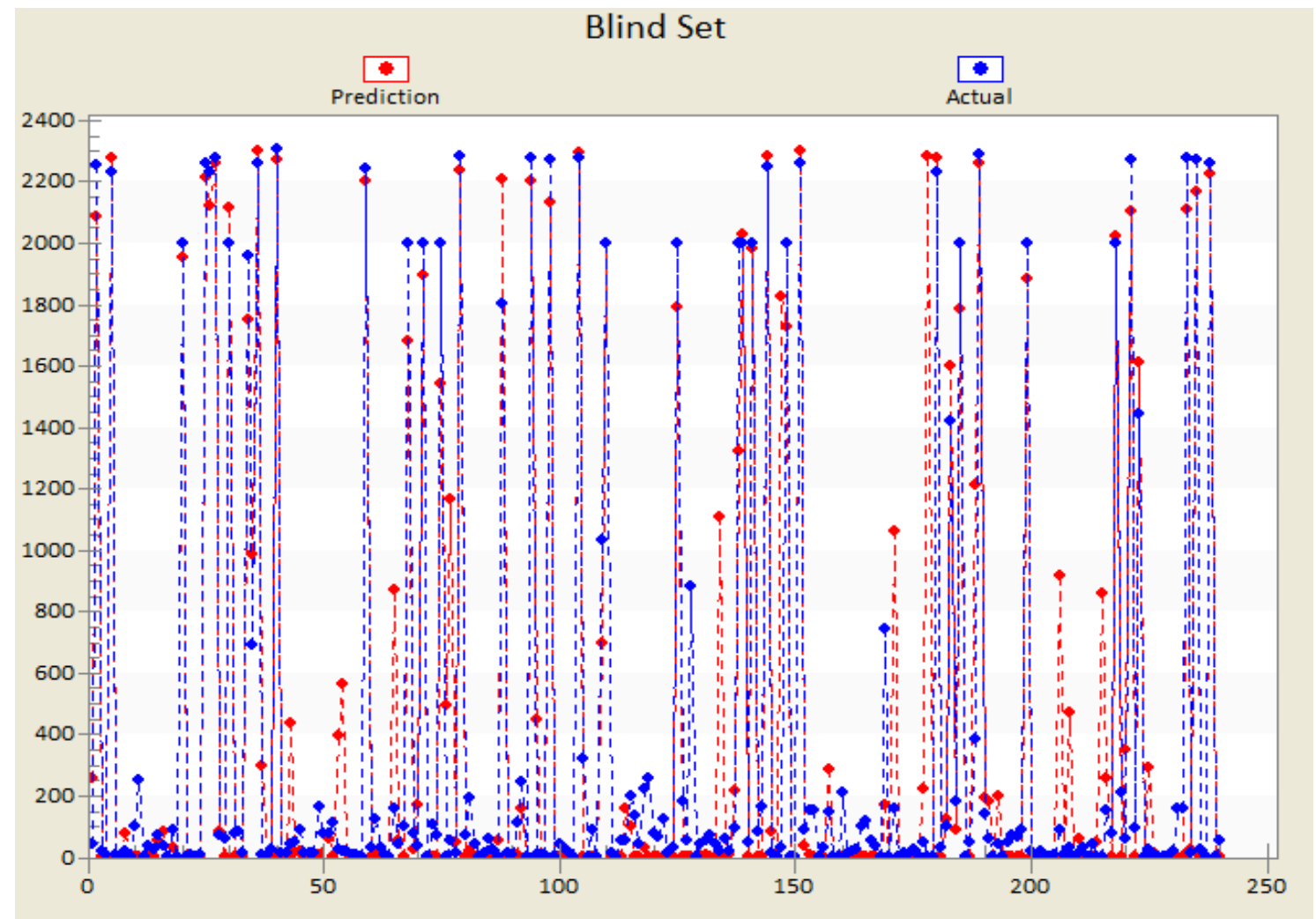

Figure 41: Blind result scatter plot 


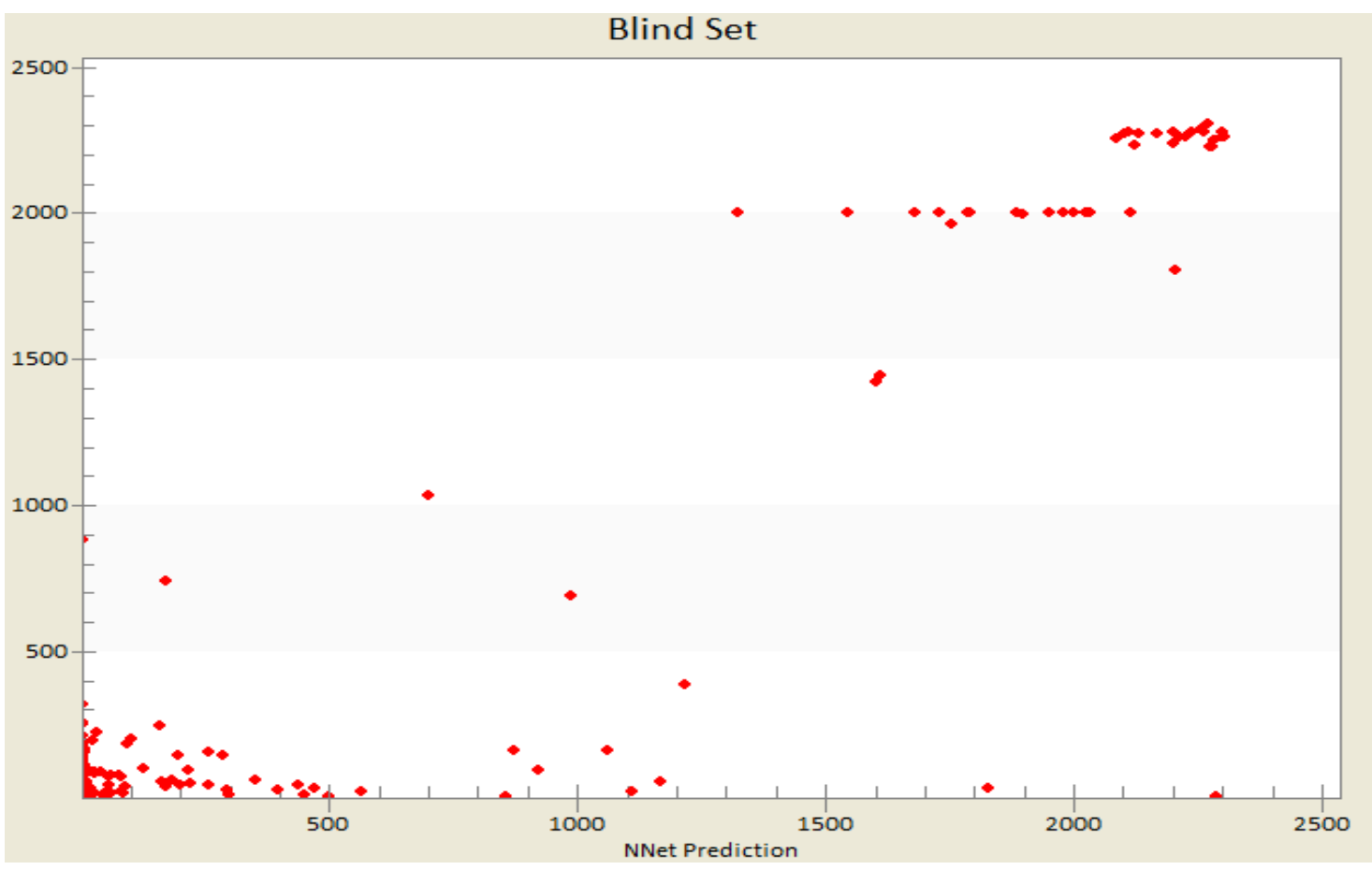

Figure 42: Blind result cross plot

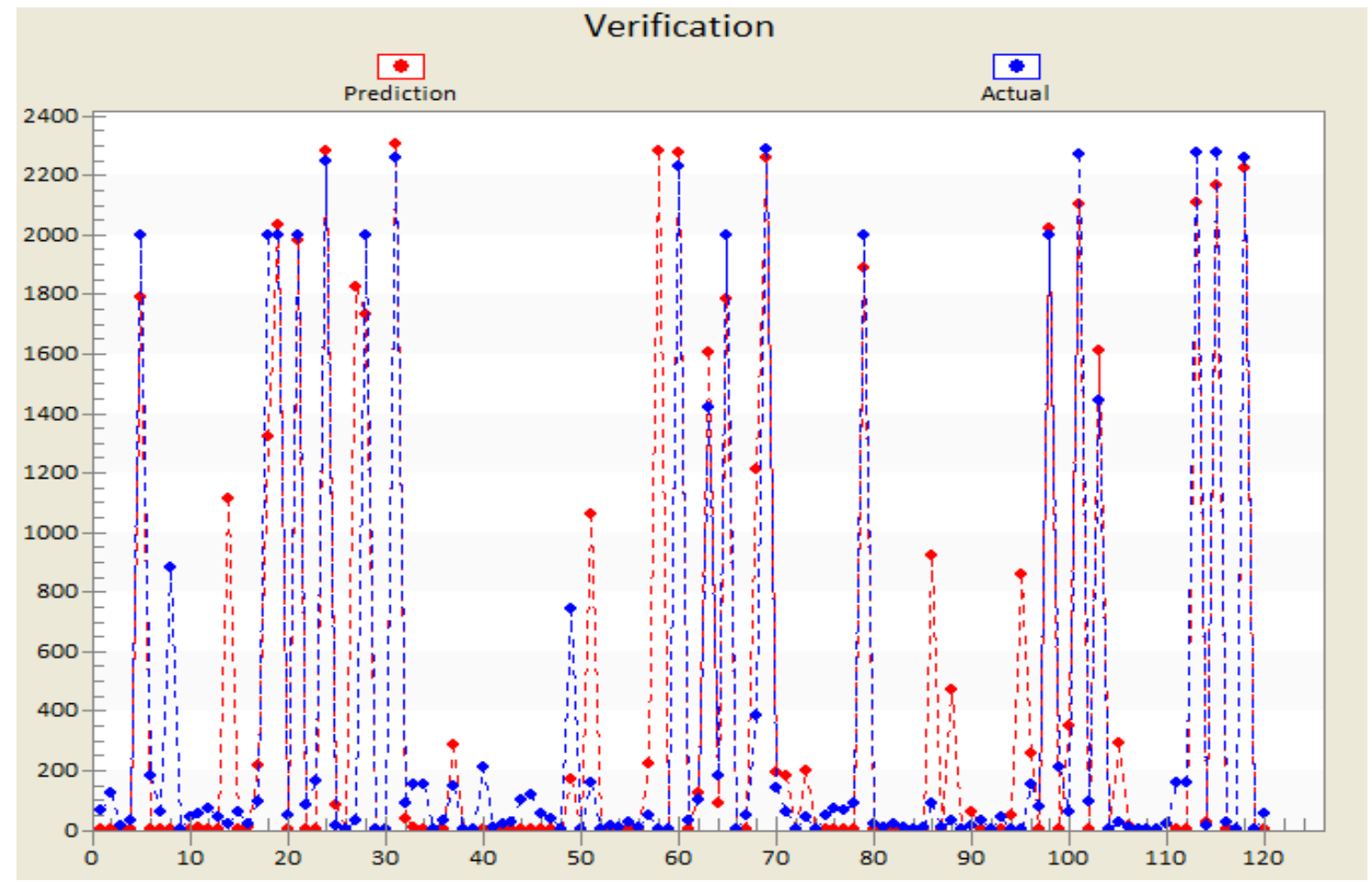

Figure 43: Verification result scatter plot 


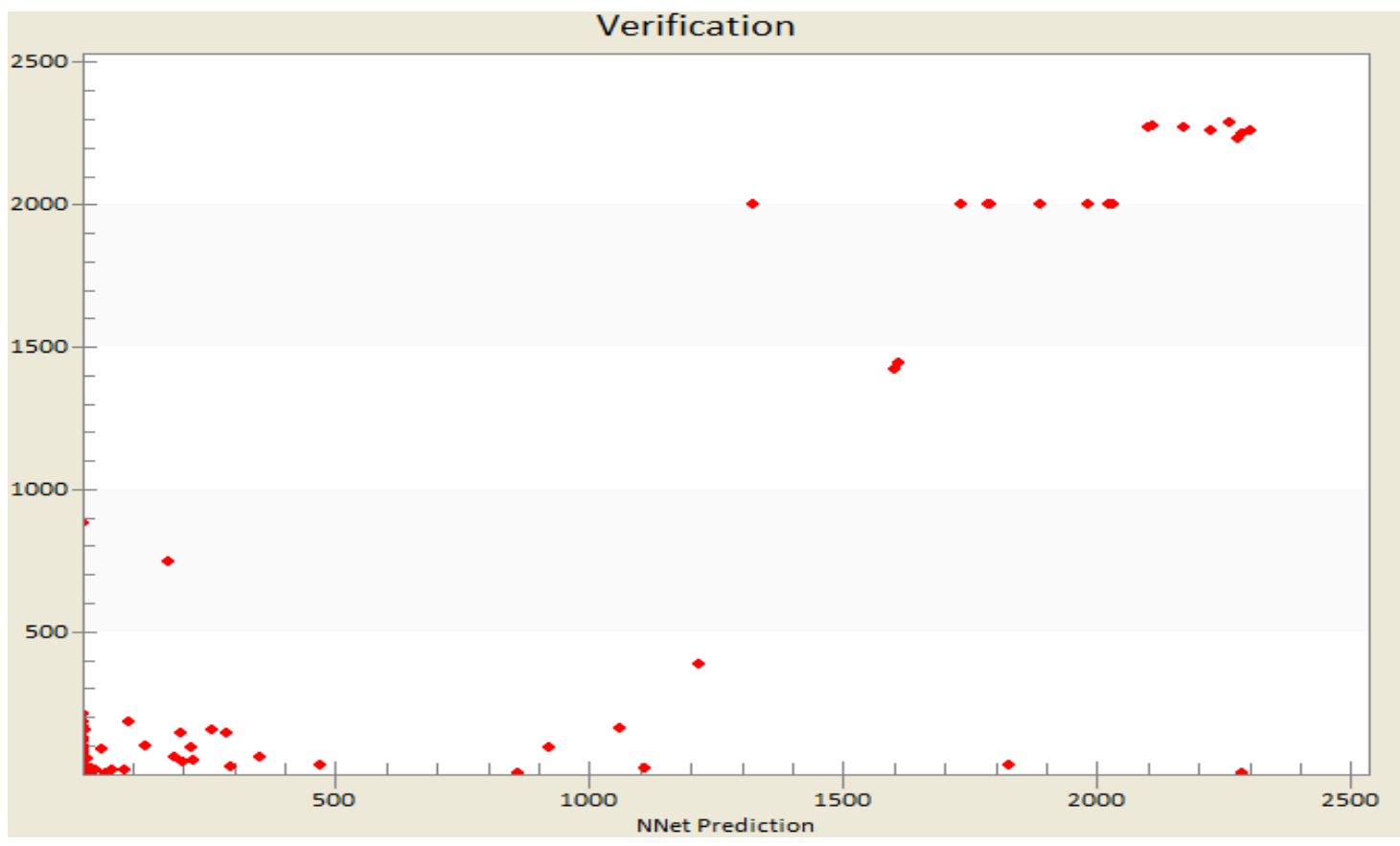

Figure 44: Verification result cross plot
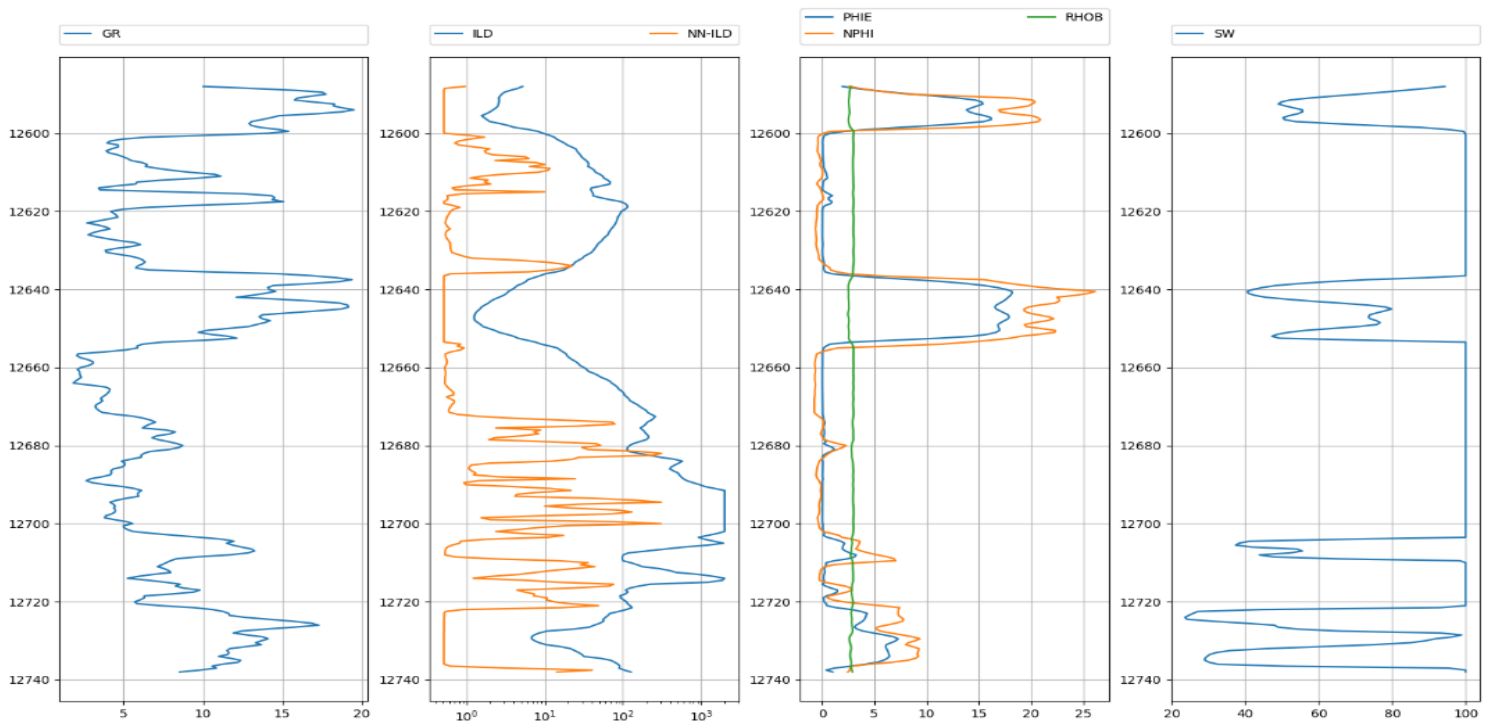

Figure 45: Outcomes for scenario II 


\subsection{Scenario III}

Same run was tried with different blind well (US 113). $\mathrm{R}^{2}$ results of the training process shown in table 4 and the result of the blind well was plotted against the actual value as it shown in (figure 54).

Table 4: Scenario III-- $R^{2}$ results

\begin{tabular}{|c|c|c|c|c|c|}
\hline Partitioning & All & Training & Calibration & Verification & Blind \\
\hline $80-10-10$ & 94.8 & 96.9 & 87.9 & 81.9 & 85.4 \\
\hline
\end{tabular}

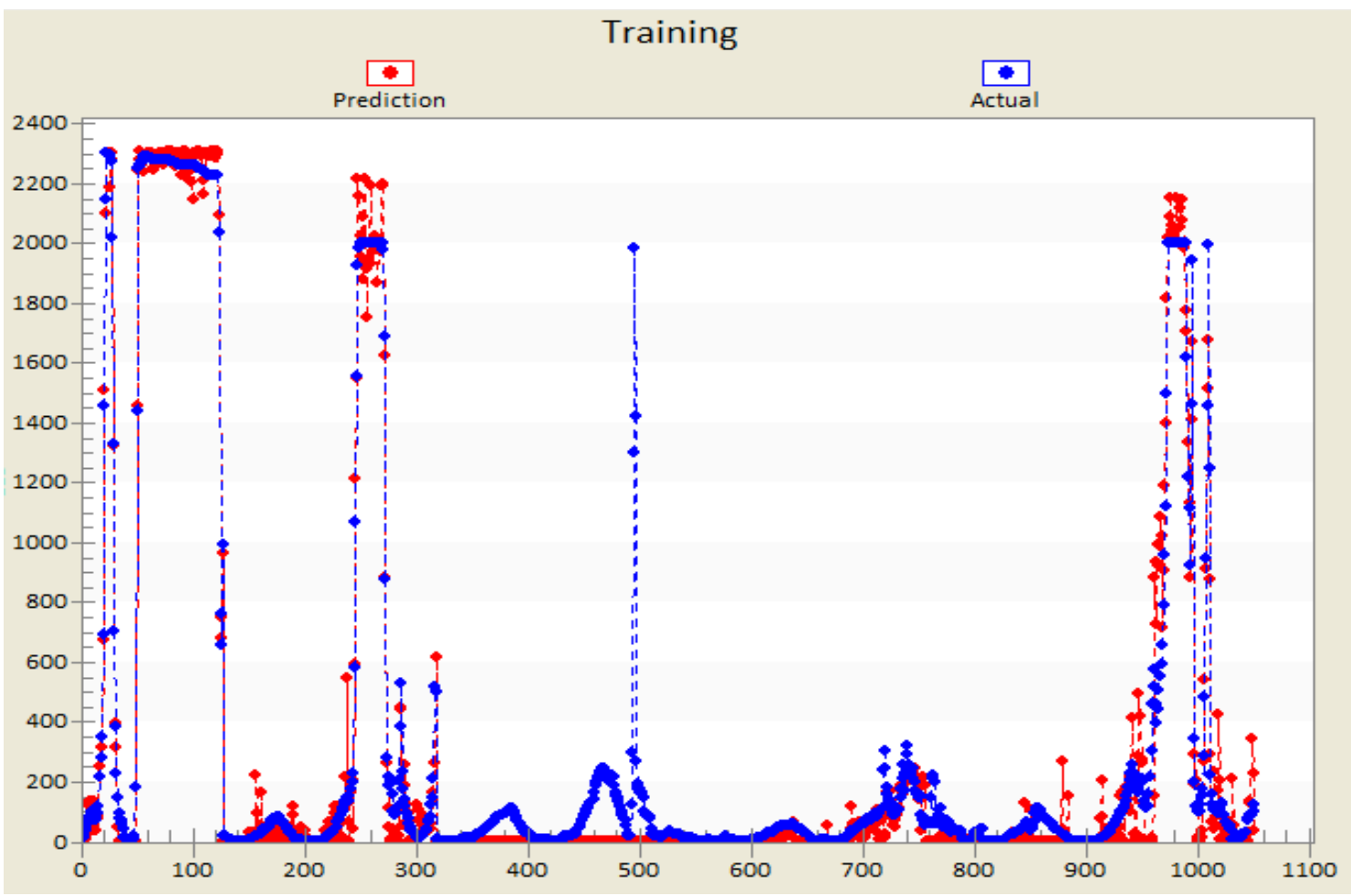

Figure 46: Training result scatter plot 


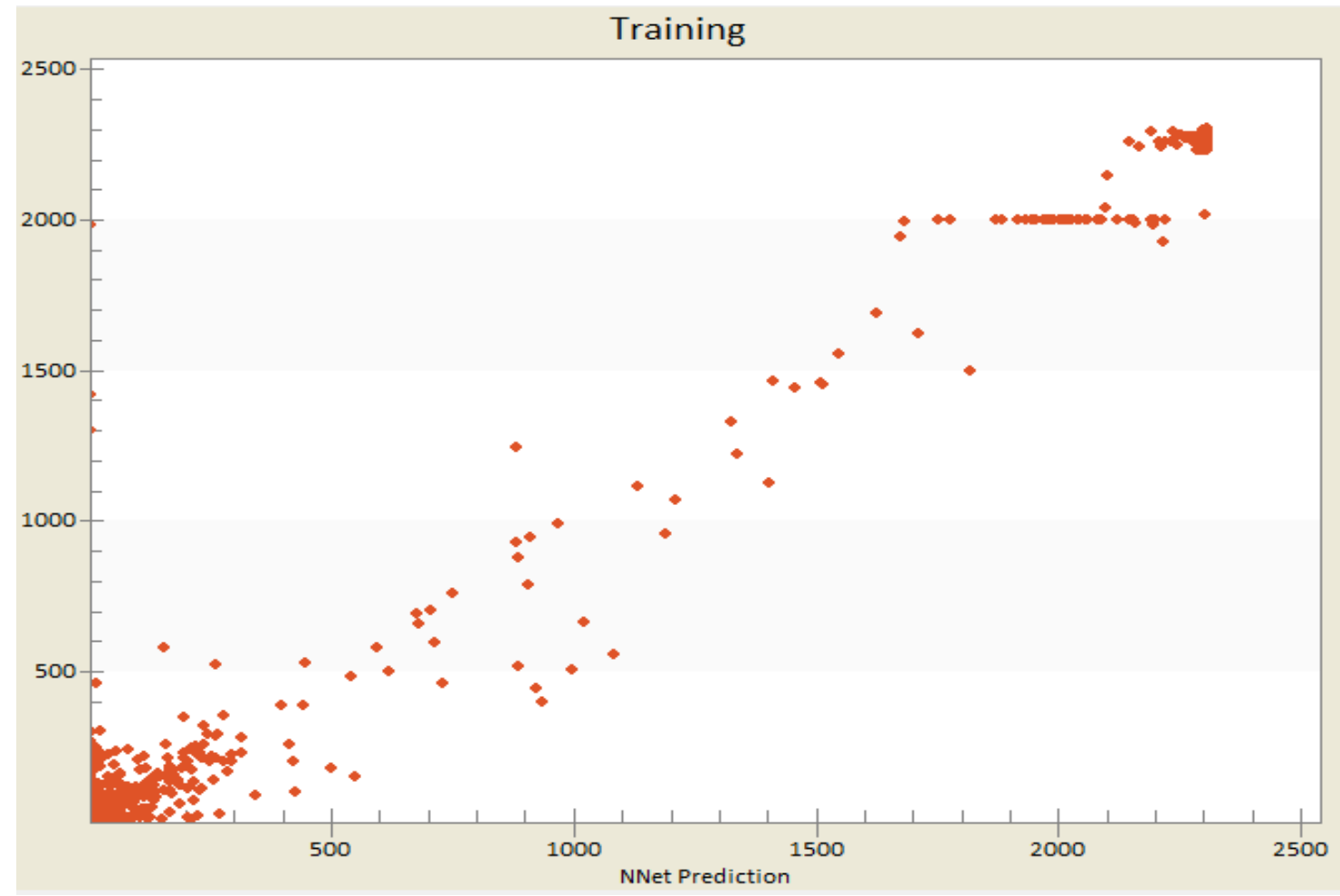

Figure 47: Training result cross plot

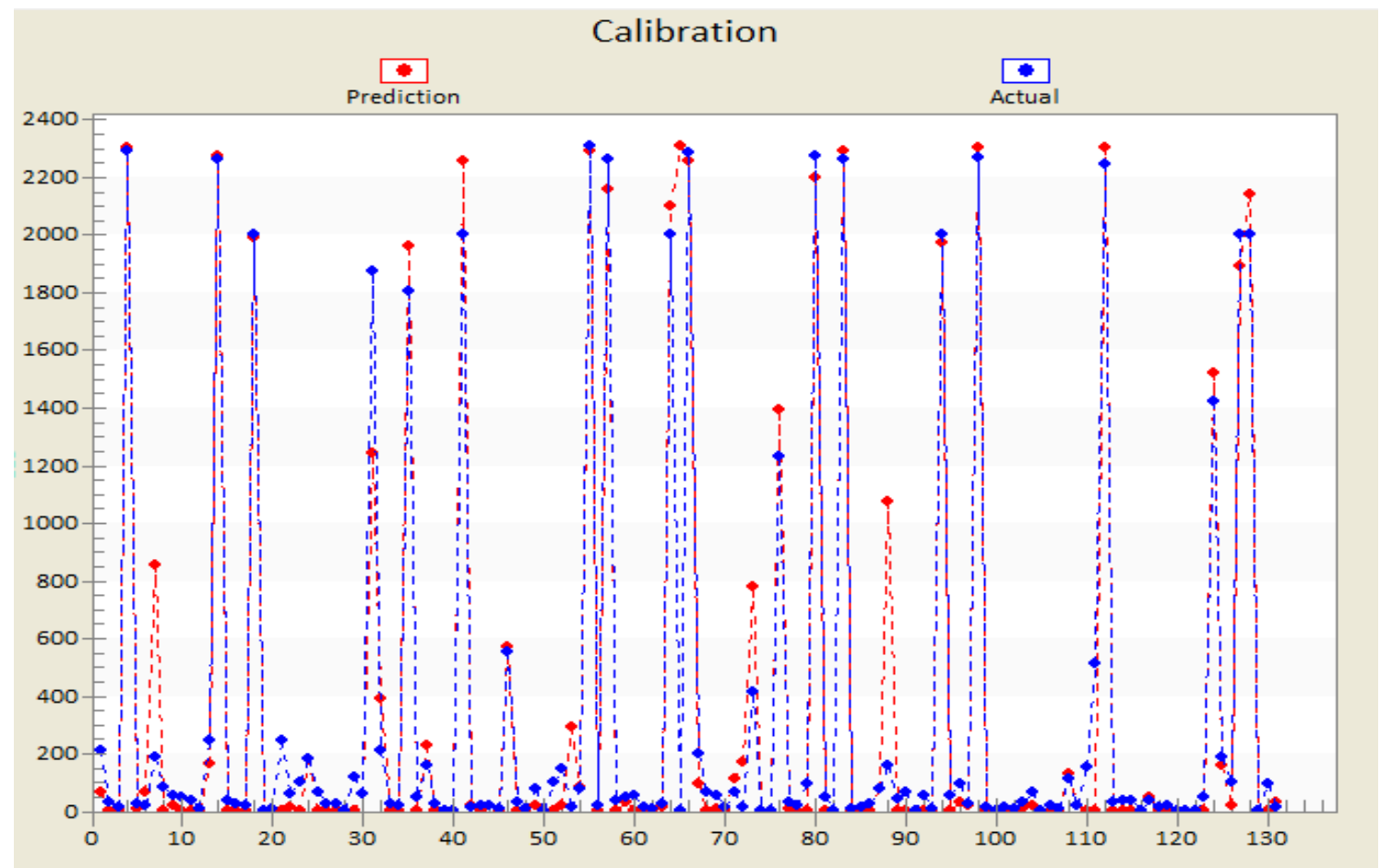

Figure 48: Calibration result scatter plot 


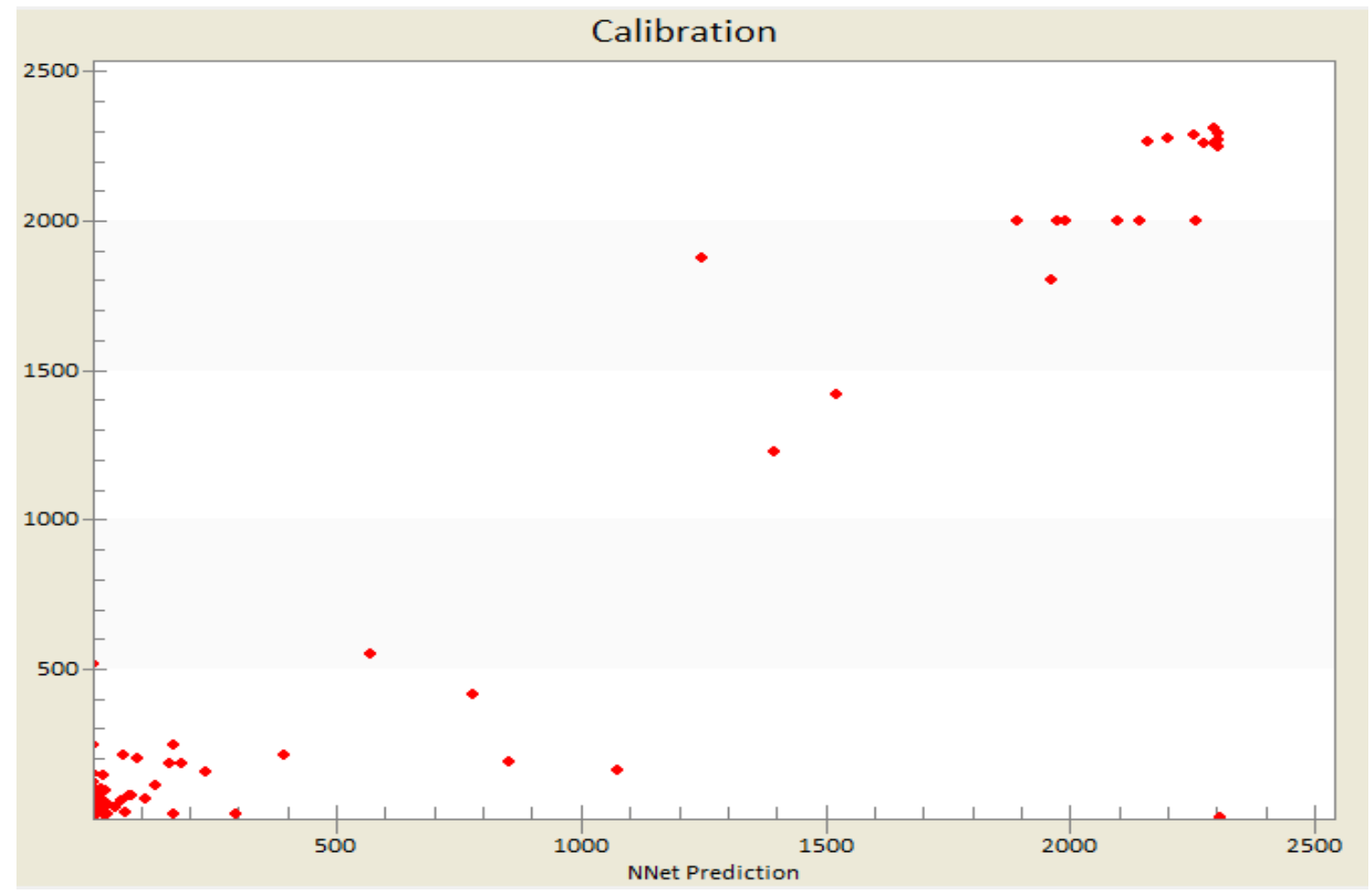

Figure 49: Calibration result cross plot

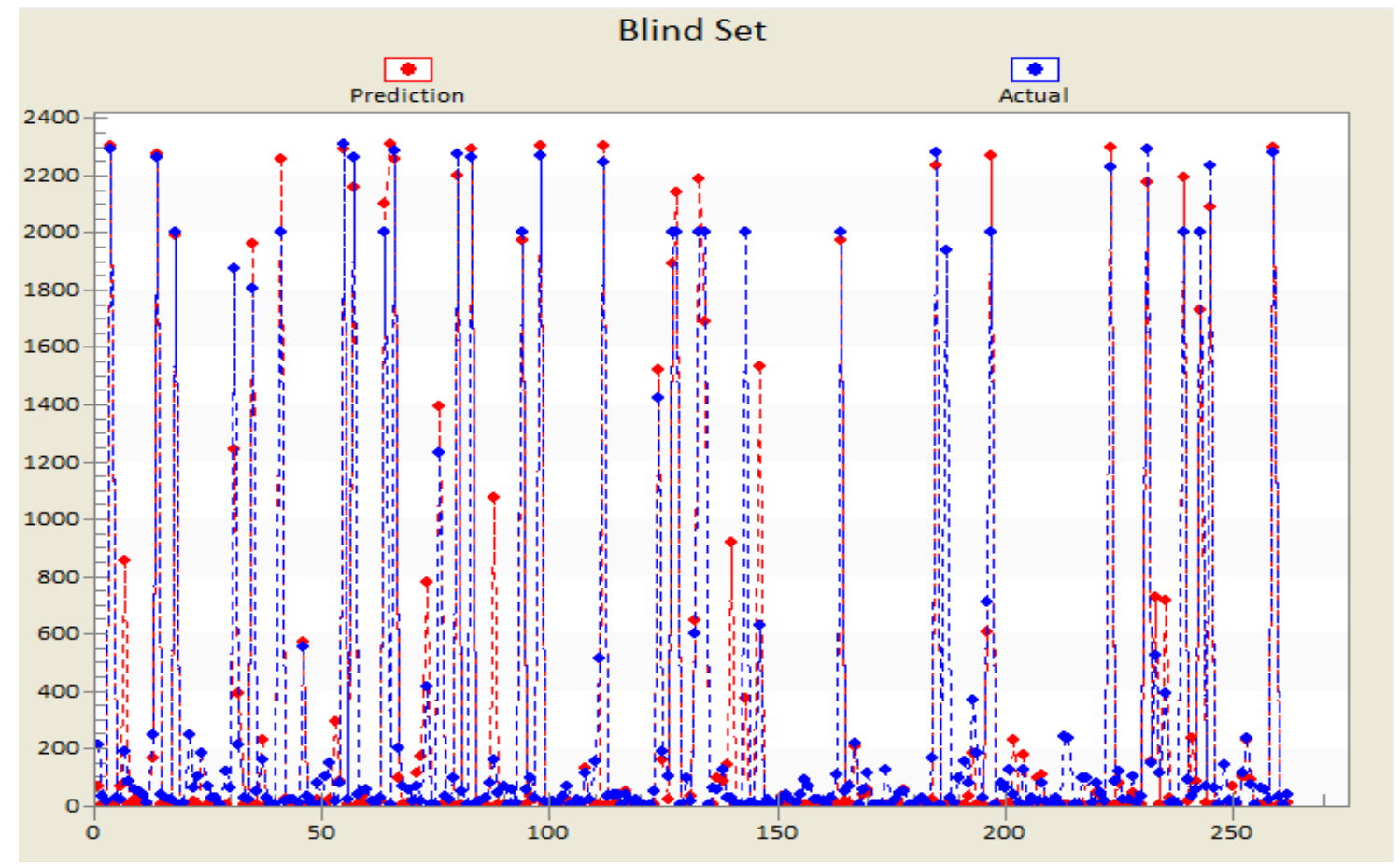

Figure 50: Blind result scatter plot 


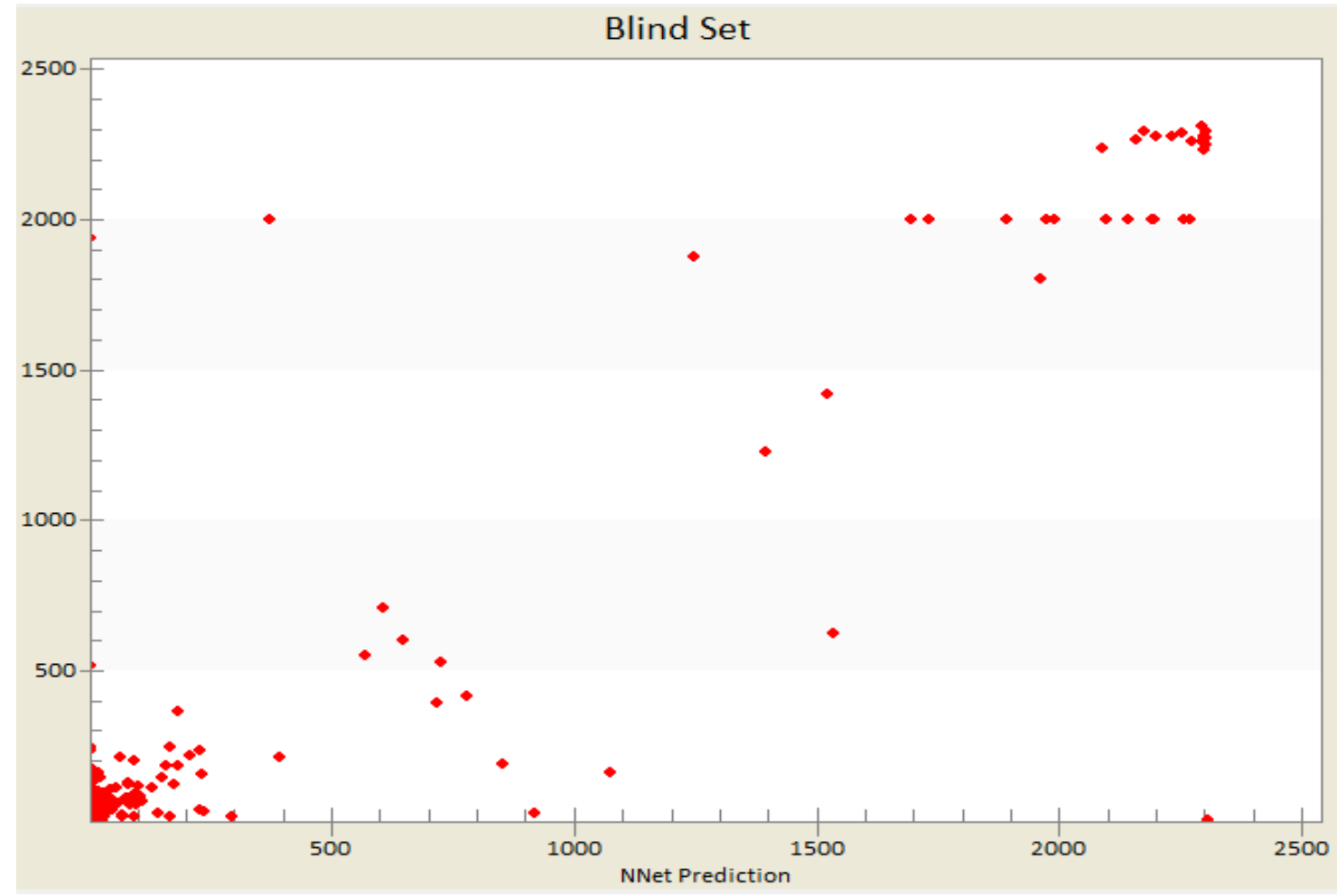

Figure 51: Blind result cross plot

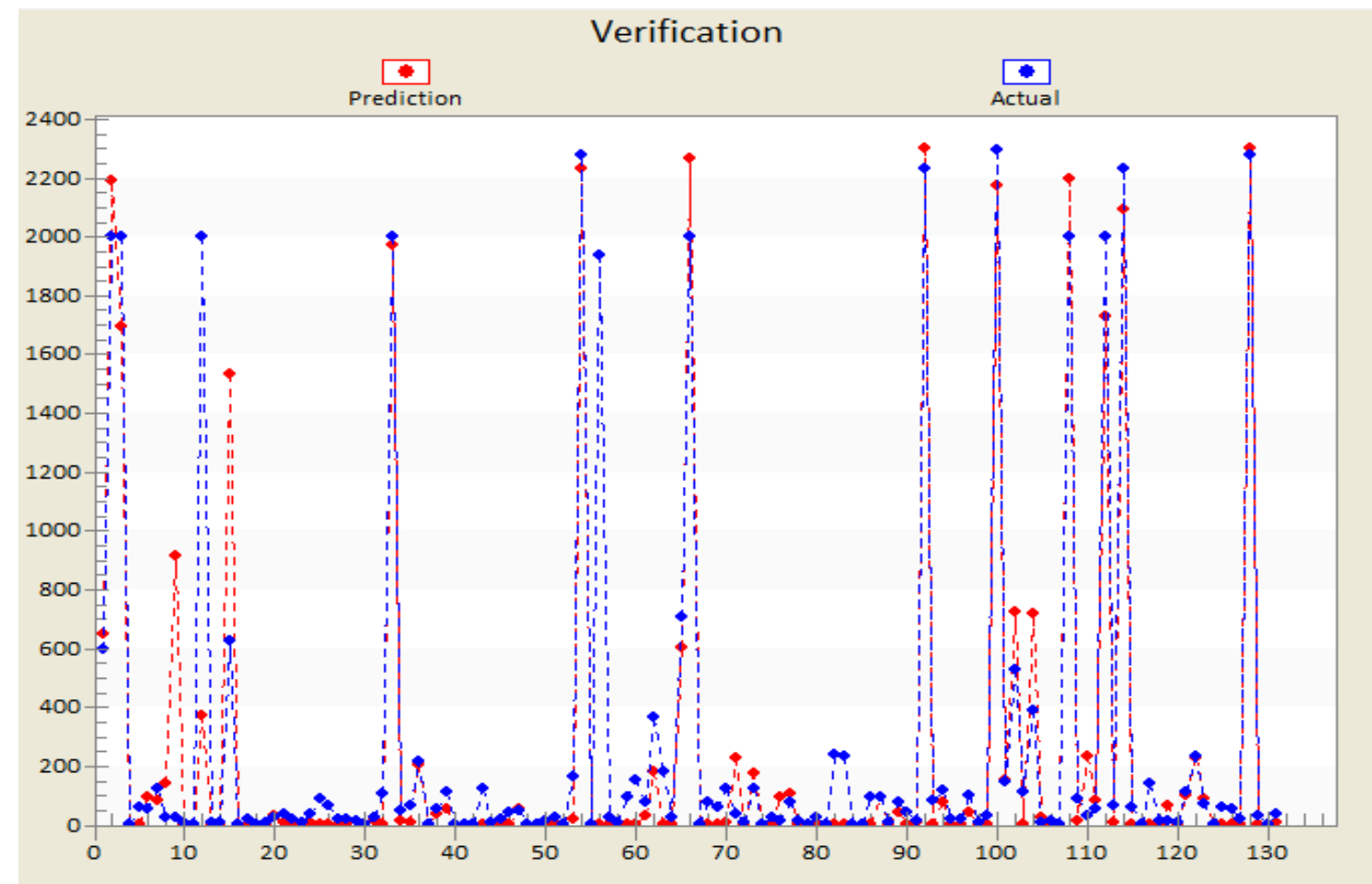

Figure 52: Verification result scatter plot 


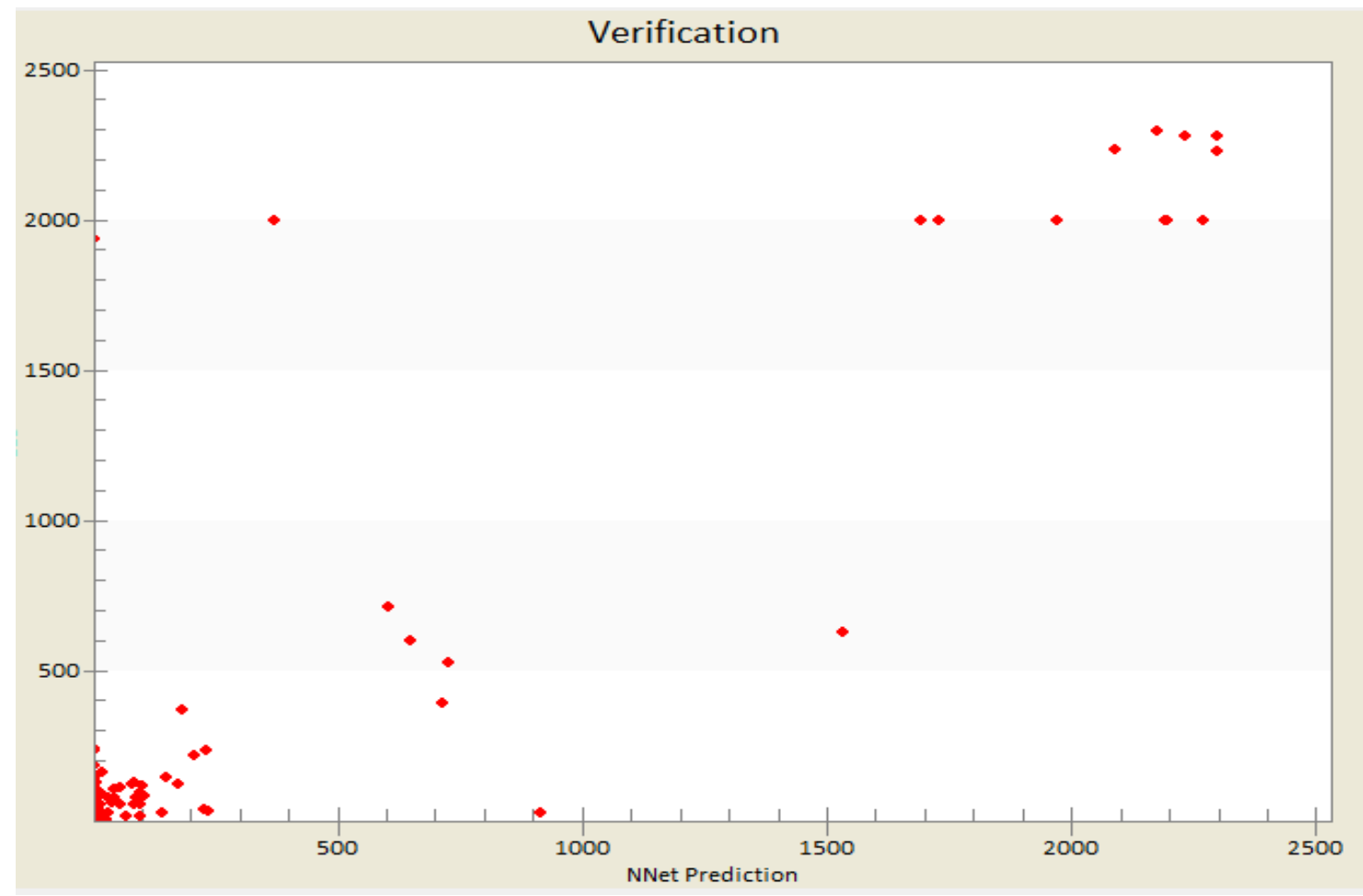

Figure 53: Verification result cross plot

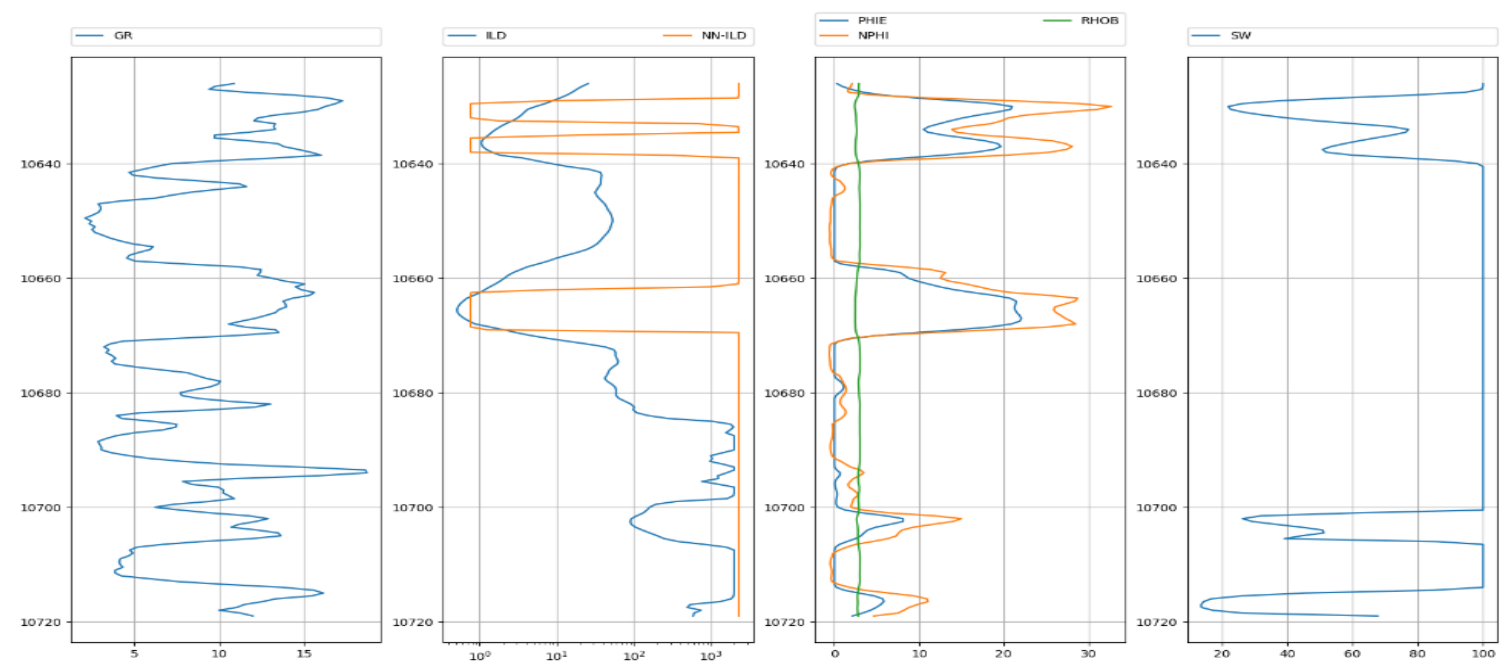

Figure 54: Outcomes for scenario III

\subsection{Scenario IV}

Same run was tried with different blind well (US 71-01V). $\mathrm{R}^{2}$ results of the training process shown in table 5 and the result of the blind well was plotted against the actual value as it shown in (figure 63). 


\begin{tabular}{|c|c|c|c|c|c|}
\hline Partitioning & All & Training & Calibration & Verification & Blind \\
\hline $80-10-10$ & 85.6 & 88.4 & 90.9 & 59.5 & 76.3 \\
\hline
\end{tabular}

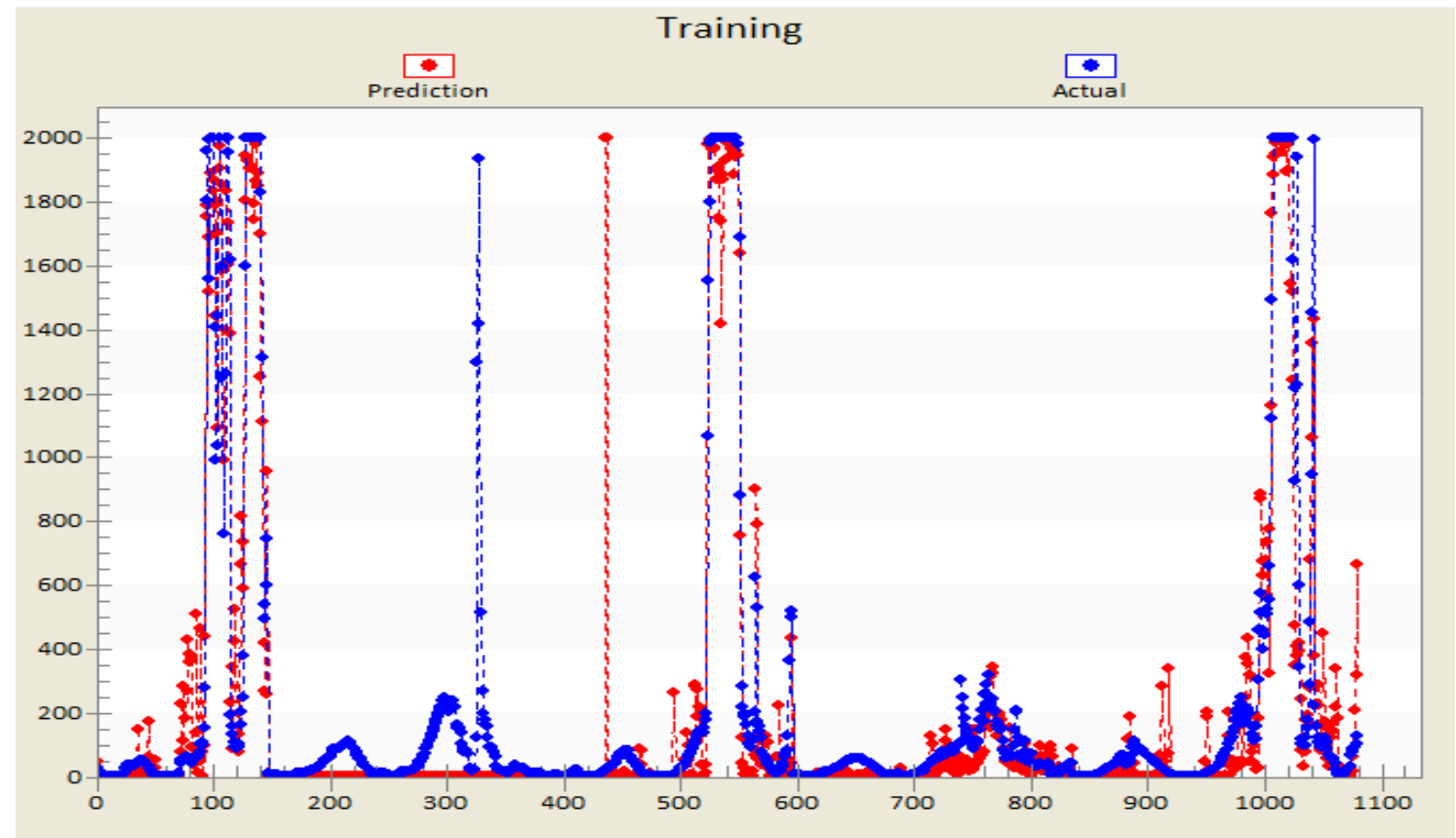

Figure 55: Training result scatter plot

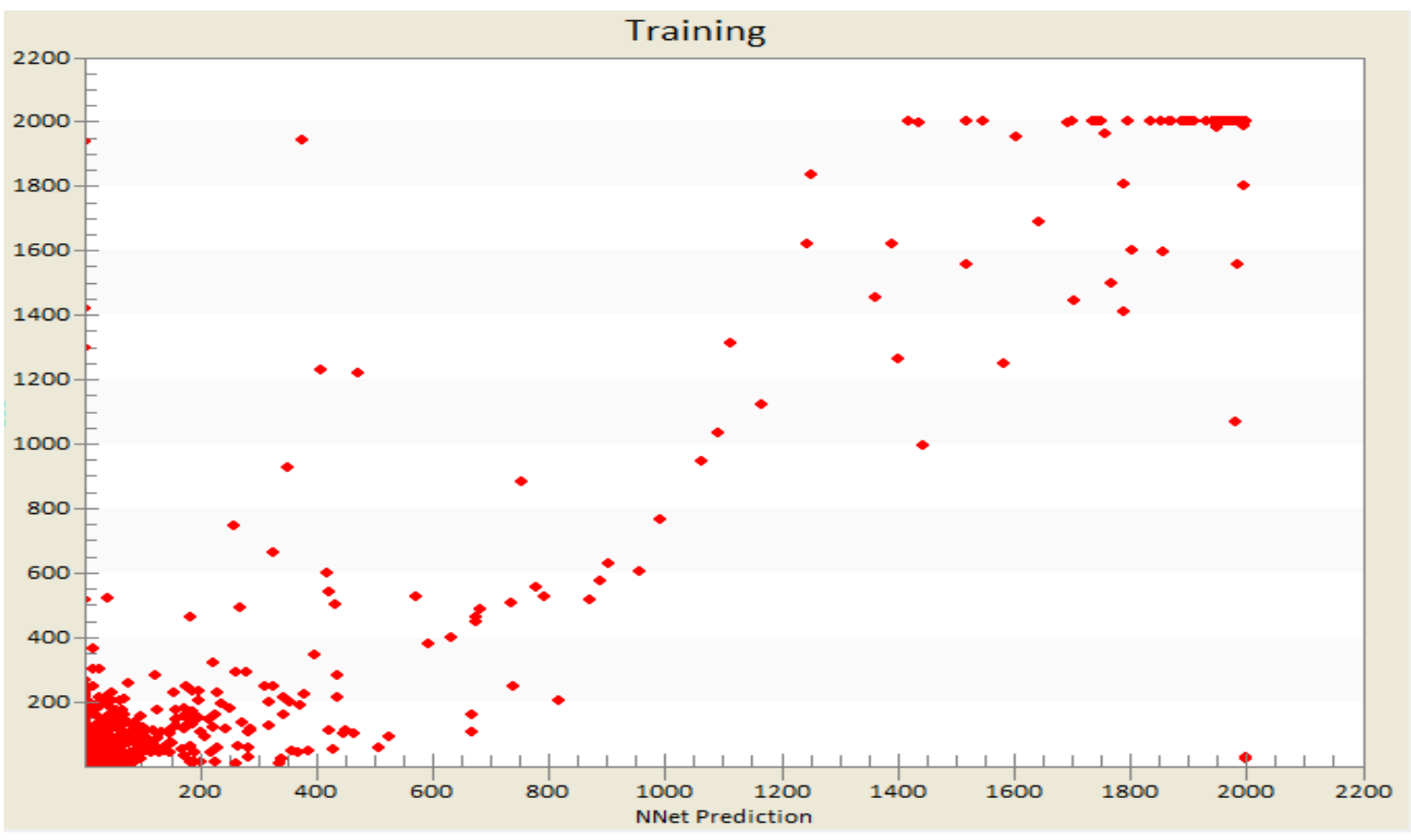

Figure 56: Training result cross plot 


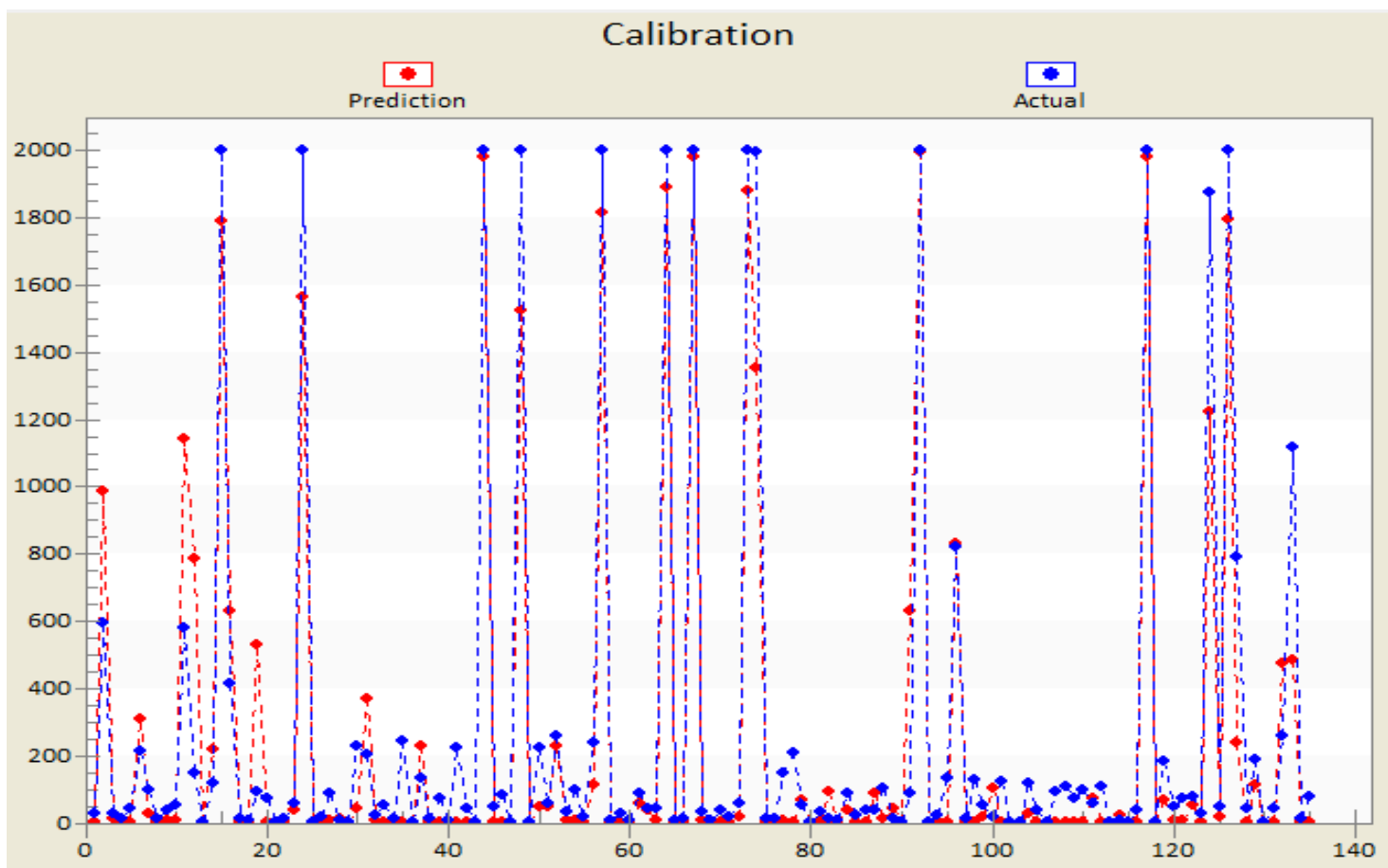

Figure 57: Calibration result scatter plot

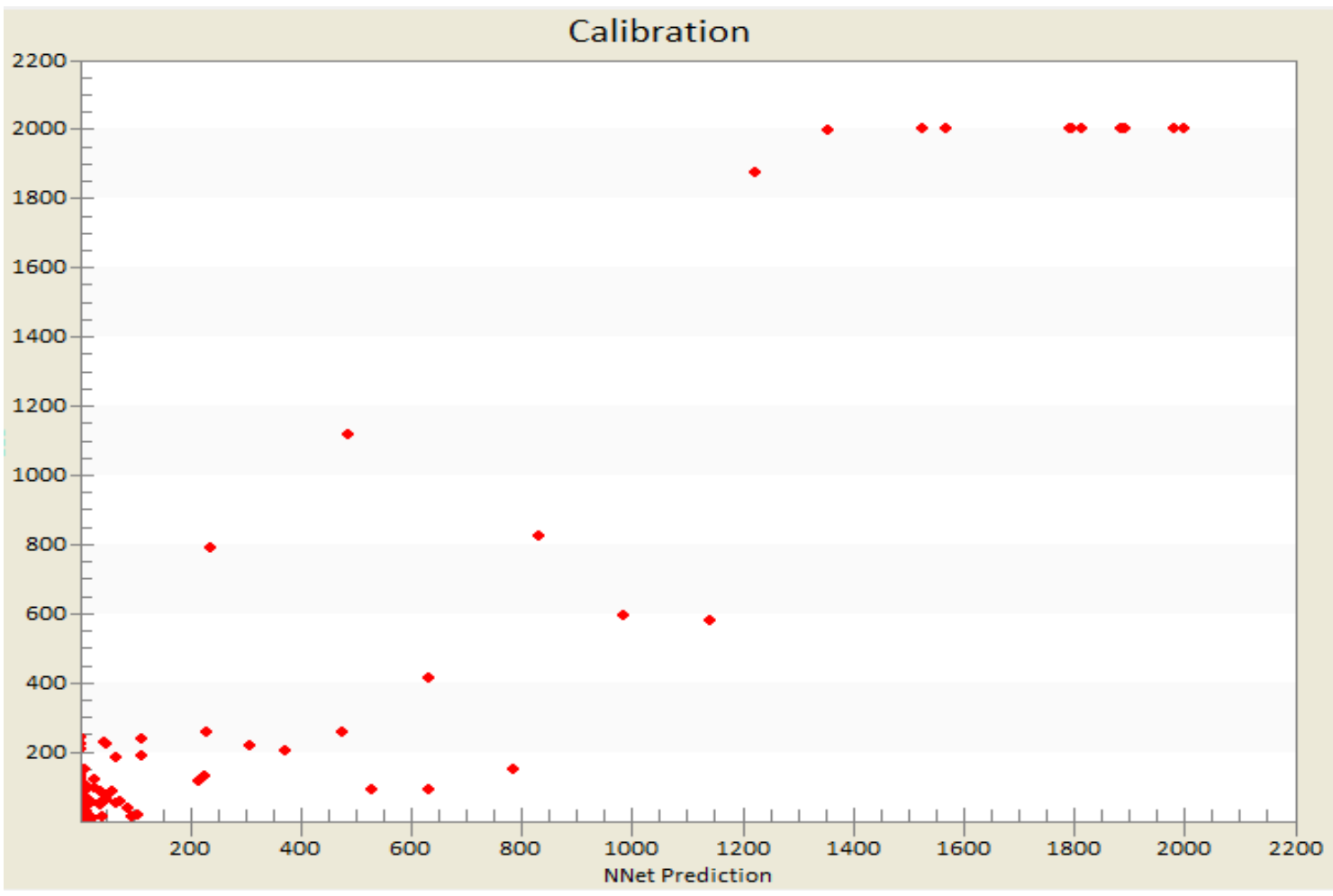

Figure 58: Calibration result cross plot 


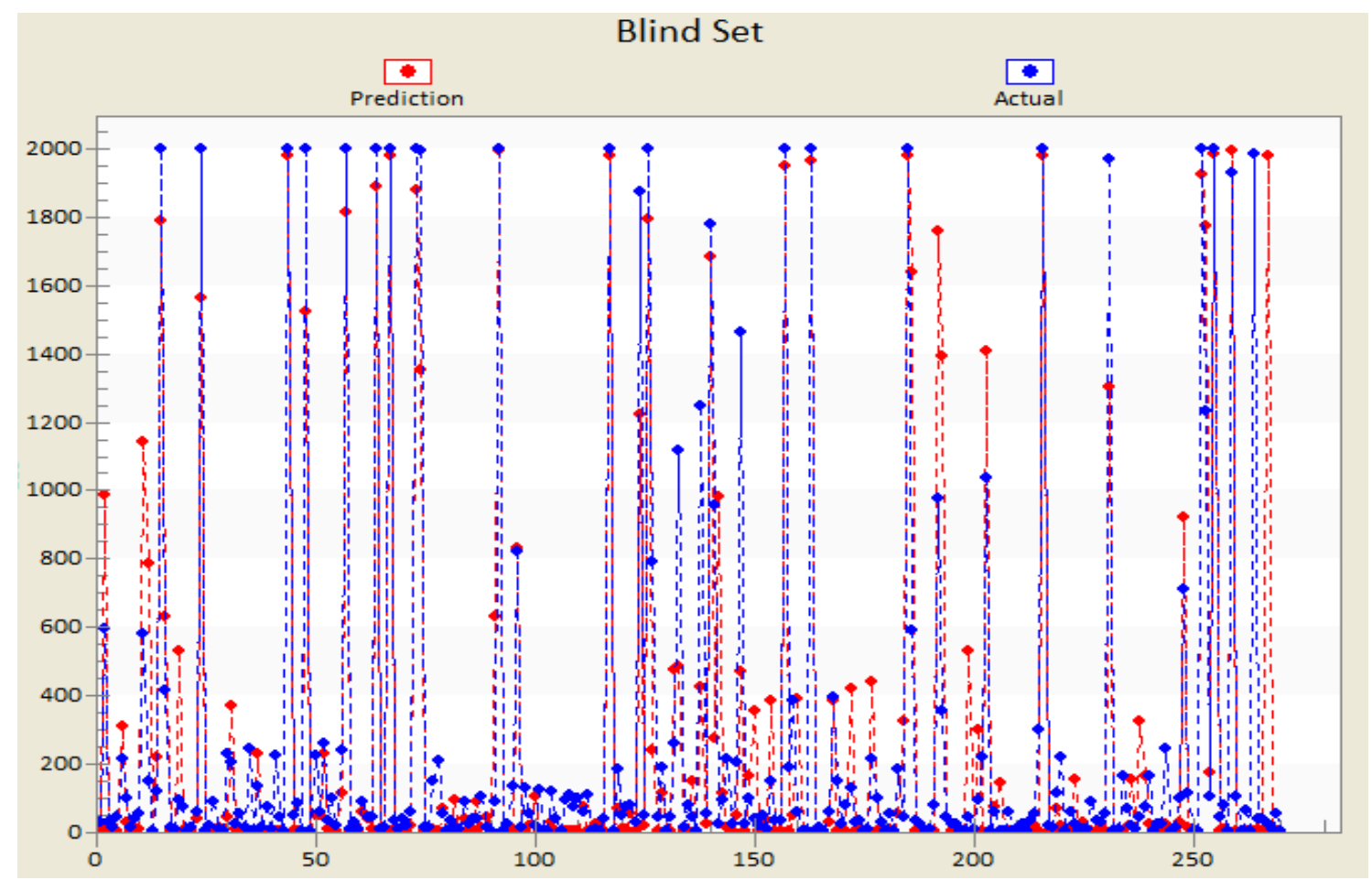

Figure 59: Blind result scatter plot

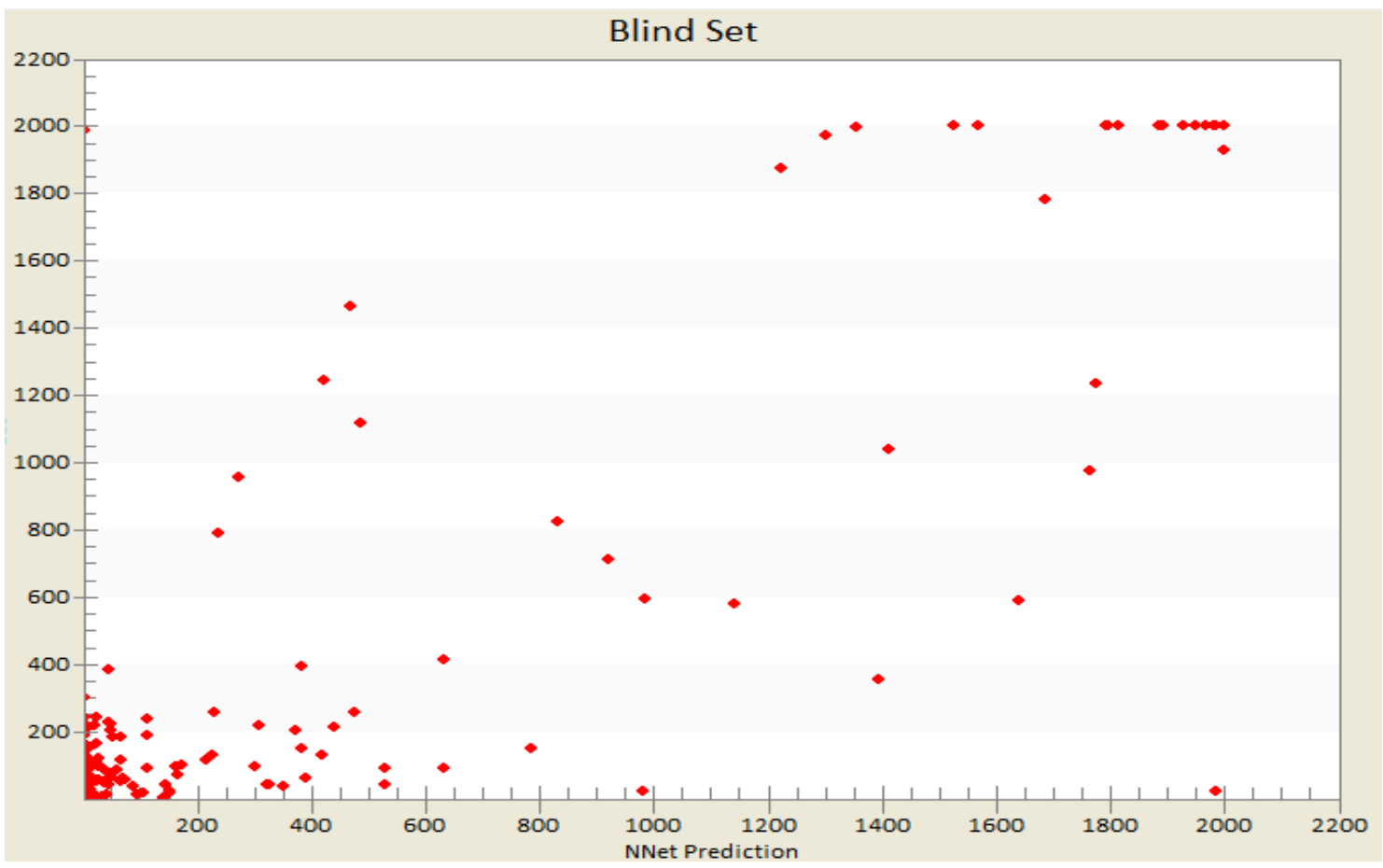

Figure 60: Blind result cross plot 


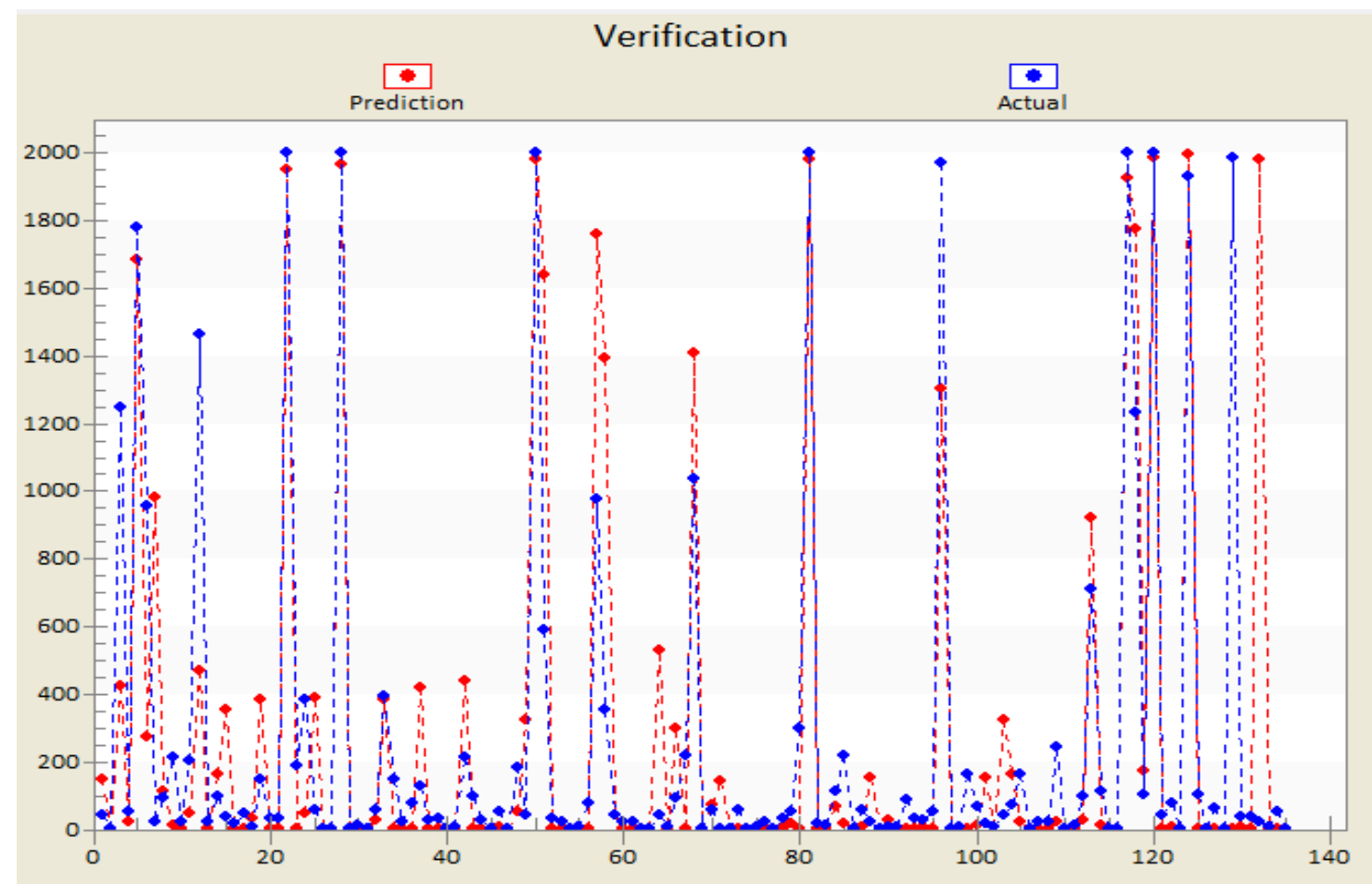

Figure 61: Verification result scatter plot

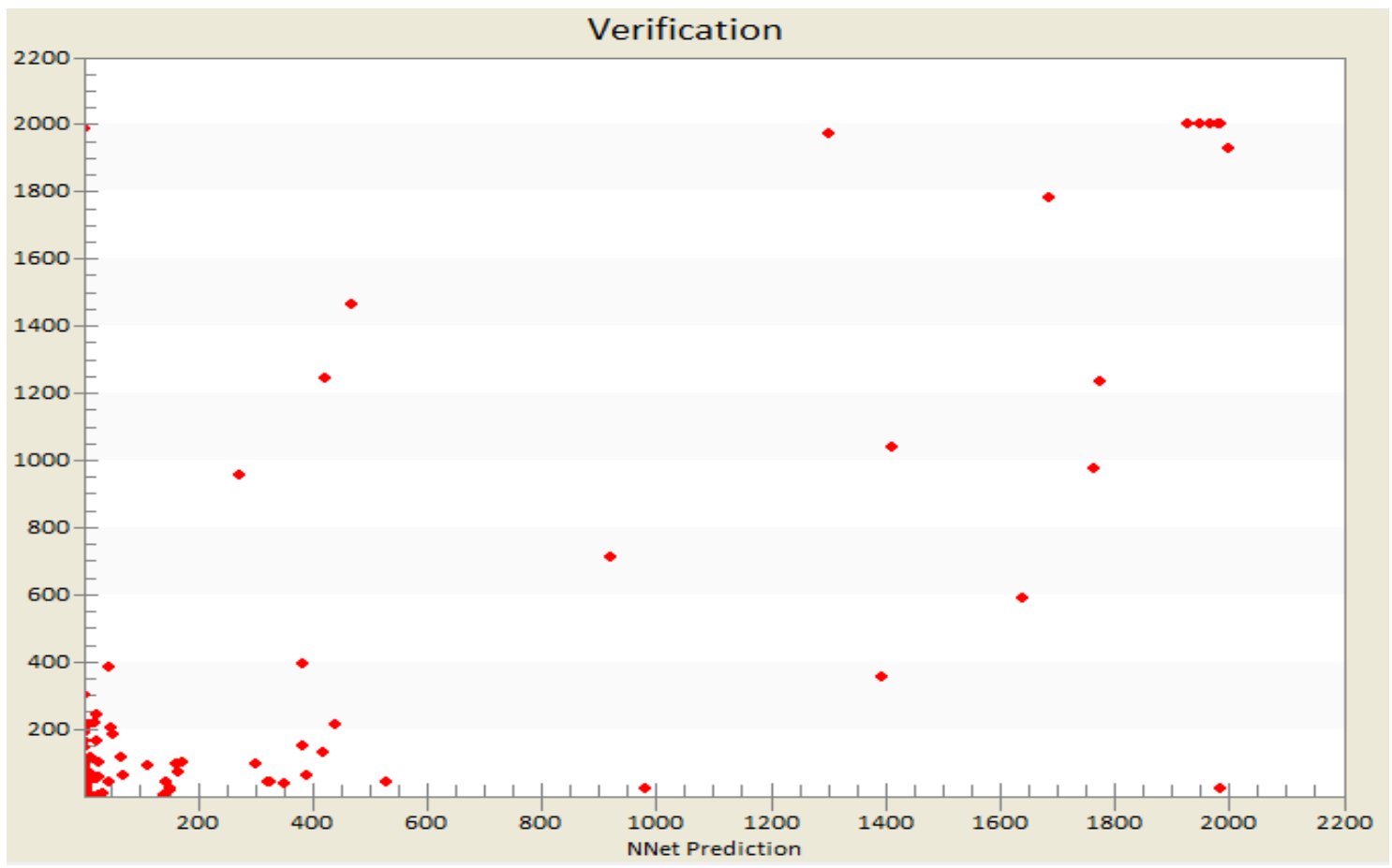

Figure 62: Verification result cross plot 

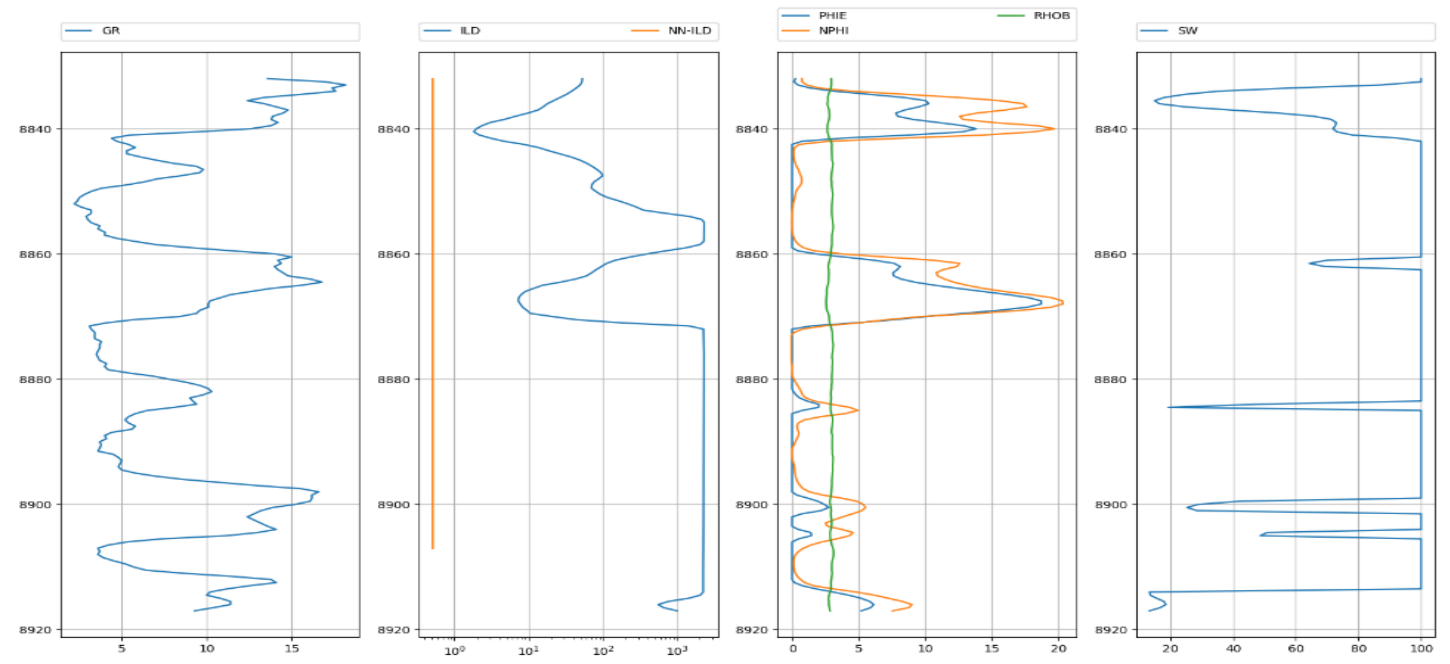

Figure 63: Outcomes for scenario IV

\subsection{Scenario V}

After trying many different sets of blind wells and still getting huge errors, it was decided to investigate only water injectors by using different data partitioning values and monitor their behavior. First, started with $80 \%$ training, $10 \%$ verification and $10 \%$ blind and generated ILD for all of the 6 water injectors, then it was repeated using the same settings with different partitioning (60/20/20) and (40/30/30).

$\mathrm{R}^{2}$ results of the training process shown in table 6 and the result of the blind well was plotted against the actual value as it shown in figure 24.

Table 6: Scenario $V--R^{2}$ results

\begin{tabular}{|c|c|c|c|c|c|}
\hline Partitioning & All & Training & Calibration & Verification & Blind \\
\hline $80-10-10$ & 92.3 & 95.5 & 84.8 & 79.3 & 81.8 \\
\hline $60-20-20$ & 86.8 & 88.9 & 82.5 & 84.8 & 83.7 \\
\hline $40-30-30$ & 81.8 & 91.2 & 77.9 & 74.5 & 76.2 \\
\hline
\end{tabular}



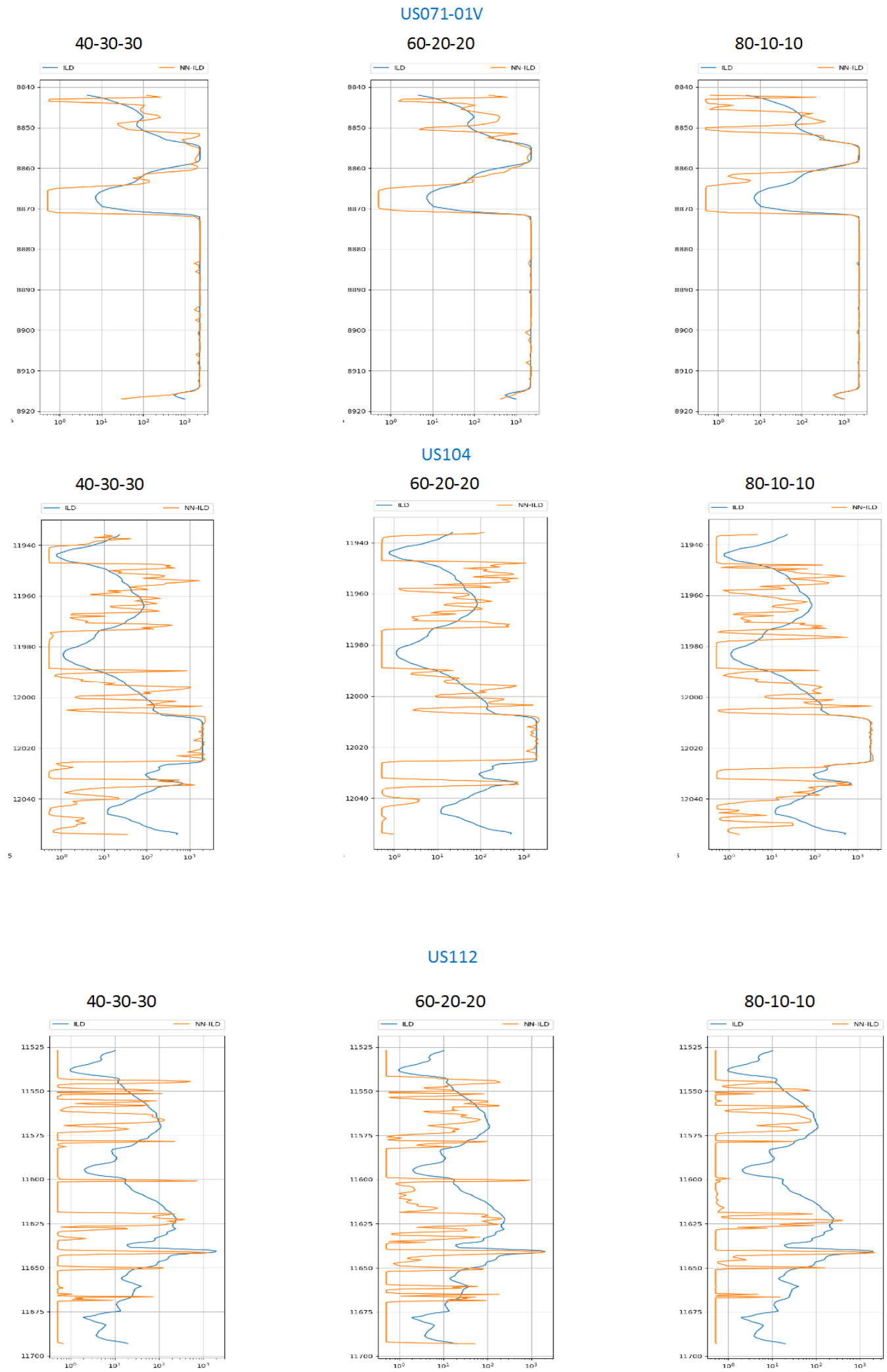

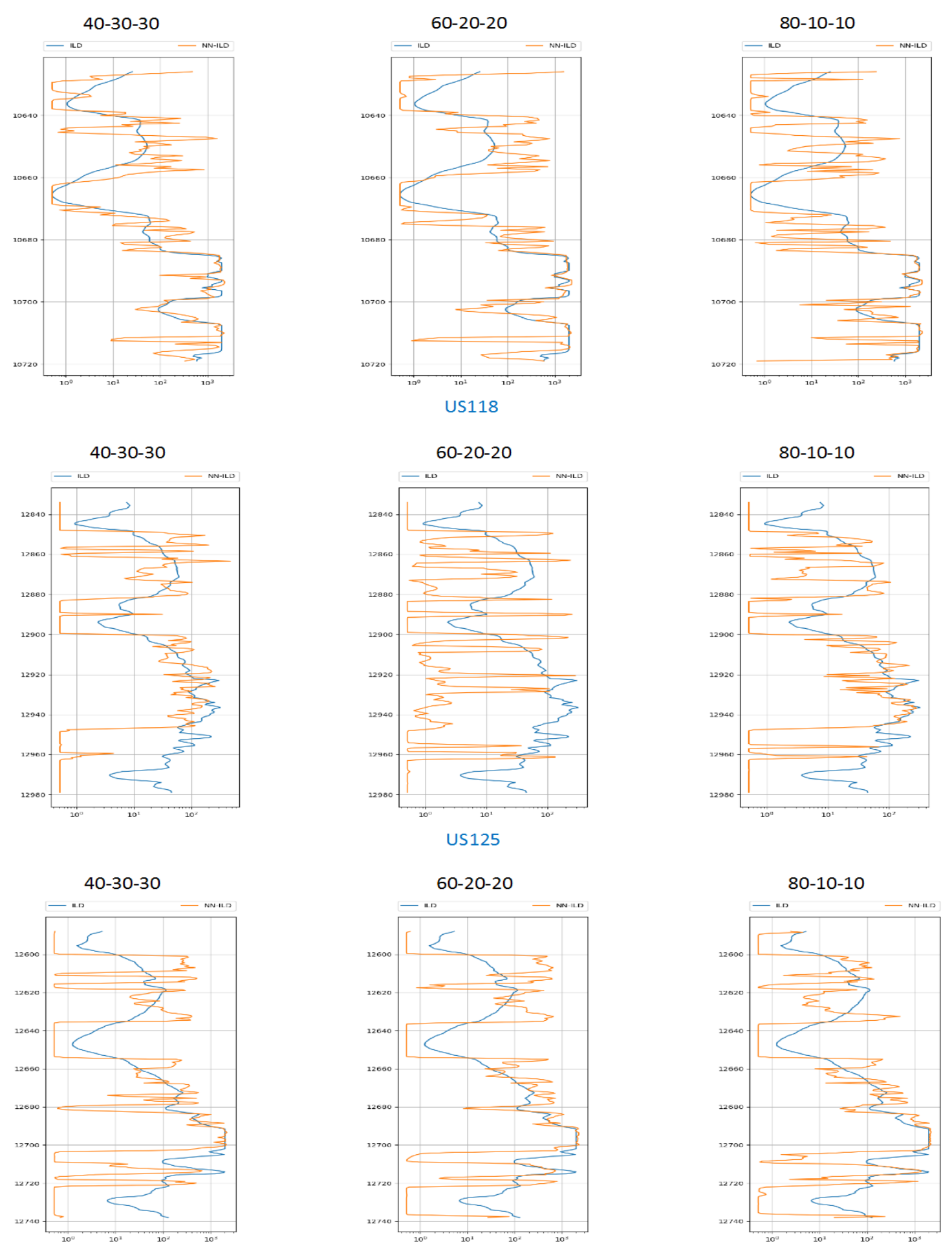

Figure 64: Outcomes for scenario V 


\subsection{Scenario VI}

Next, repeating the same partitioning method, LLS logs were generated for the injectors. $\mathrm{R}^{2}$ results of the training process shown in table 7 and the result of the blind well was plotted against the actual value as it shown in figure 25.

Table 7: Scenario VI-- $R^{2}$ results

\begin{tabular}{|c|c|c|c|c|c|}
\hline Partitioning & All & Training & Calibration & Verification & Blind \\
\hline $80-10-10$ & 91.5 & 92.7 & 85.1 & 88.4 & 86.8 \\
\hline $60-20-20$ & 91.7 & 94.5 & 89.3 & 86.8 & 88 \\
\hline $40-30-30$ & 86.6 & 97.9 & 82.6 & 79.4 & 80.9 \\
\hline
\end{tabular}
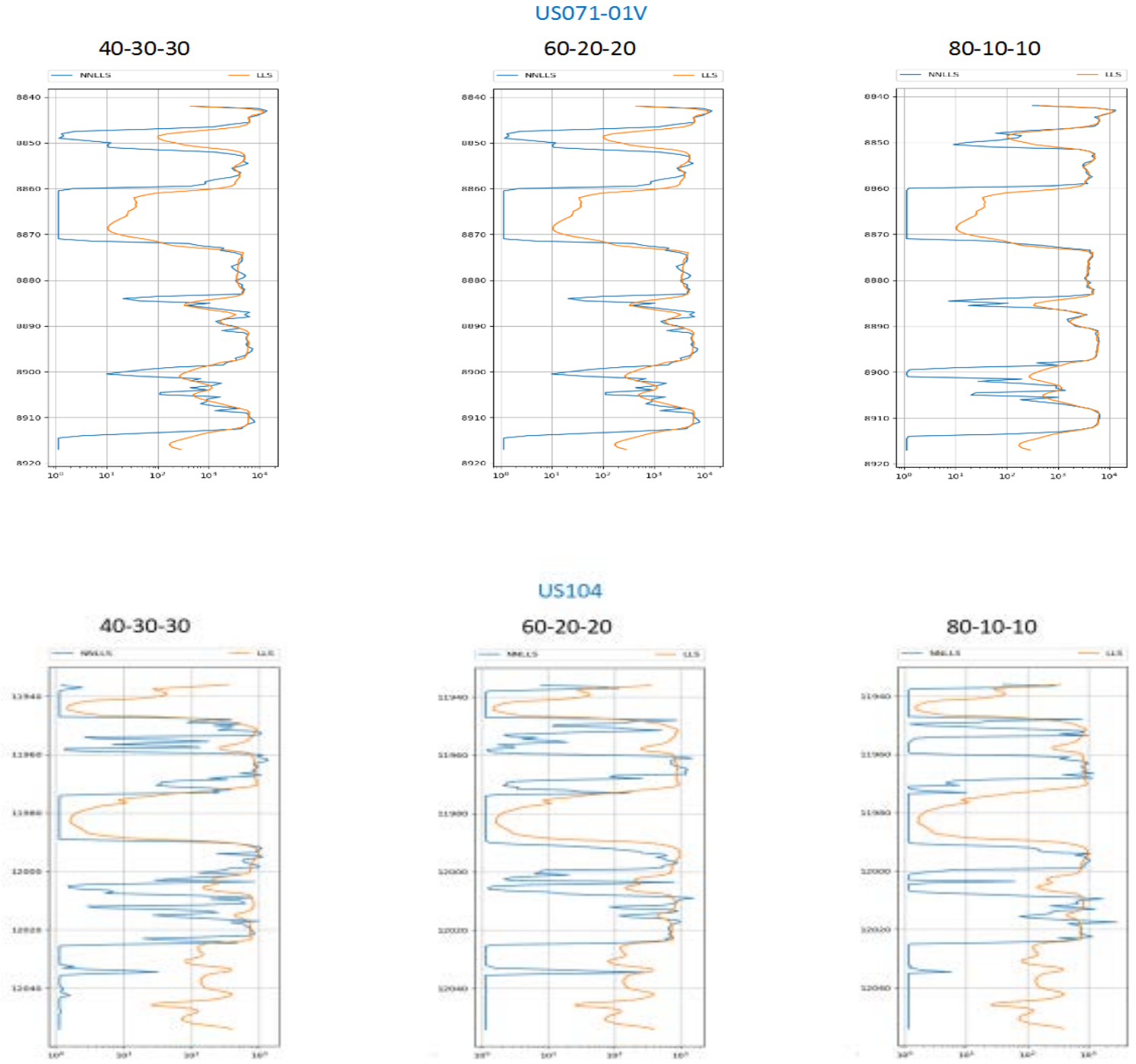

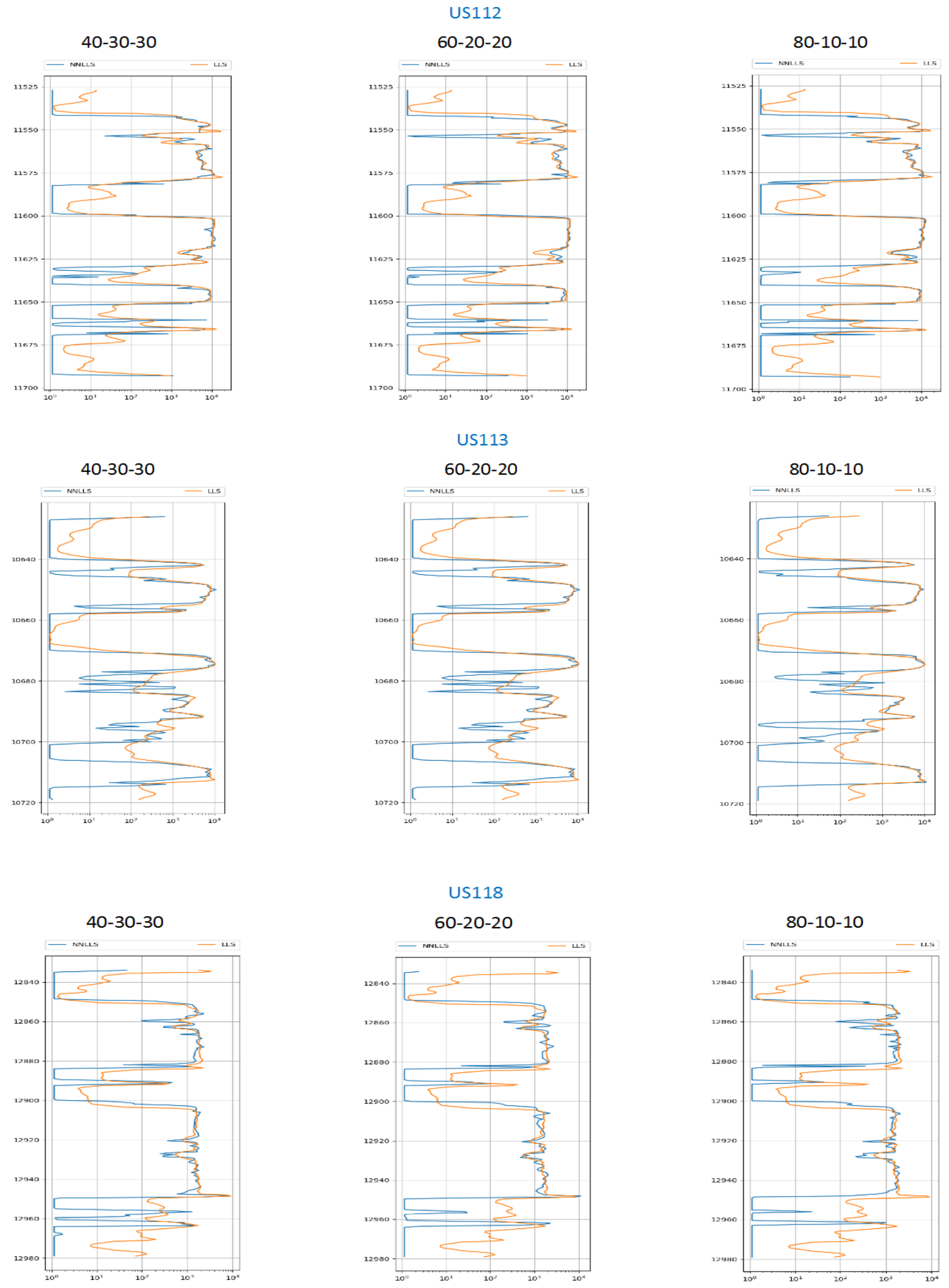

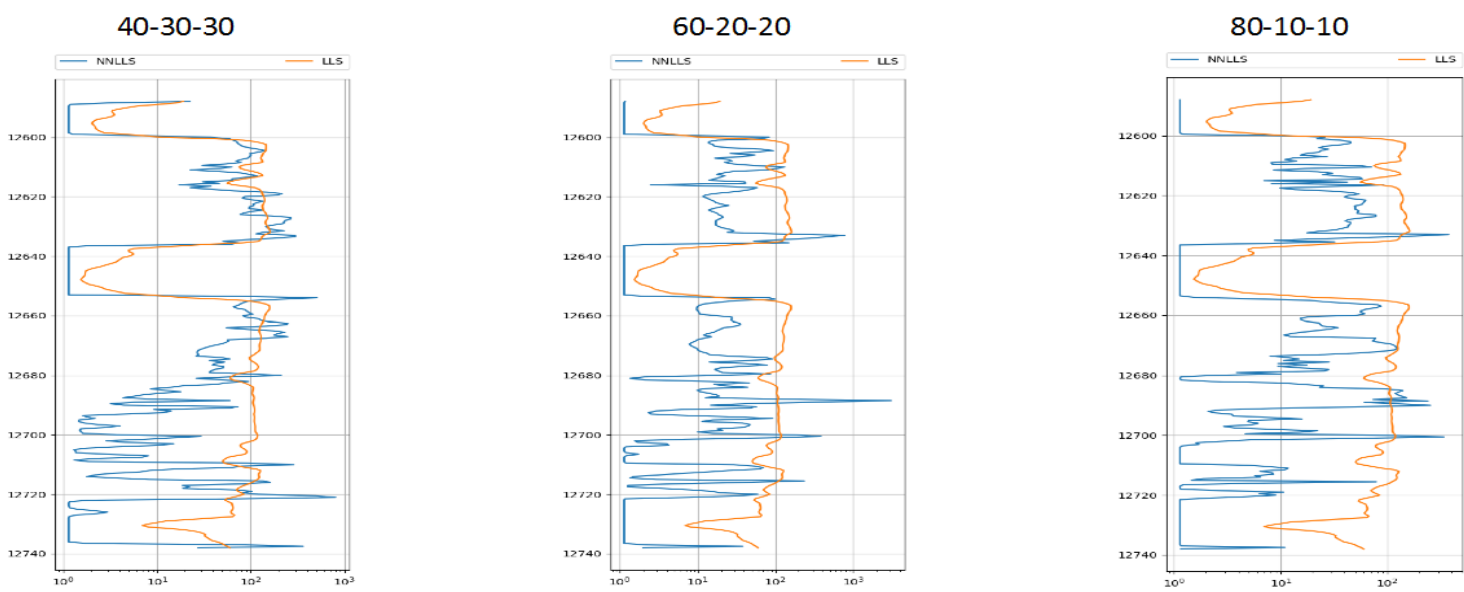

\subsection{Scenario VII}

Figure 65: Outcomes for scenario VI

Repeating the same partitioning method, MSFL logs were generated for the injectors. $\mathrm{R}^{2}$ results of the training process shown in table 8 and the result of the blind well was plotted against the actual value as it shown in figure 26.

Table 8: Scenario VII-- $R^{2}$ results

\begin{tabular}{|c|c|c|c|c|c|}
\hline Partitioning & All & Training & Calibration & Verification & Blind \\
\hline $80-10-10$ & 91.5 & 92.7 & 85.1 & 88.4 & 86.8 \\
\hline $60-20-20$ & 90.2 & 90.7 & 89.6 & 88.9 & 89.3 \\
\hline $40-30-30$ & 86.3 & 90.5 & 82.9 & 84.3 & 83.7 \\
\hline
\end{tabular}
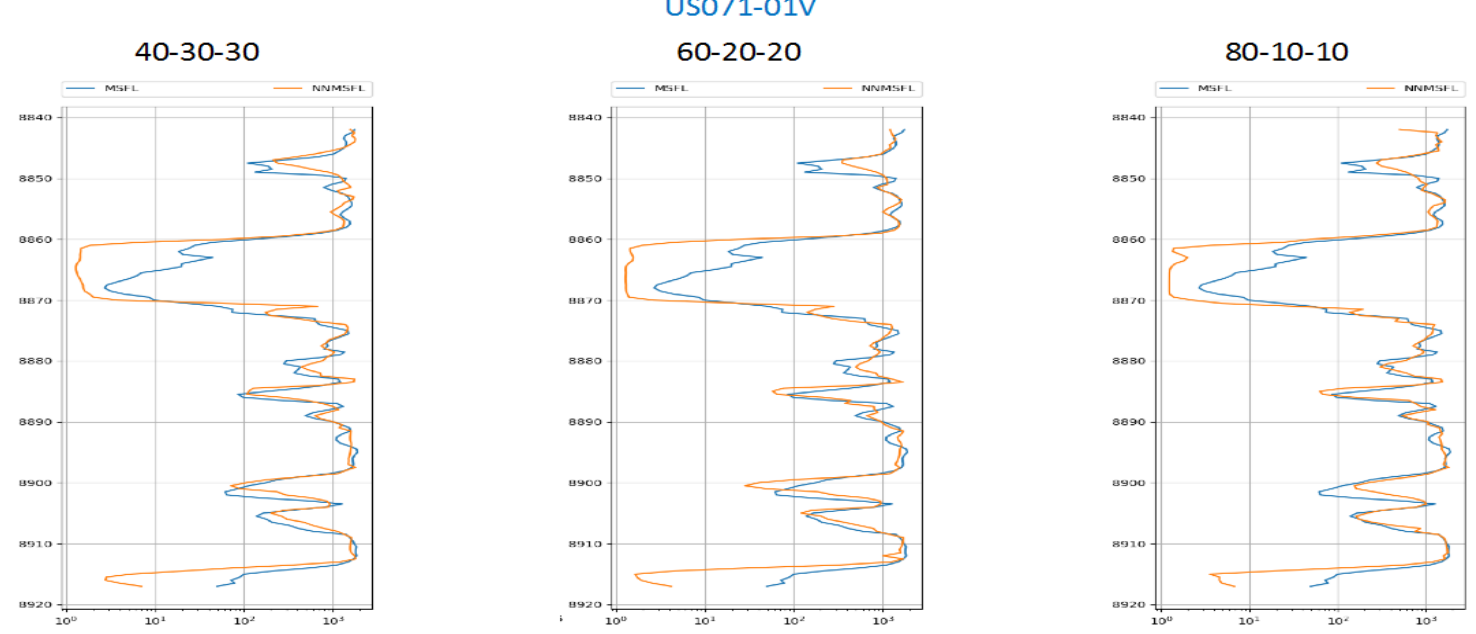

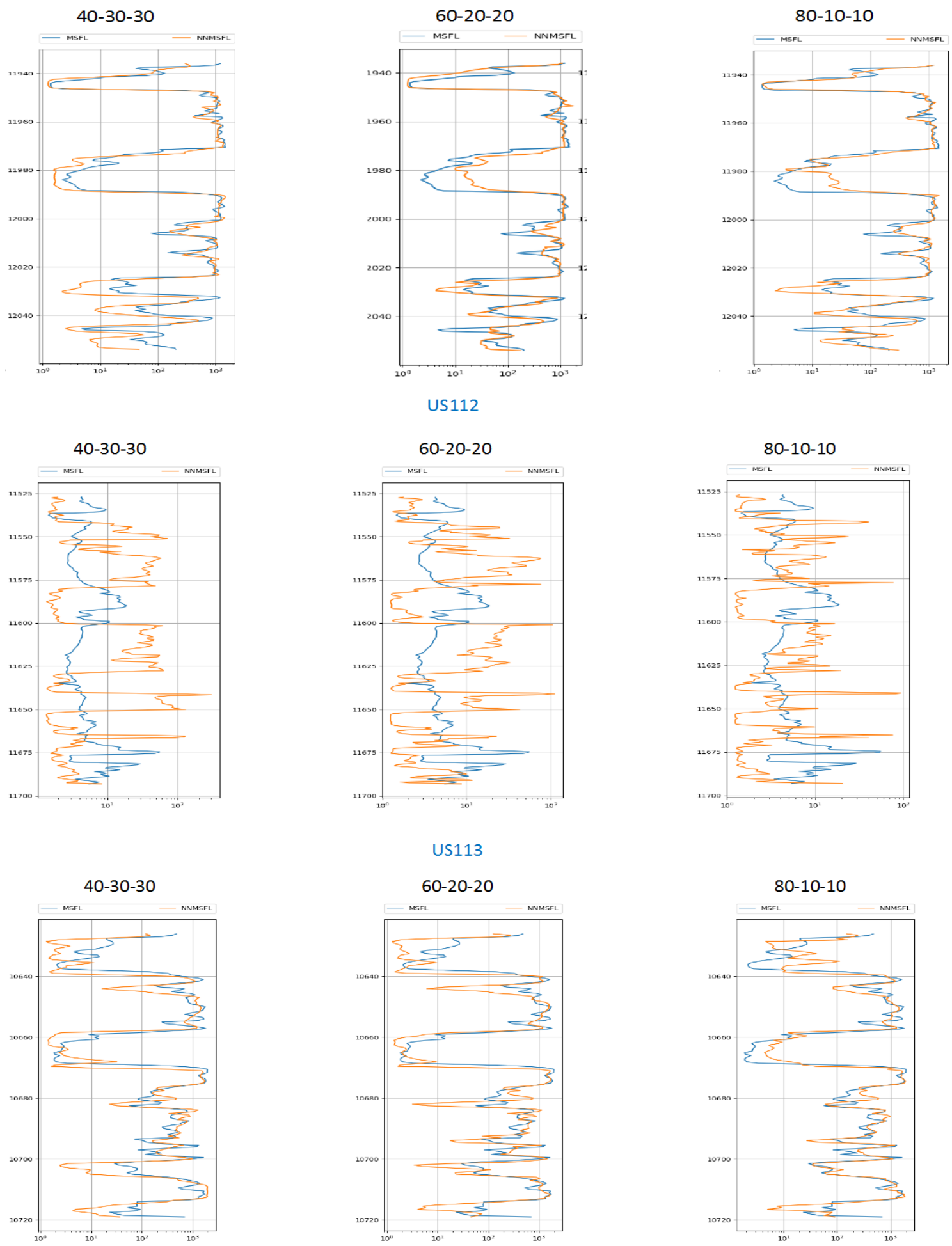

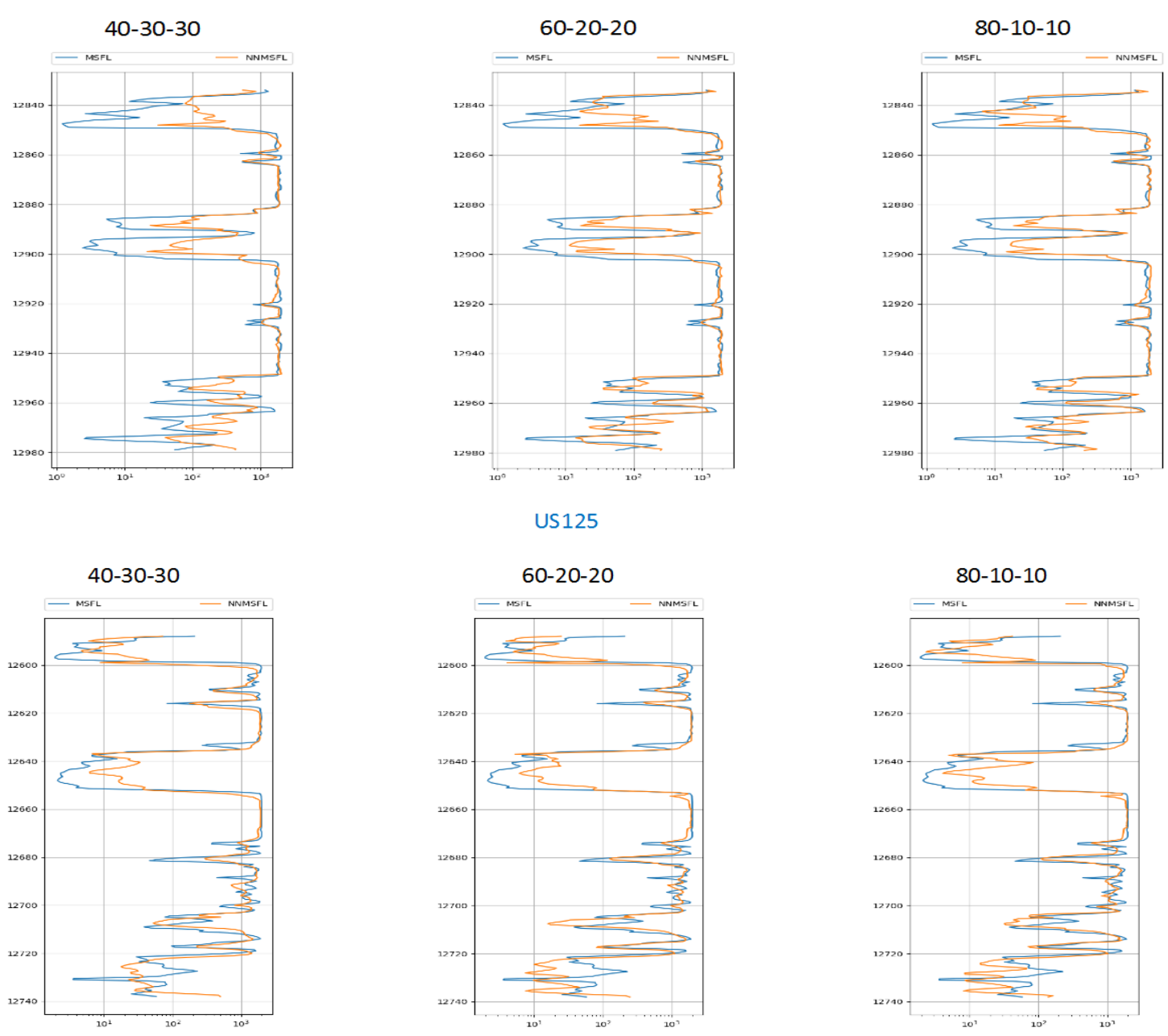

Figure 66: Outcomes for scenario VII

\subsection{Scenario VIII}

After evaluating all of the results from water injectors runs, it has been confirmed that resistivity logs behave in different way than oil producers due to the high-water saturation.

In this scenario, 1 oil producer (US 022) used to train the neural network to generate the missing ILD logs for the remaining 8 oil producers. $\mathrm{R}^{2}$ results of the training process shown in table 9 and the result was plotted as it shown in (figure 76). 
Table 9: Scenario VIII-- $R^{2}$ results

\begin{tabular}{|c|c|c|c|c|c|}
\hline Partitioning & All & Training & Calibration & Verification & Blind \\
\hline $80-10-10$ & 97.3 & 97.8 & 95.1 & 95.6 & 95.4 \\
\hline
\end{tabular}

\section{Oil producers}

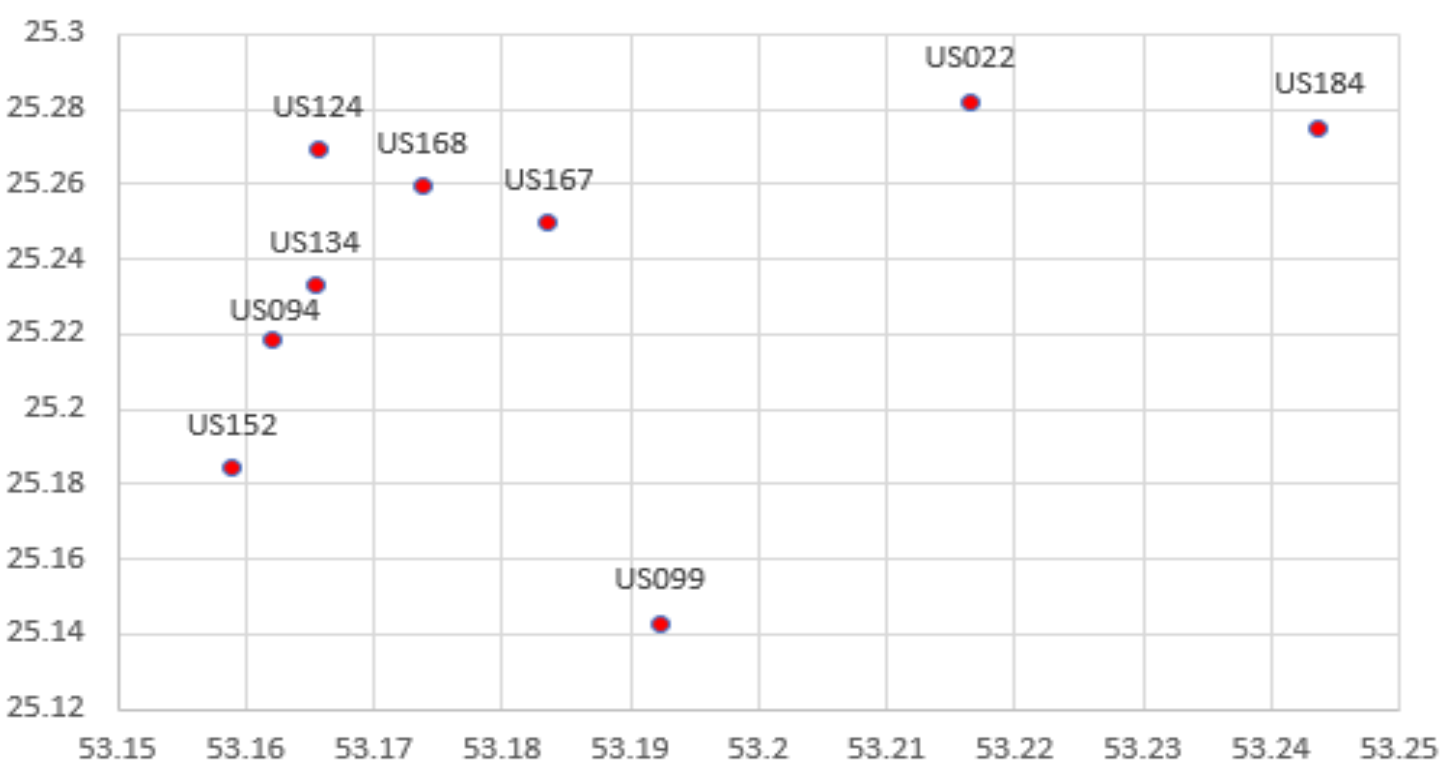

Figure 67: Oil producers

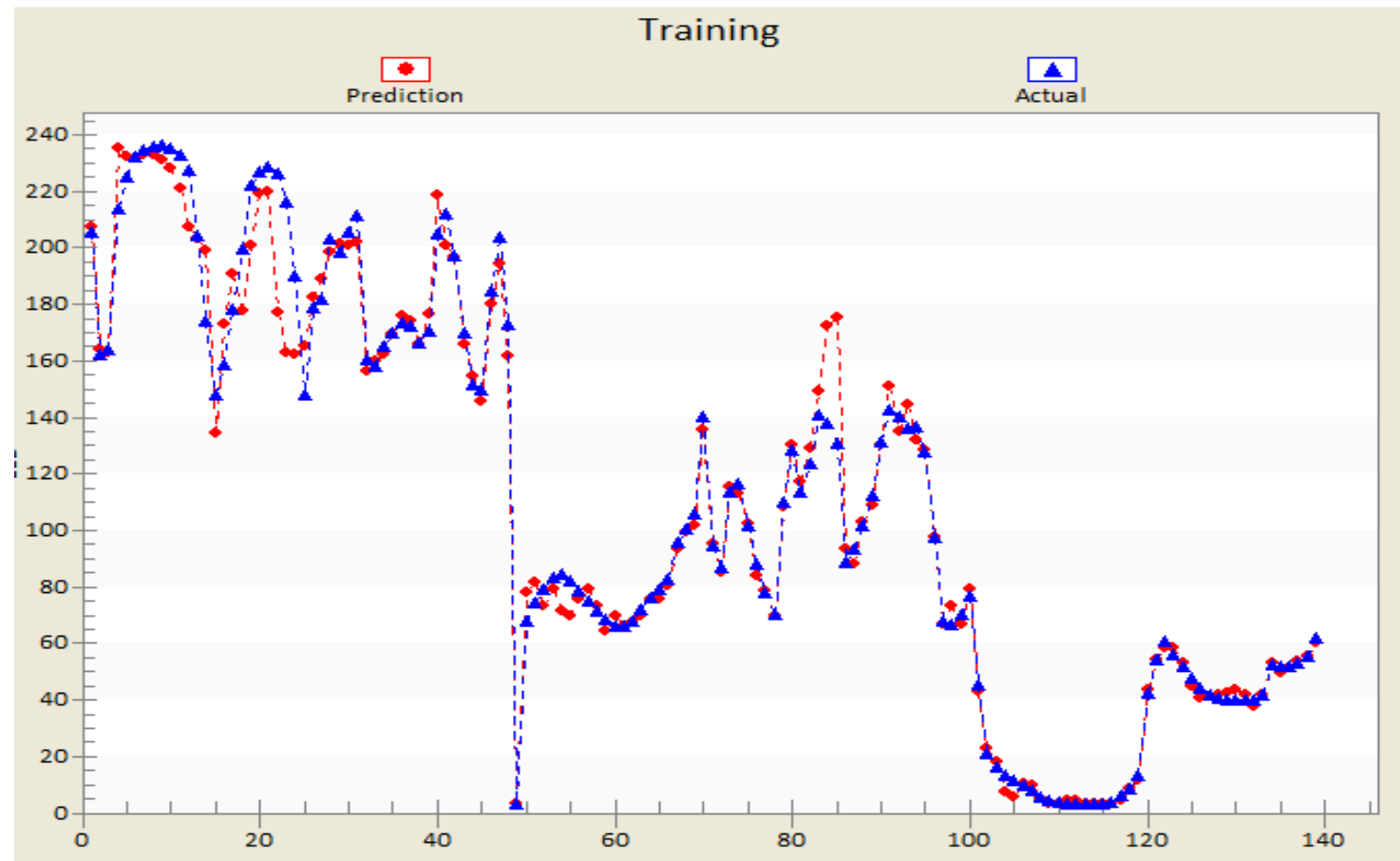

Figure 68: Training result scatter plot 


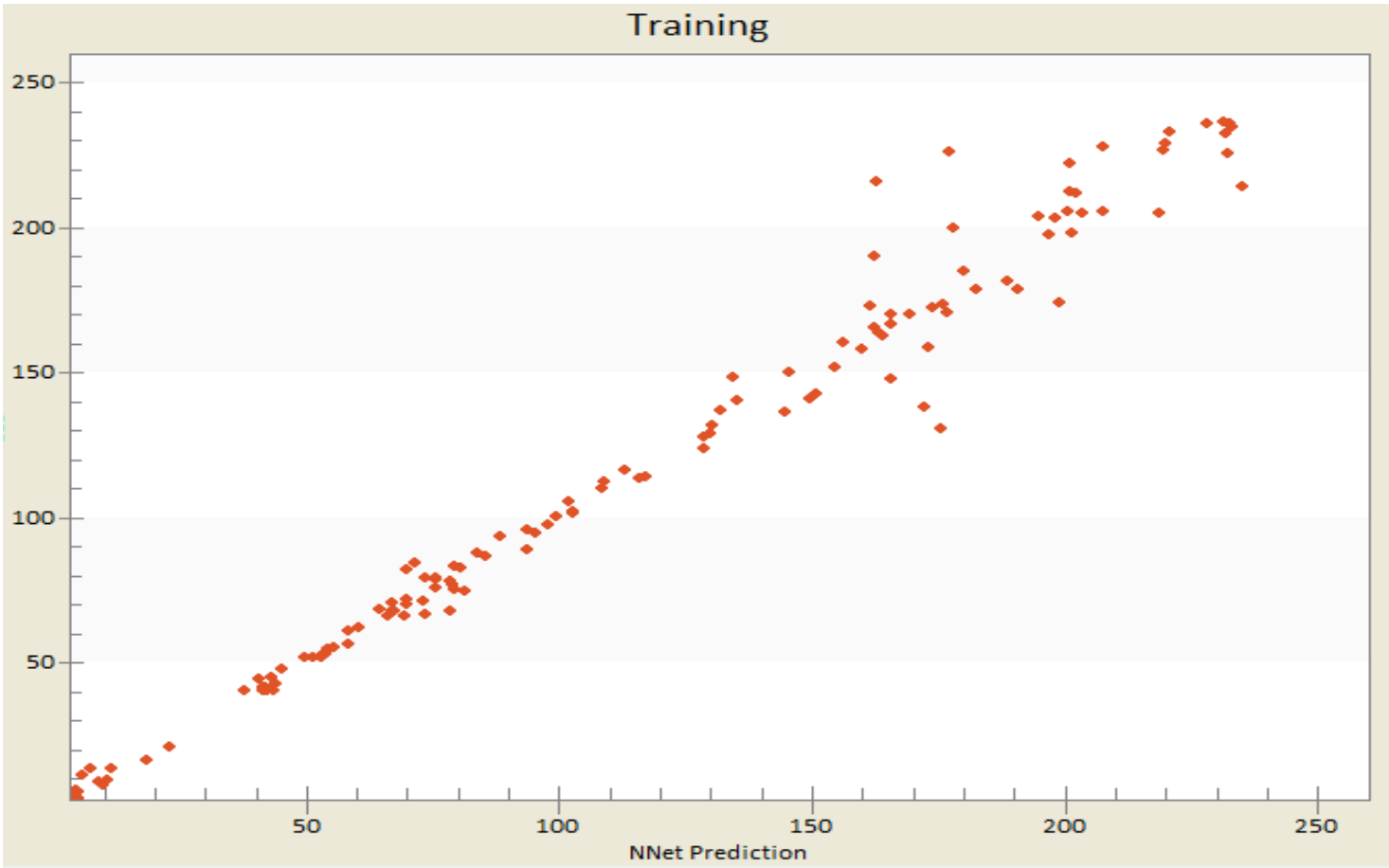

Figure 69: Training result cross plot

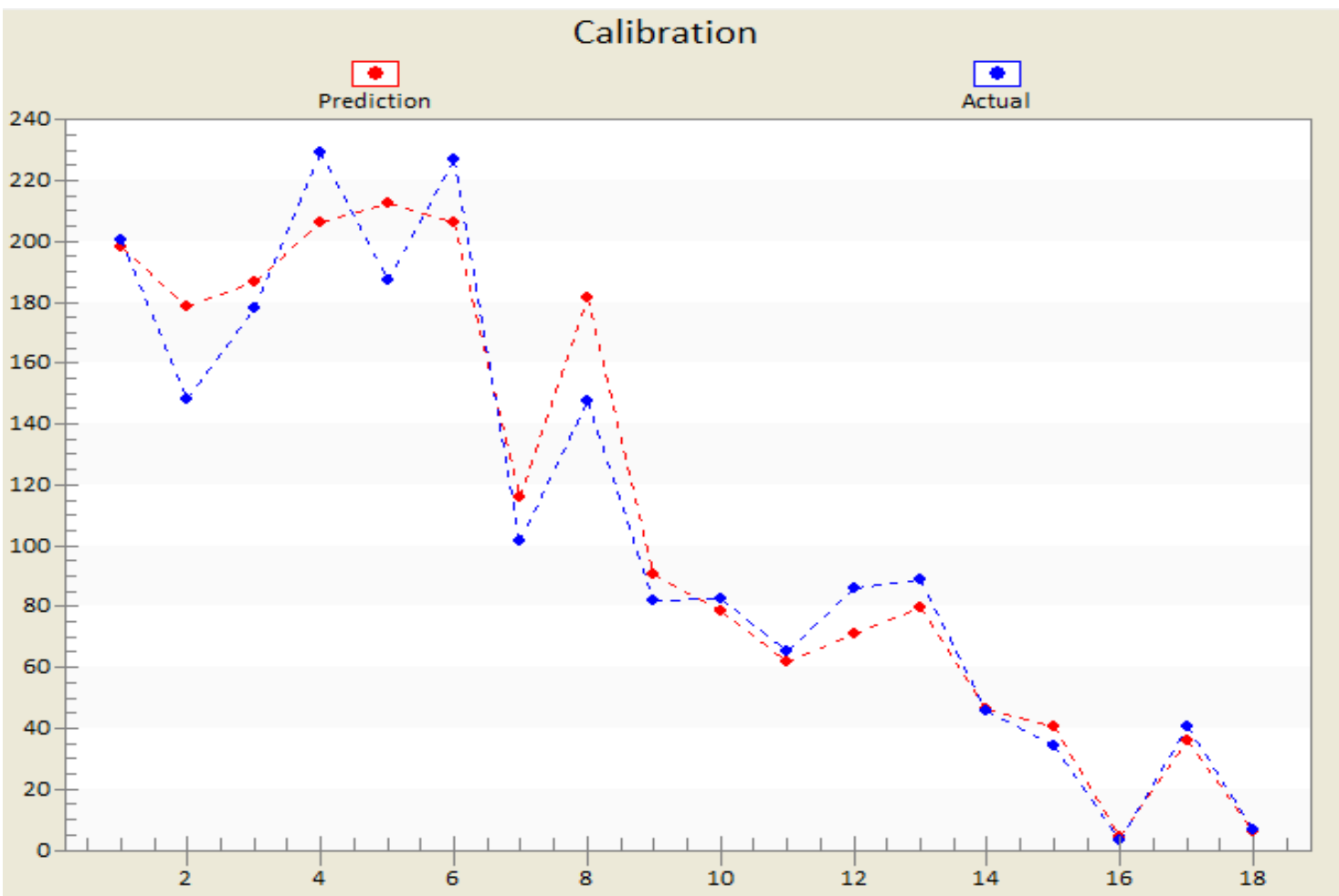

Figure 70: Calibration result scatter plot 


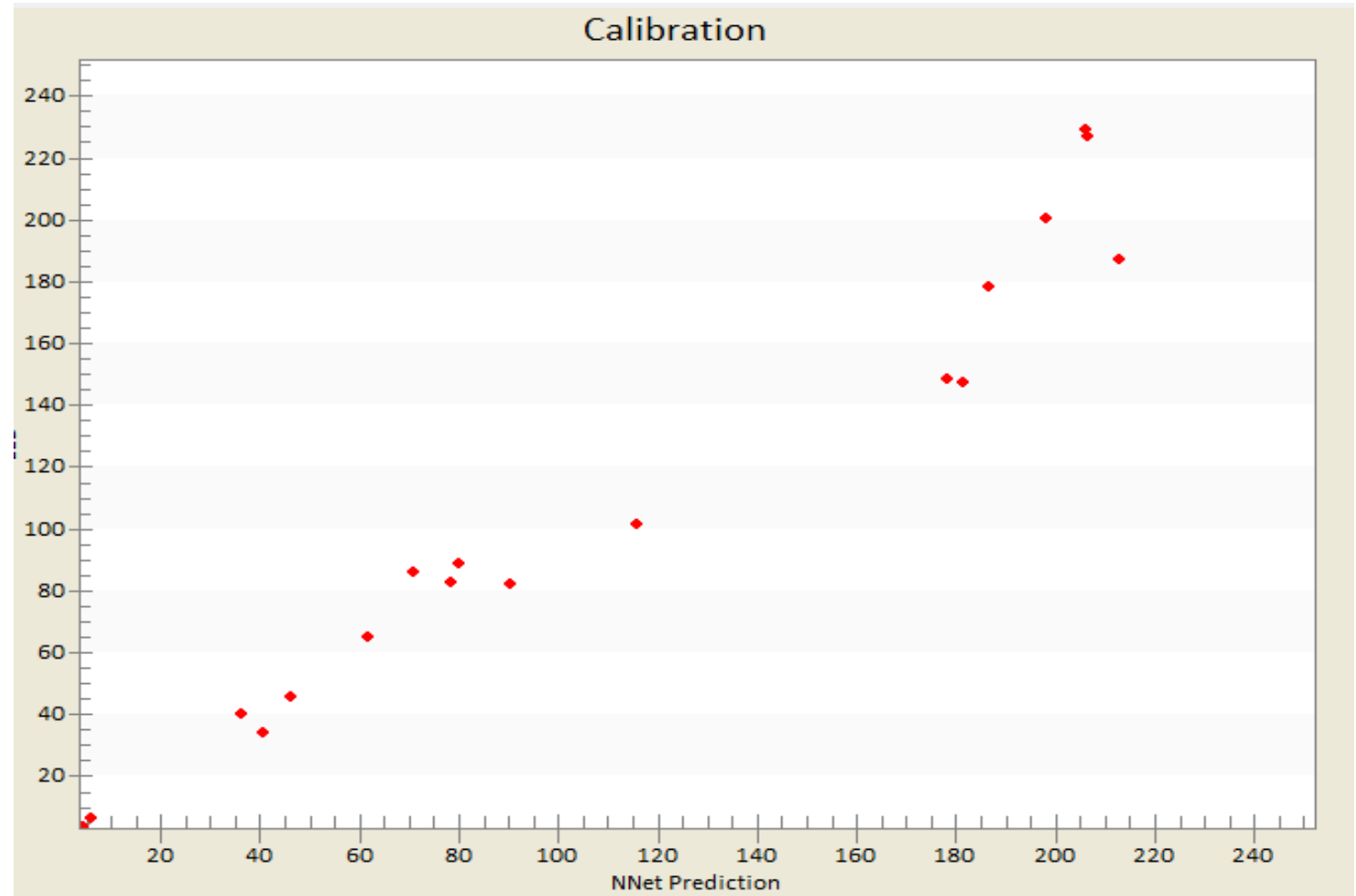

Figure 71: Calibration result cross plot

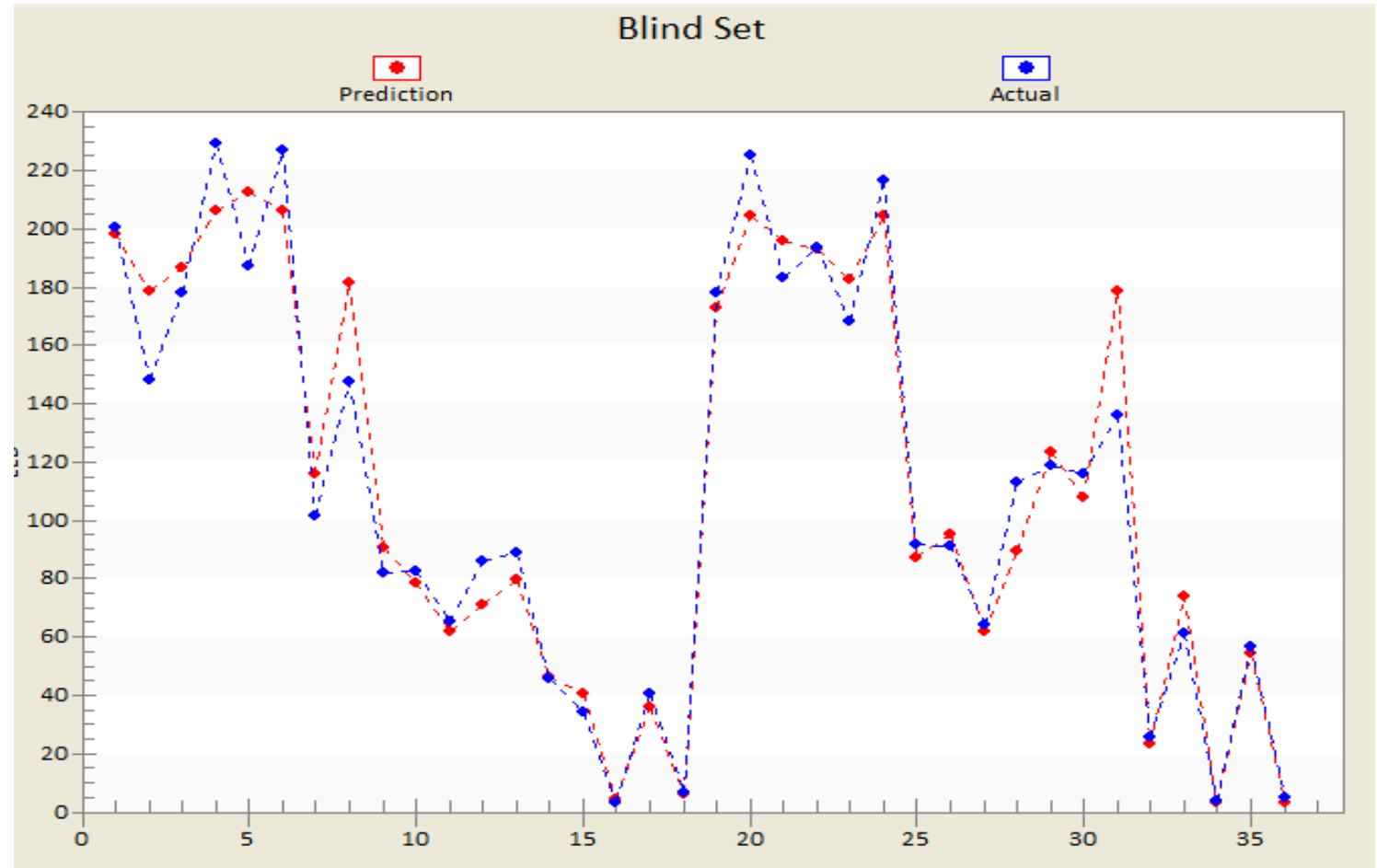

Figure 72: Blind result scatter plot 


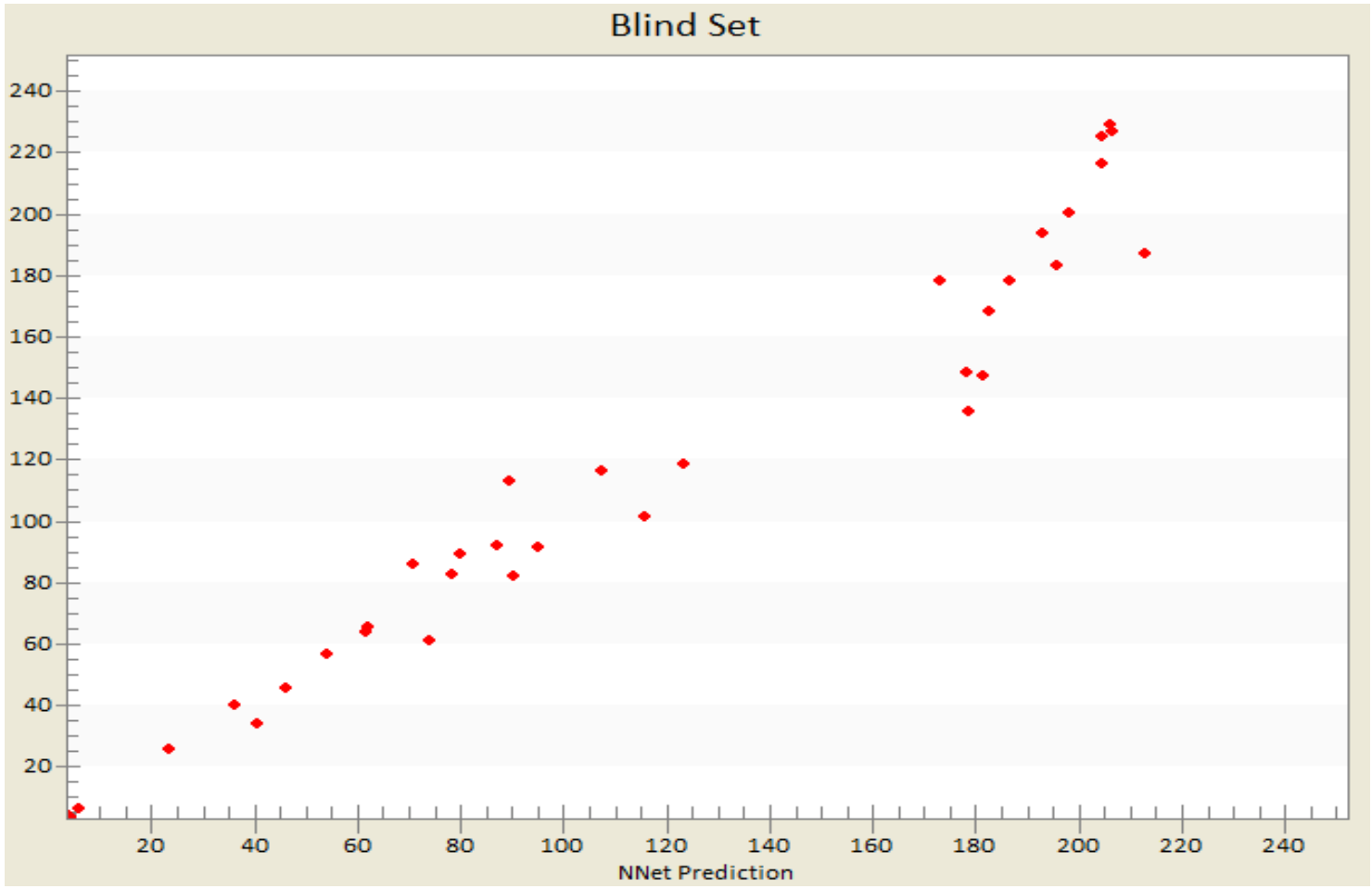

Figure 73: Blind result cross plot

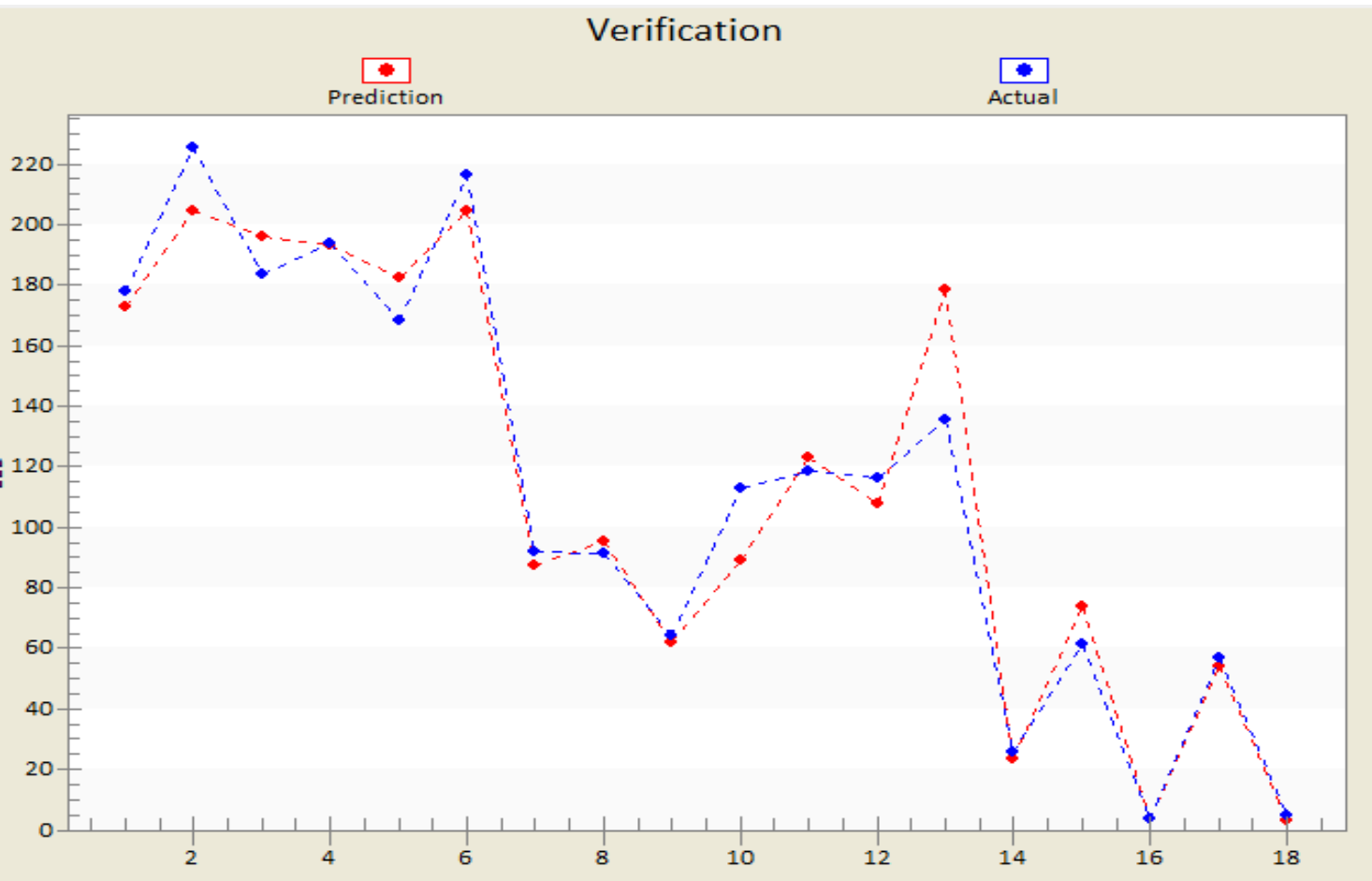

Figure 74: Verification result scatter plot 


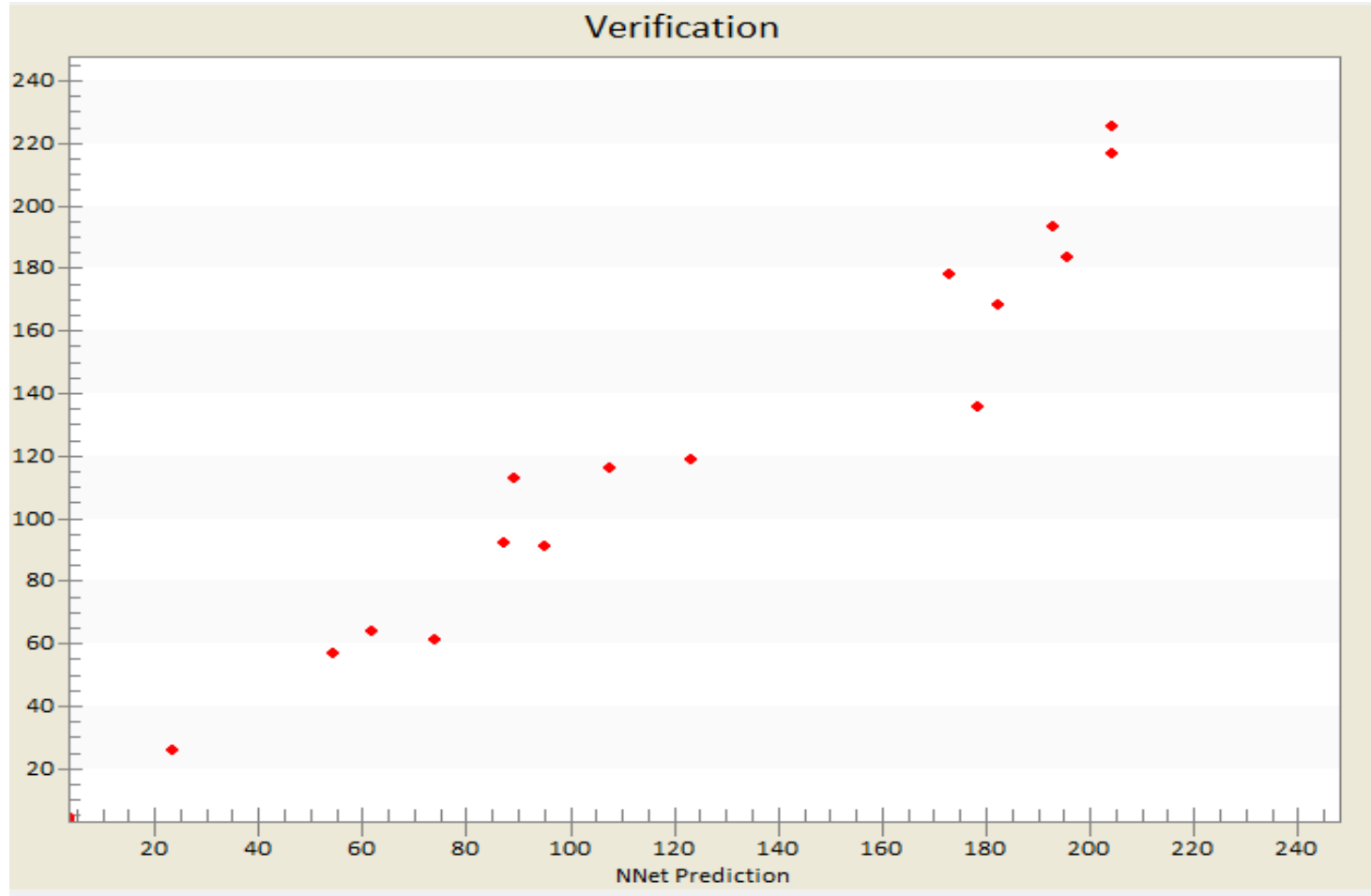

Figure 75: Verification result cross plot

\section{US022}
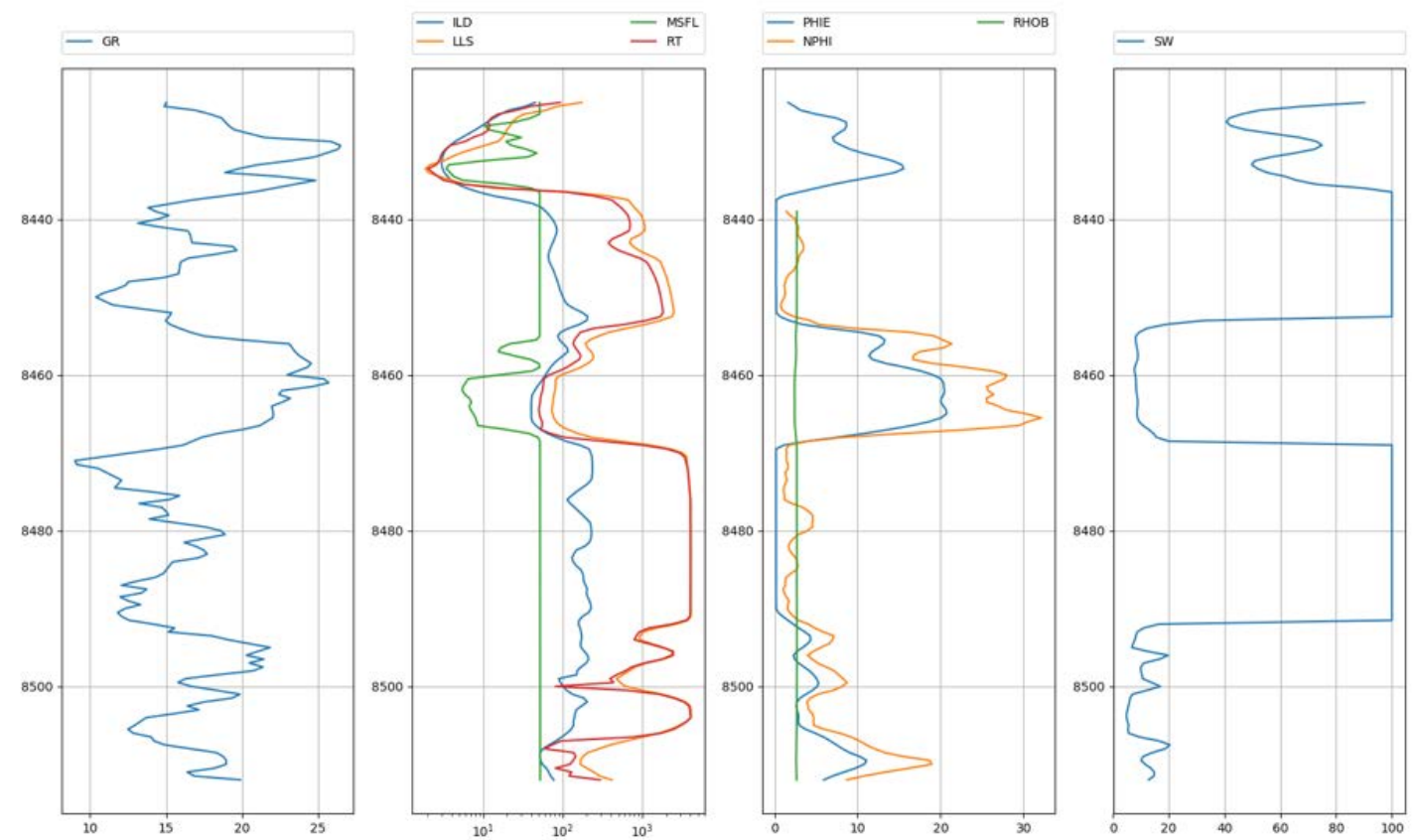
US094
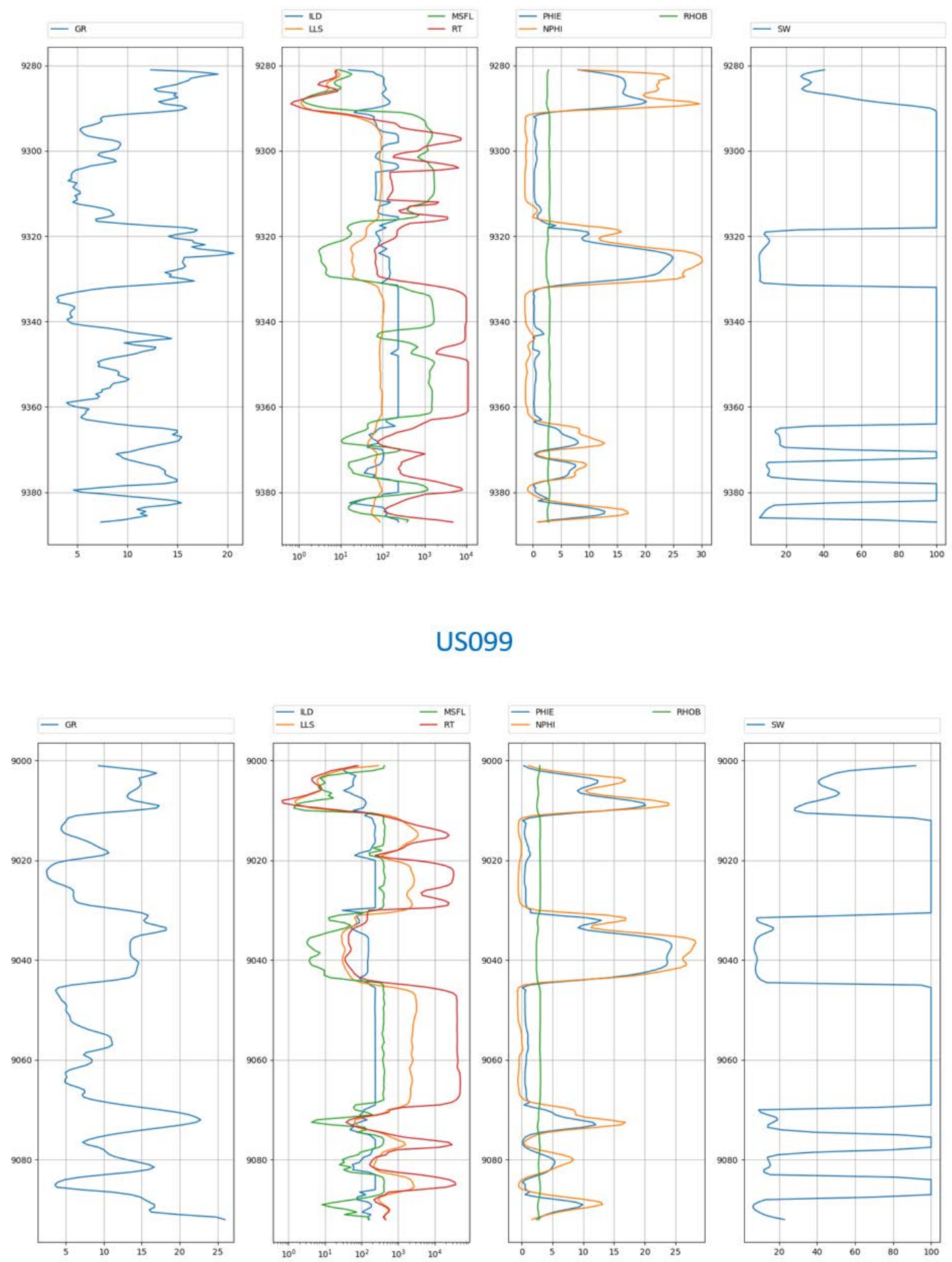

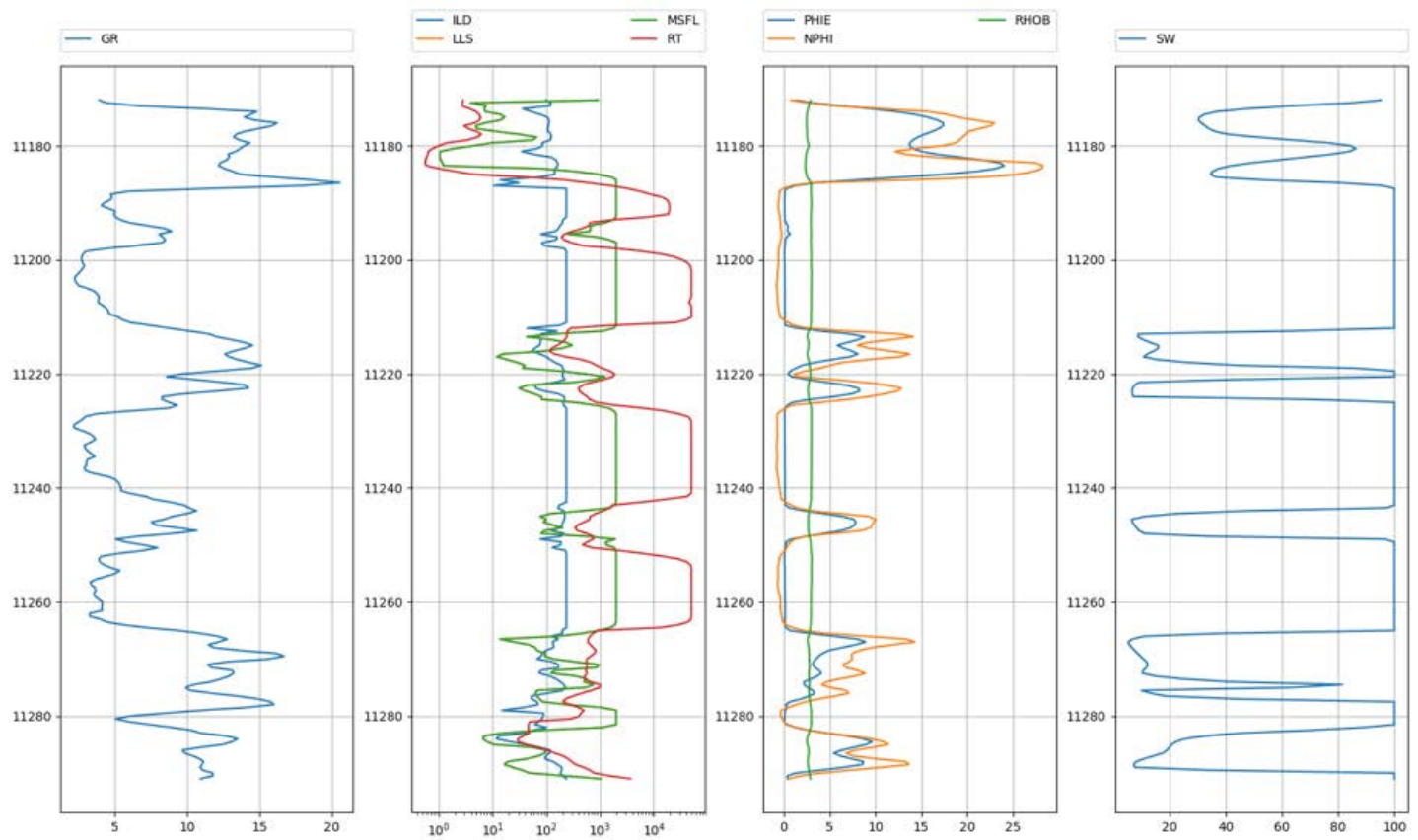

US134
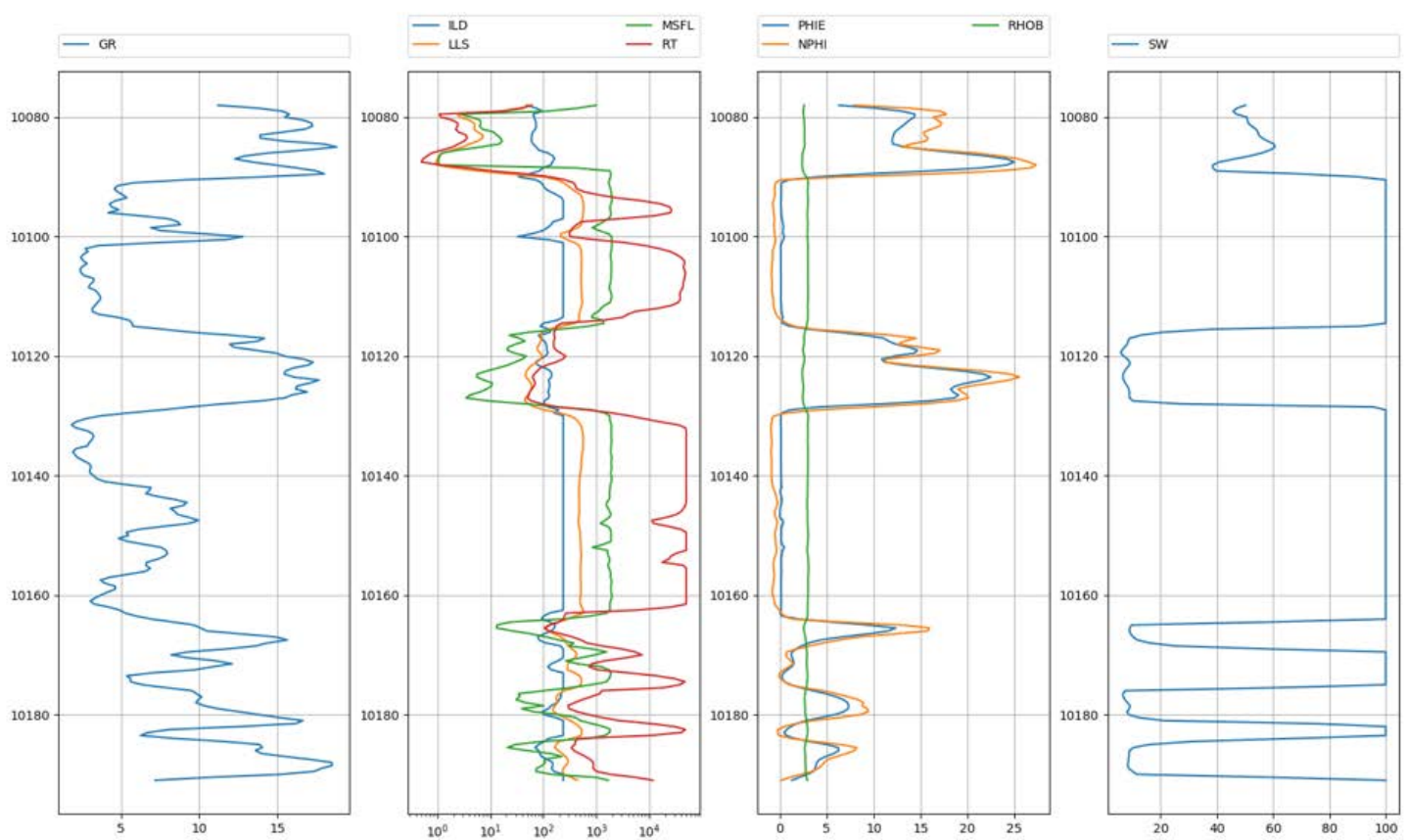
US152
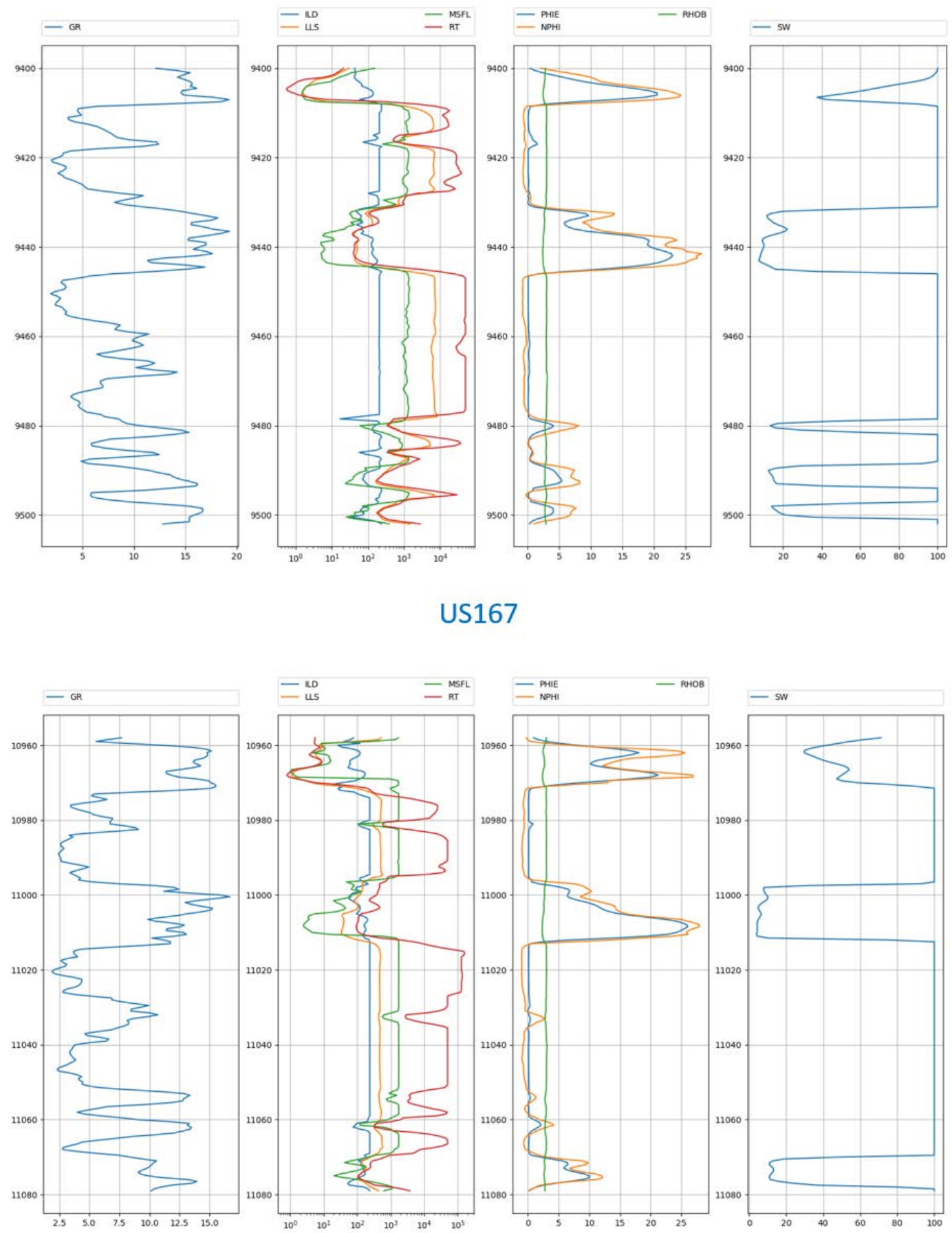
US168
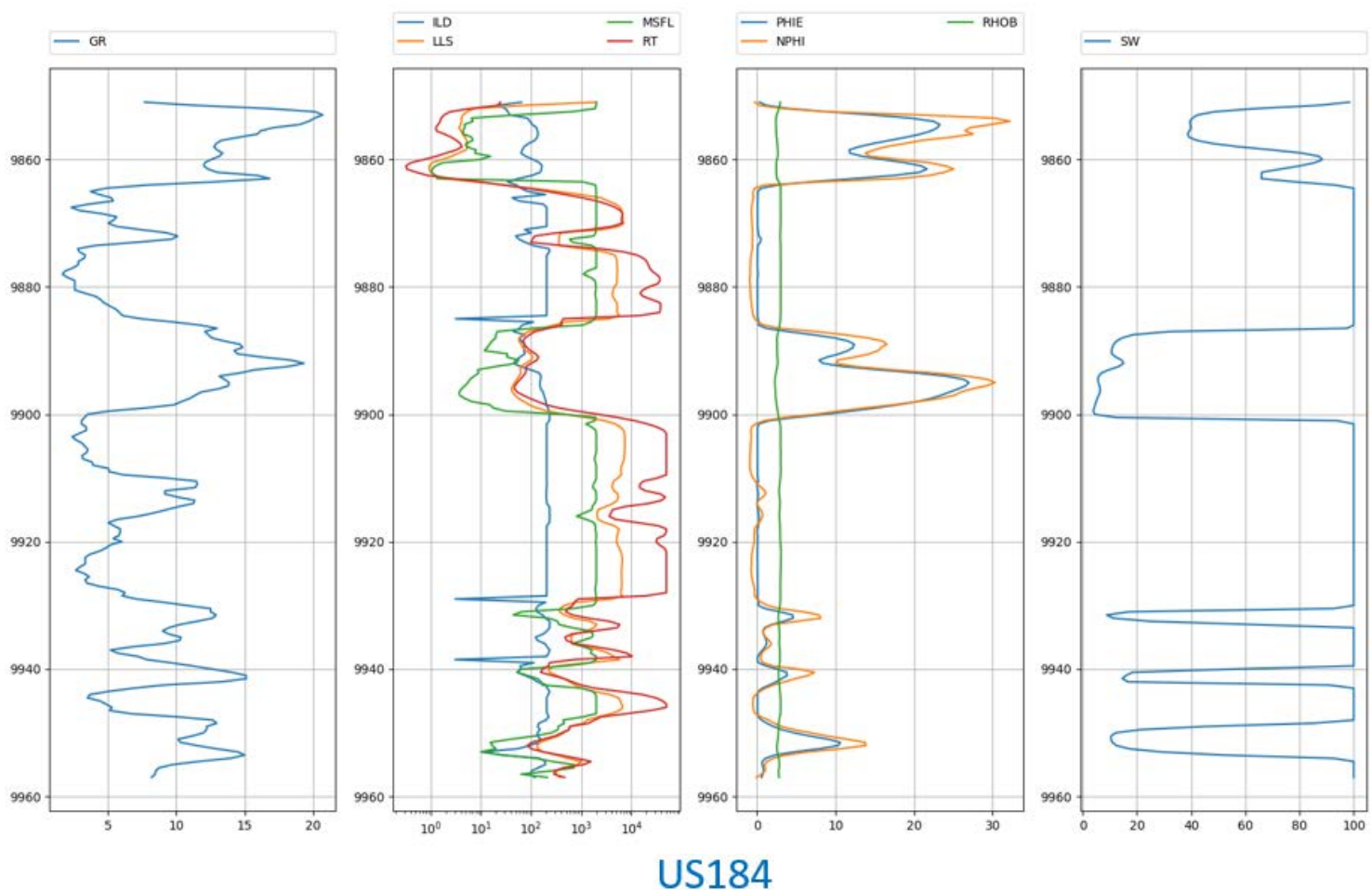

\section{US184}

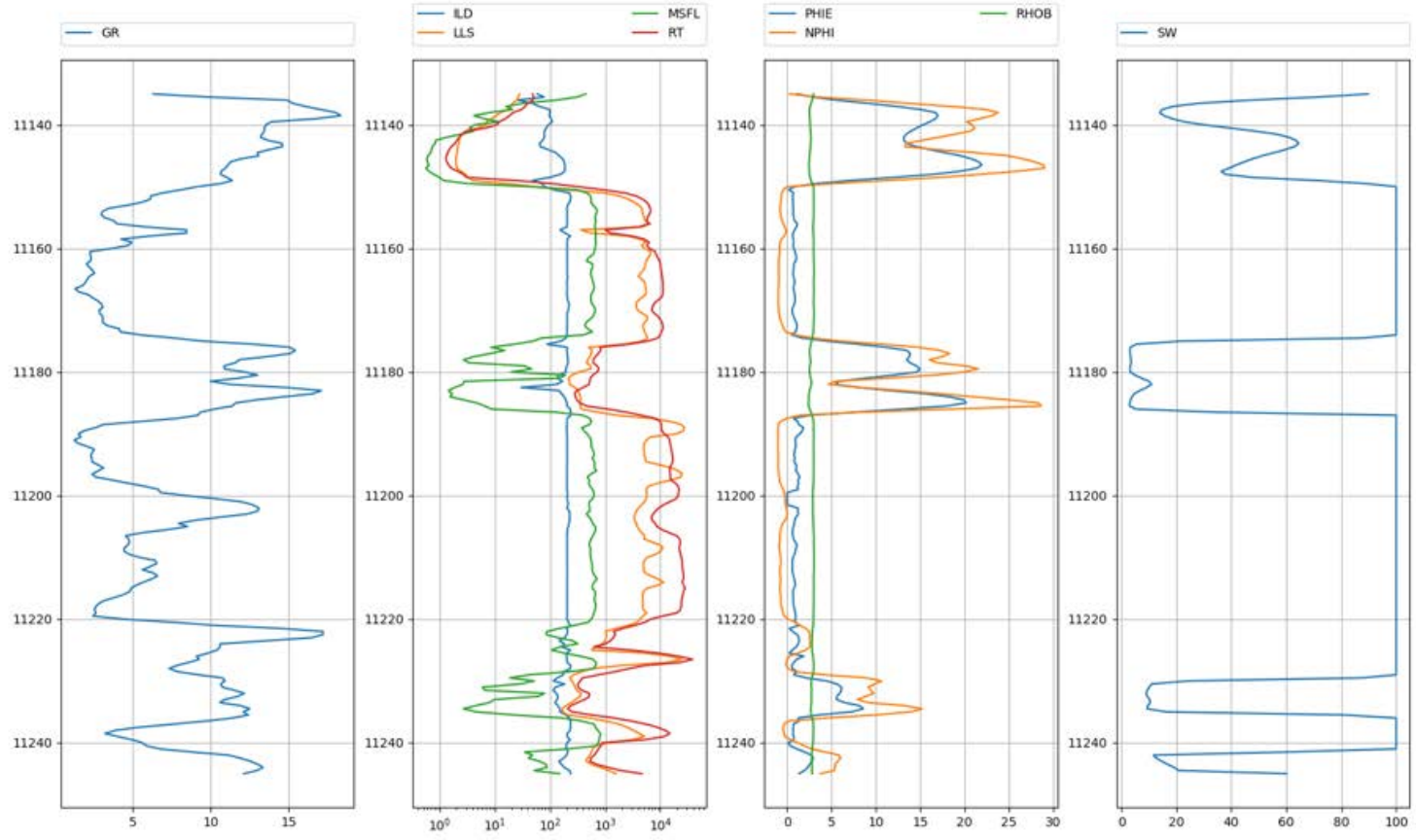

Figure 76: Outcomes for scenario VIII 


\subsection{Scenario IX}

To confirm the previous step, same oil producer (US 022) was used to train the neural network and generate LLS of 4 oil producers that their actual LLS values are known and will compare the generated LLS with the actual.

$\mathrm{R}^{2}$ results of the training process shown in table 10 and the result of the blind well was plotted against the actual value as it shown in (figure 85).

Table 10: Scenario $I X--R^{2}$ results

\begin{tabular}{|c|c|c|c|c|c|}
\hline Partitioning & All & Training & Calibration & Verification & Blind \\
\hline $80-10-10$ & 99.8 & 99.8 & 99.8 & 99.5 & 99.7 \\
\hline
\end{tabular}

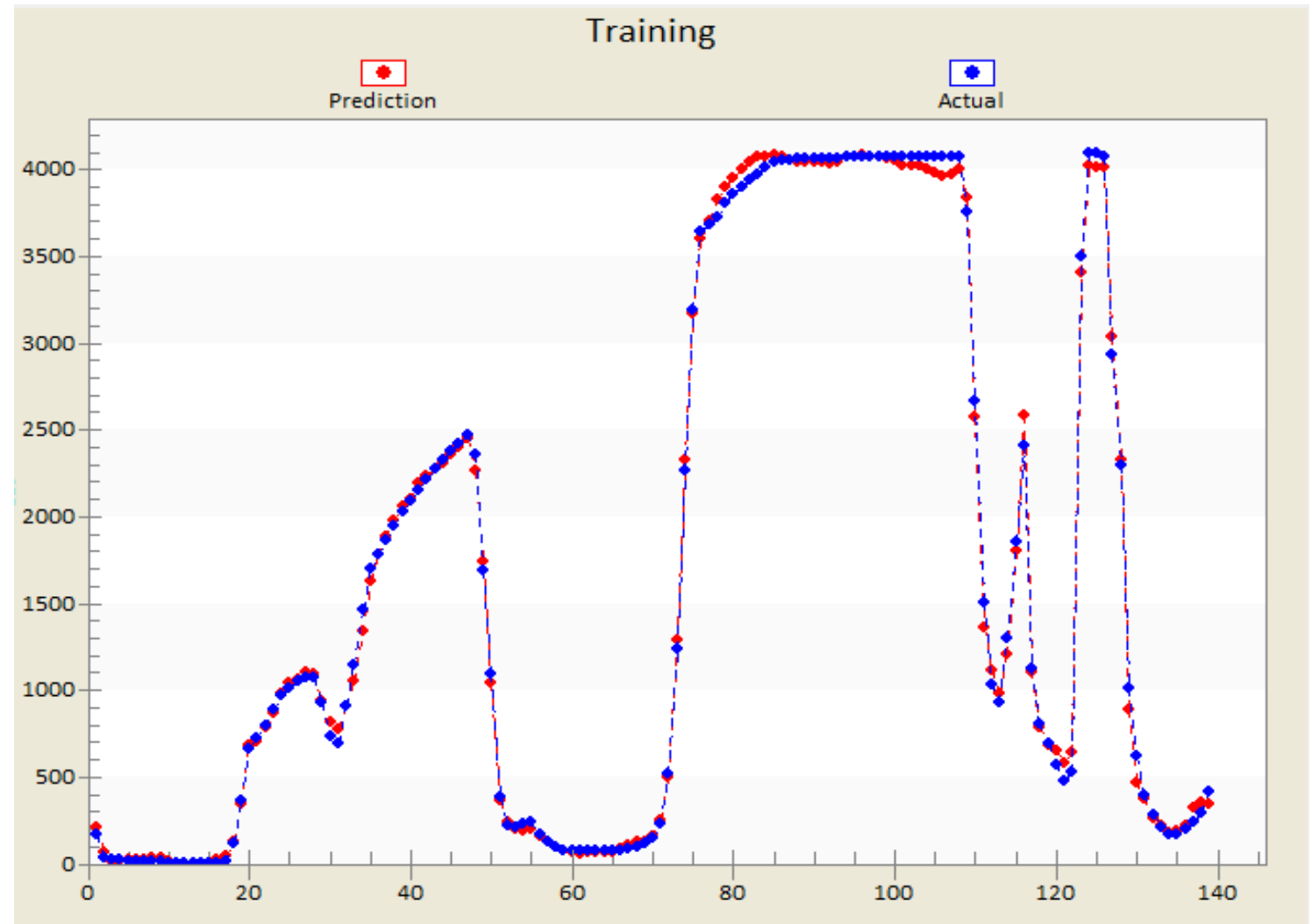

Figure 77: Training result scatter plot 


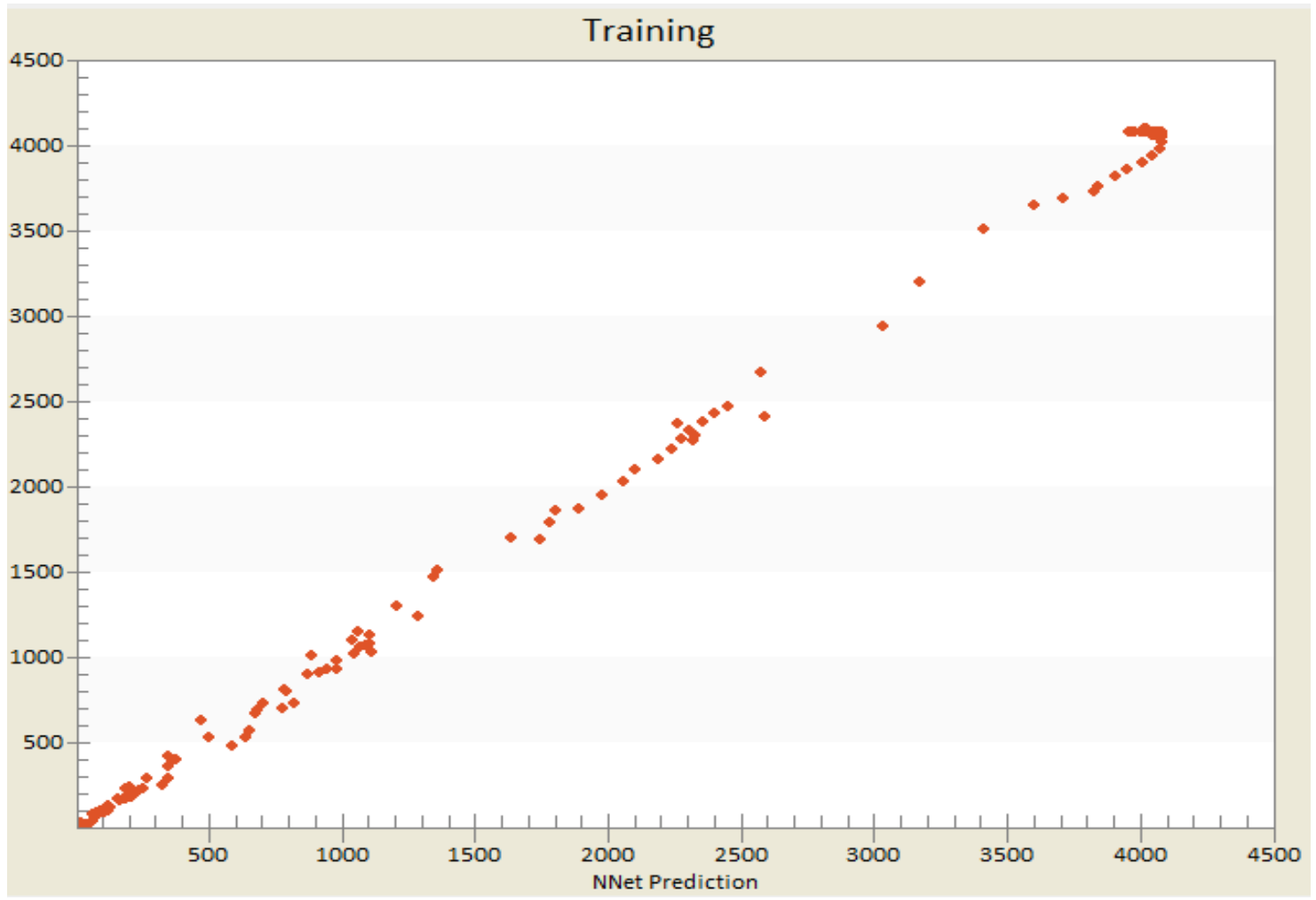

Figure 78: Training result cross plot

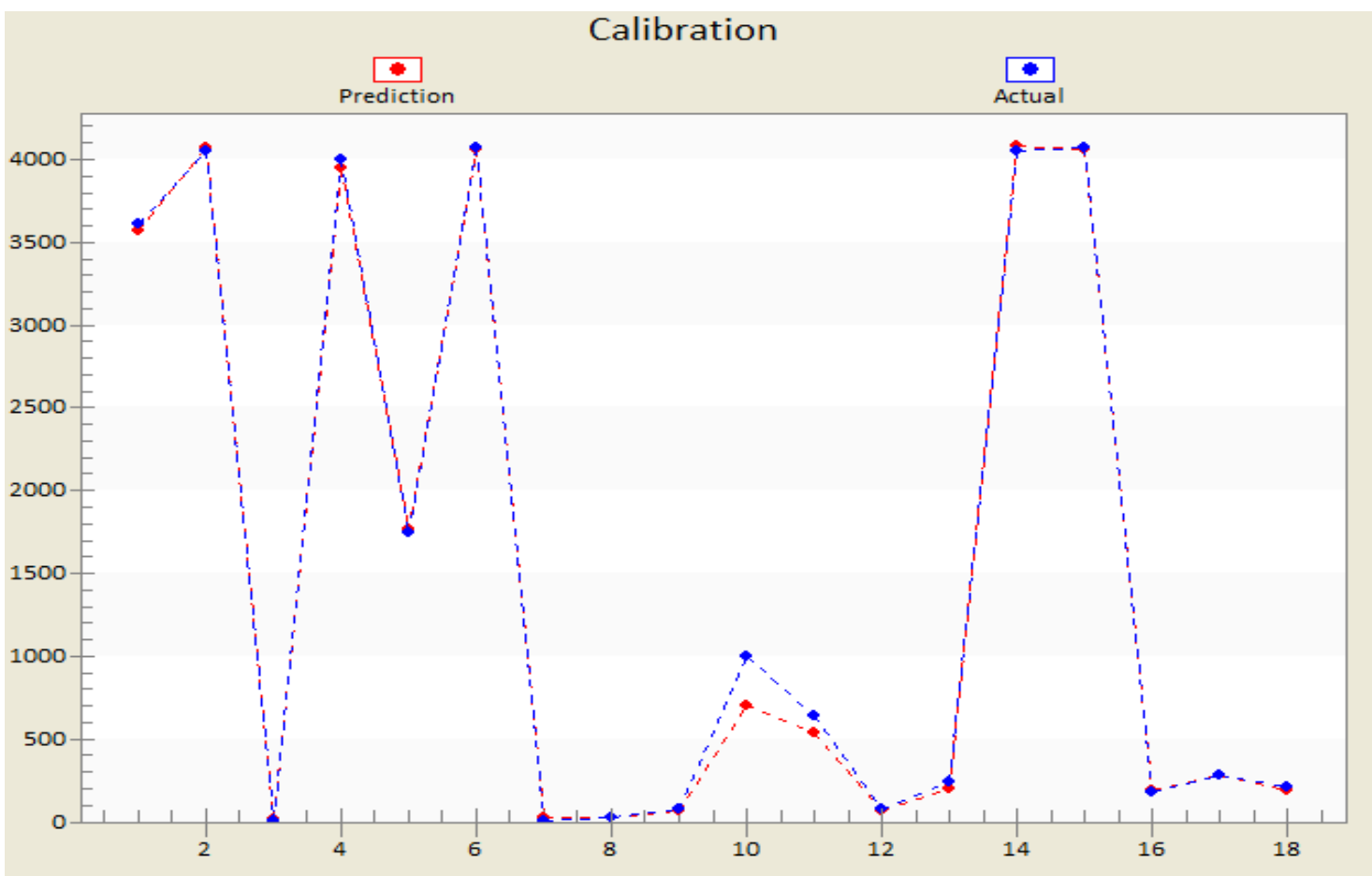

Figure 79: Calibration result scatter plot 


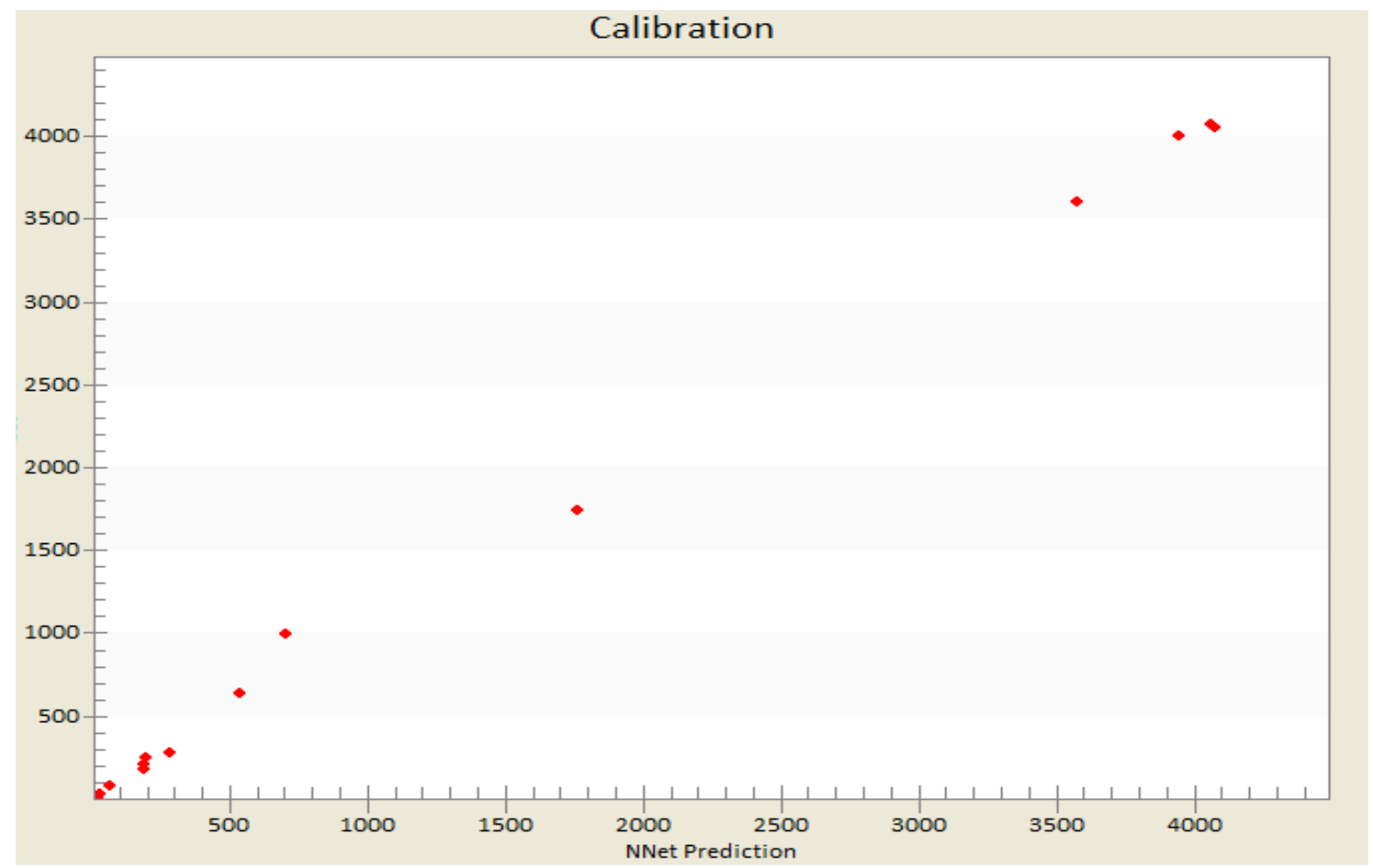

Figure 80: Calibration result cross plot

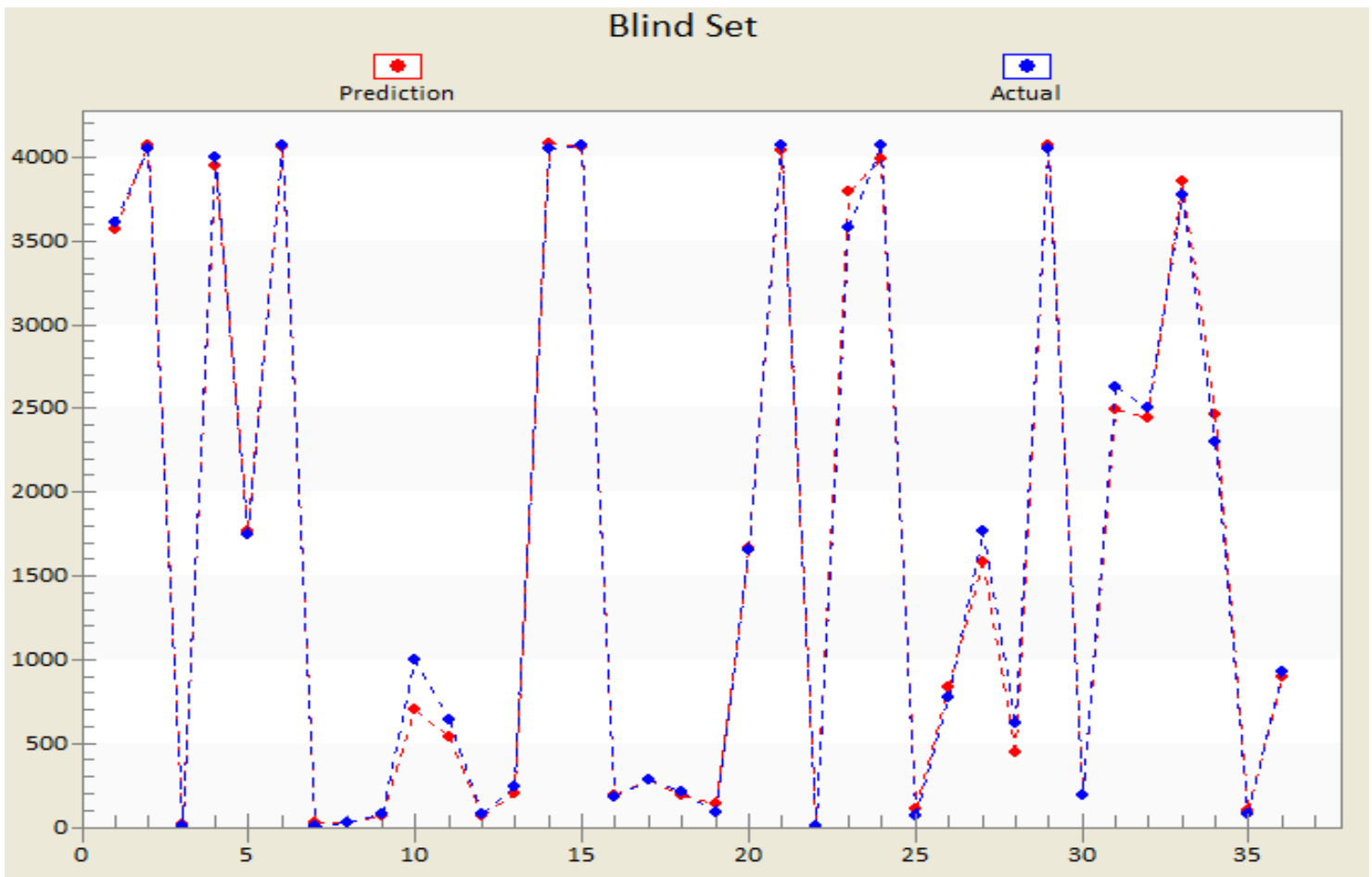

Figure 81: Blind result scatter plot 


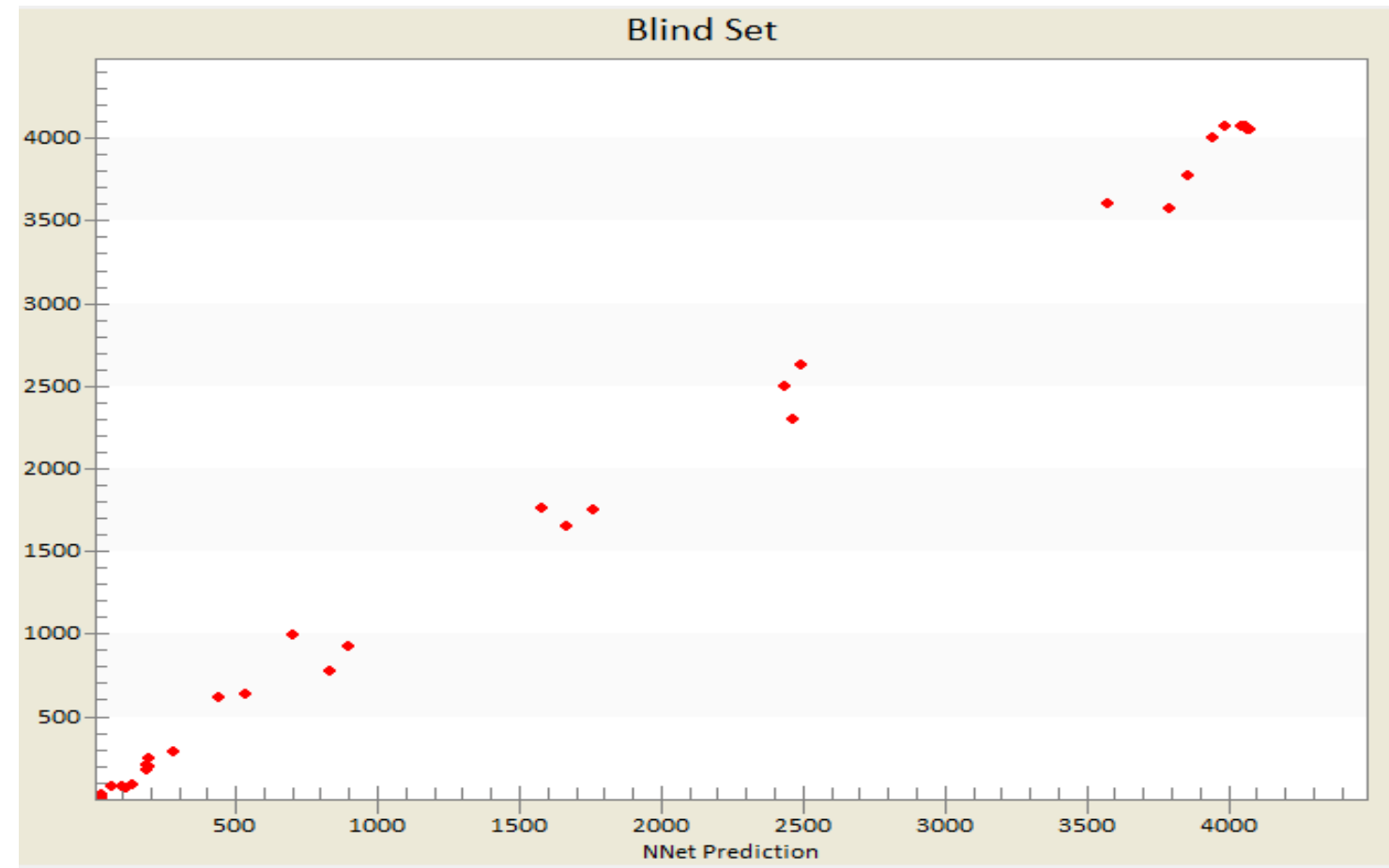

Figure 82: Blind result cross plot

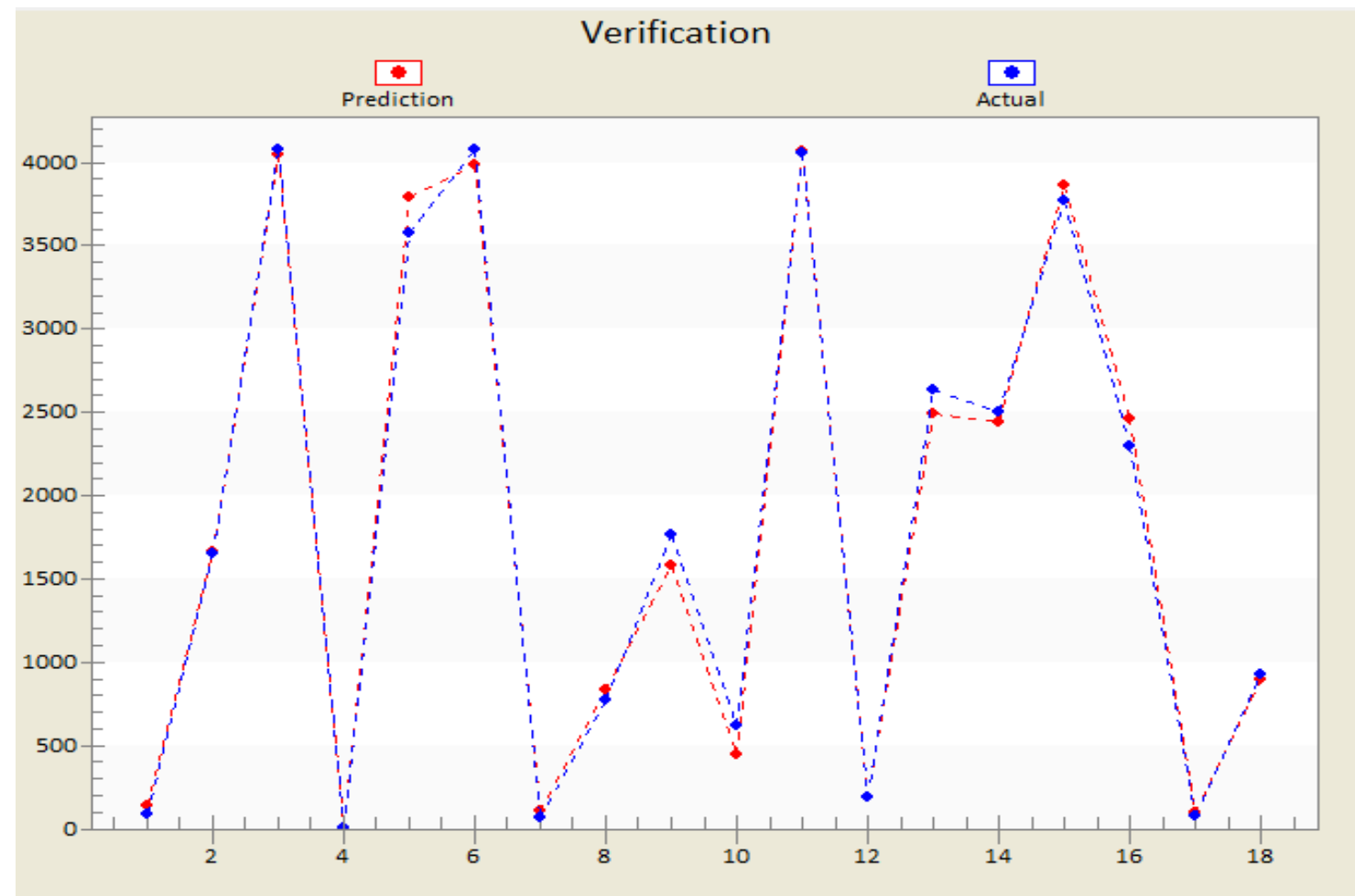

Figure 83: Verification result scatter plot 


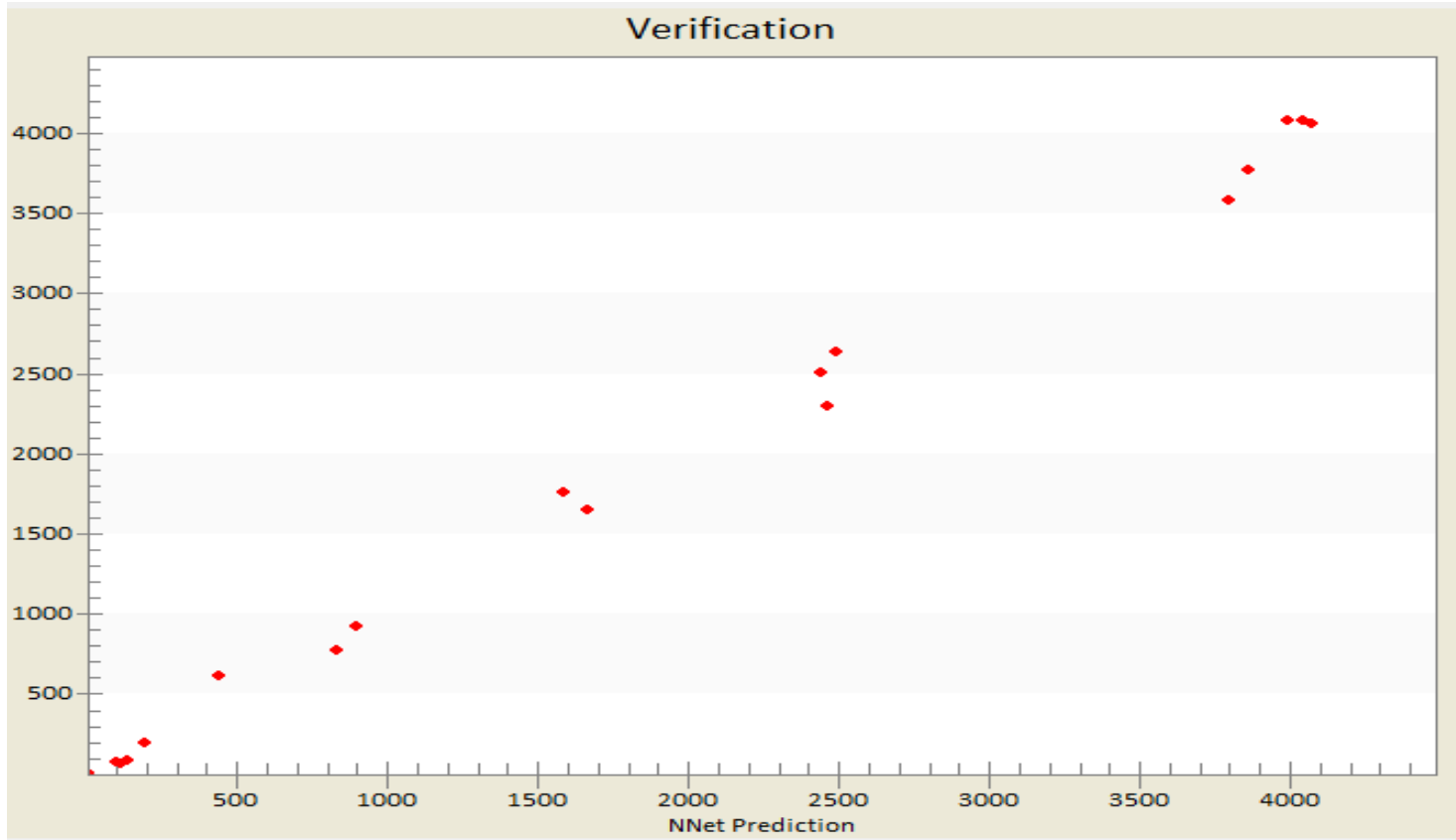

Figure 84: Verification result cross plot

US168
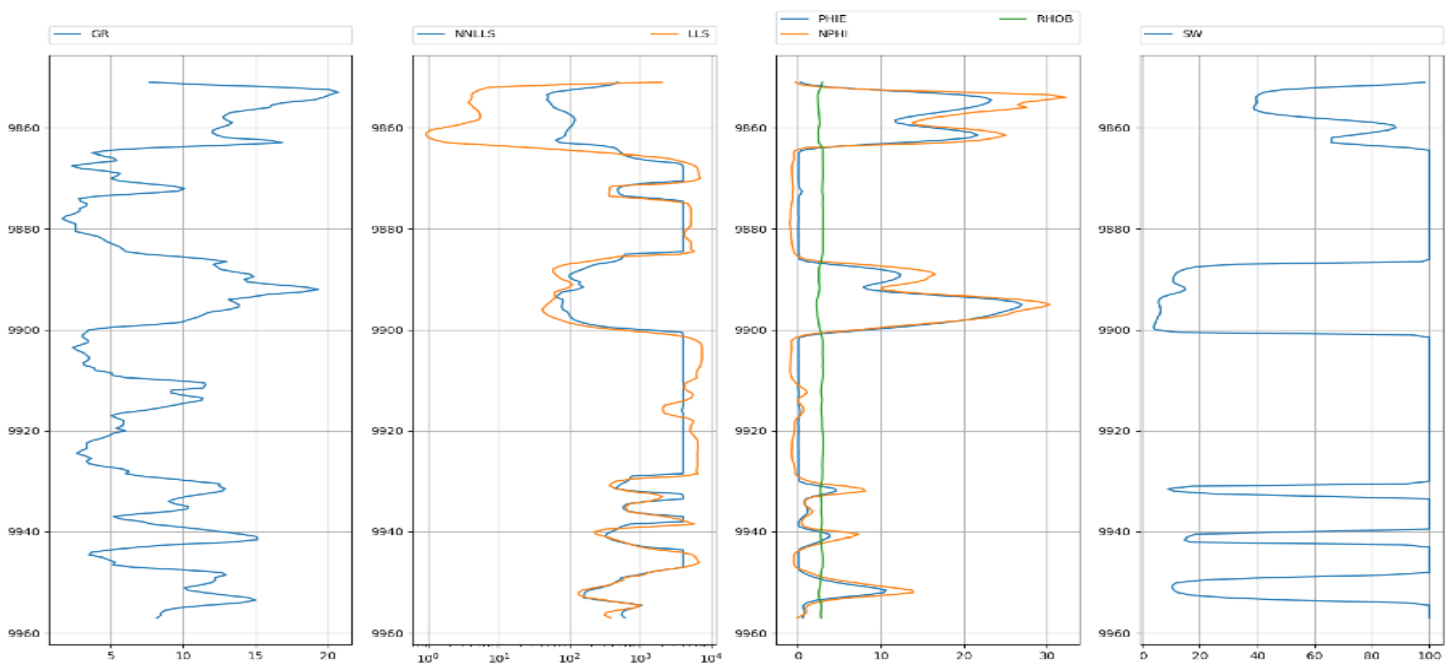
US184
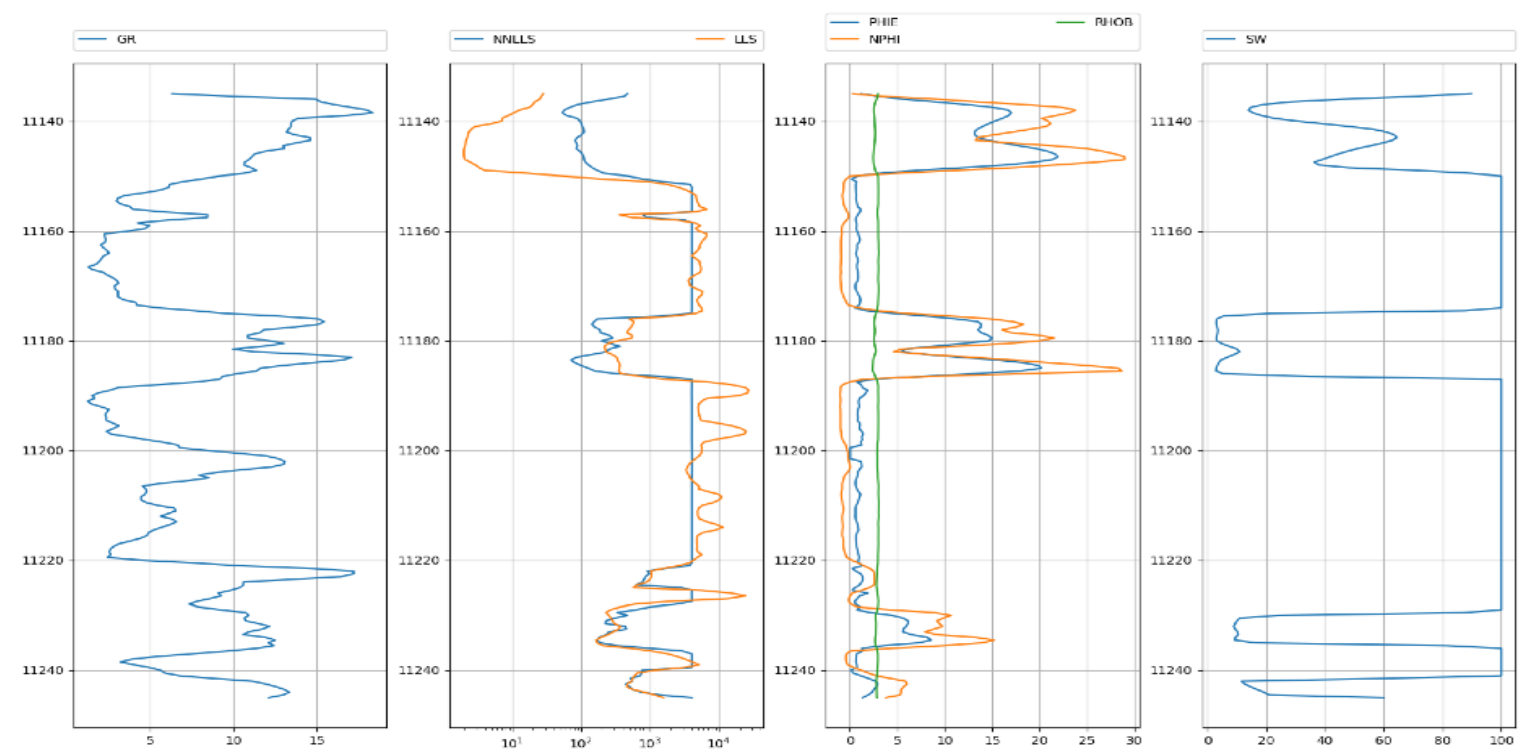

US099
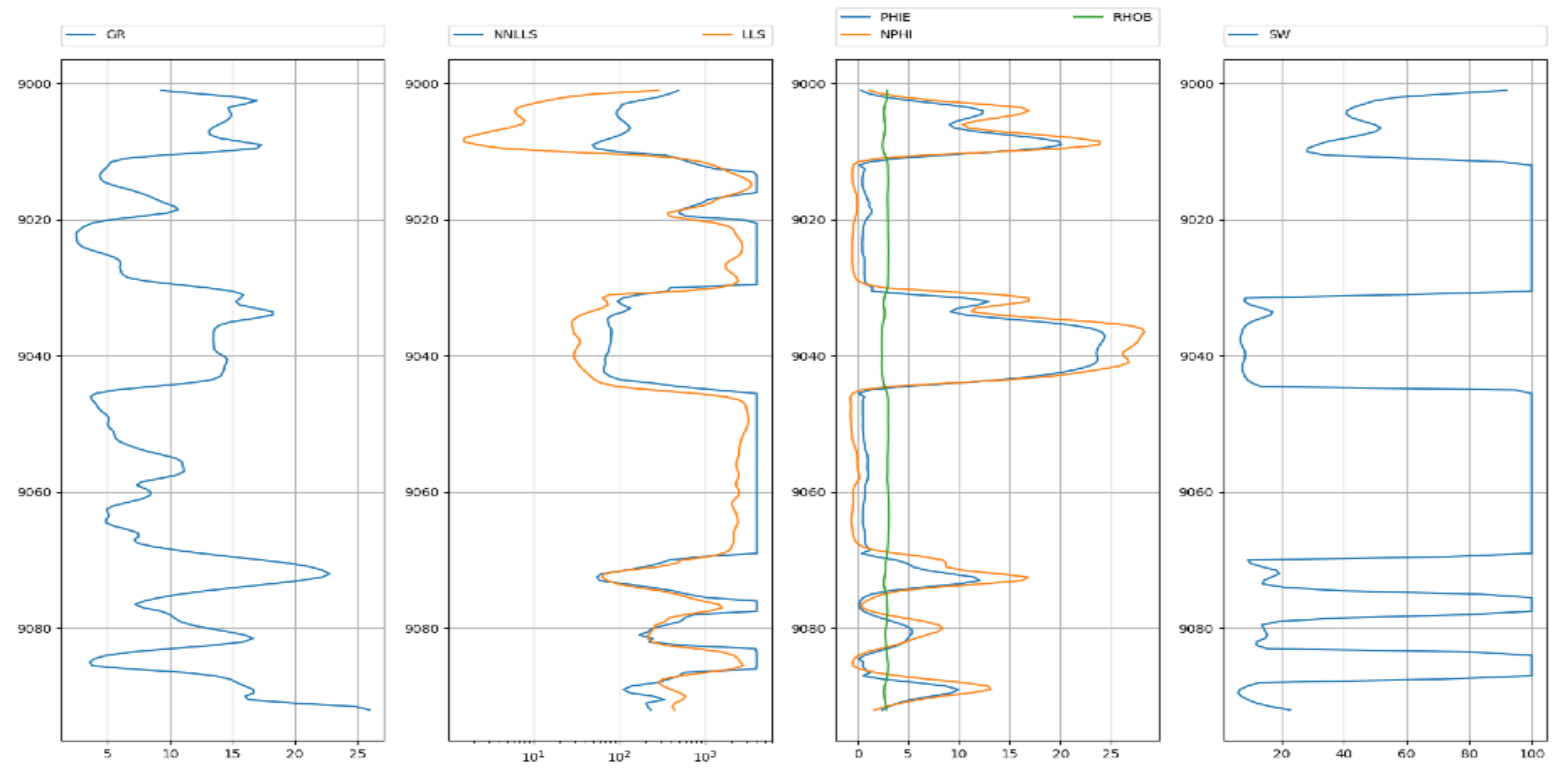
US152
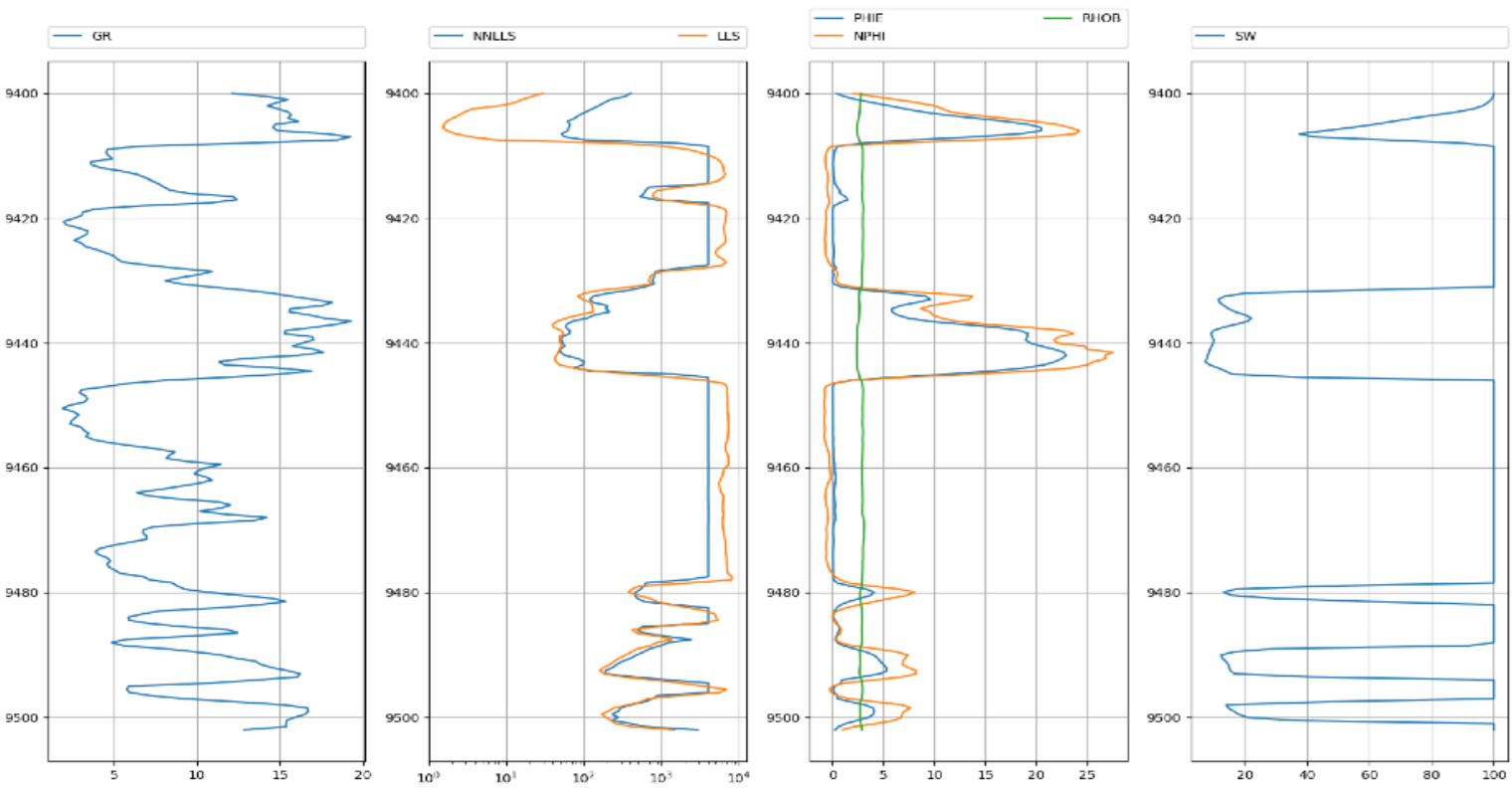

Figure 85: Outcomes for scenario IX 


\section{CHAPTER V: CONCLUSION AND RECOMMENDATIONS}

\subsection{Conclusion}

As argued, obtaining data directly from the field has very many limitations. Due to these limitations present, artificial intelligence work has been viewed as the best and strongest tool which can aid in supplementing such information and help generate the synthetic well logs. The sets of tools that are used in this research address the need for developing the respective well logs in synthetic form. This topic is important to the petroleum engineering because of the fact that synthetic well logs are designed to analyze the reservoir characteristic in regions that require log sets of where they are incomplete or absent. The implementation is important as much value may be extracted to help in production exploration.

However, using that technology has its own challenges, especially in data preparation stage where is the most important part of the whole process in my opinion. That's why computer science engineers were failing to success most of the time when they tried to solve petroleum engineering problems using artificial intelligence technology since domain expertise is highly required to get the engineering sense about which attributes and parameters should be used or eliminated according to their relation to the desired output.

In this research, it has been noticed that training neural network using injector wells to generate resistivity logs for producer wells is not a good approach, specially, if the injection is taking place in the aquifer for pressure maintenance. This may not be true if the injection is taking place in the middle of the field for water flooding. The difference between these two potential cases has to do with the quality of the formation that is used for pressure maintenance versus water flooding. For pressure maintenance the water is injected in portions of the field with high water saturation while for water flooding water may be injected in portions of the field that was (or still is) part of the production process.

Neural network doesn't differentiate between types of wells or formations, it just picks the pattern from the data and build a relationship between different attributes and 
parameters used in the training process, injectors resistivity logs has different pattern from producers therefore the results were unsatisfying or dramatically off the range especially deep induction resistivity (ILD).

Artificial intelligence is a reliable and promising technology that can significantly contribute to solving petroleum engineering related problems especially when it comes to the importance of fast decision-making processes.

\subsection{Future research}

During this research I came across some areas that needs more investigation and further researches. Some of the areas that future studies may focus on include investigating the different well pore types (D, H and $\mathrm{V}$ ) and their effects when using machine learning techniques. In addition, there is a need for exploring the reasons behind injectors behavior in induced resistivity logs. These areas are as of now reserved for future studies. 


\section{BIBLIOGRAPHY}

Acton, Q. A. (2012). Advances in machine learning research and application. Atlanta: Scholarly Media, LLC.

Bassaganya-Riera, J. (Ed.). . (2018). Accelerated Path to Cures. Springer.

Cranganu, C., Luchian, H., \& Breaban, M. E. (2015). Artifical Intelligent Approaches in Petroleum Geoscience. Springer.

Gibert, K, Vincent Botti, and Roman Reig-Bolano. (2013). Artifical Intelligence Research and Development: . Proceedings of the 16th International Conference of the Catalan Association for Artificail Intelligence. Amsterdam: IOS Press.

Mohaghegh, S. D. (2017). Shale Analytics. Springer.

Mohaghegh, S. D. (2017). Shale Analytics. Springer, Cham. 